\title{
Exploring the public-private sector wage gap in European countries
}

\author{
Louis N Christofides* and Maria Michael
}

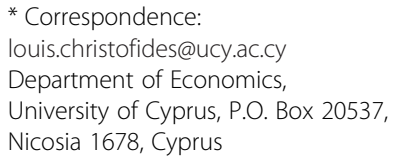

\begin{abstract}
We estimate the public-private sector pay gap for 27 European countries, using the 2008 EU SILC. The coefficients of conditional (on personal and job characteristics) public sector controls give a first impression on wage differences, while decompositions into explained and unexplained components (also accounting for selectivity) allow for a more complete analysis, which helps to identify possible causes of the gap. Regional patterns exist. Separate subsample decompositions based on age, education, gender and occupation, provide interesting insight regarding the pay structure of each country. Quantile decomposition analyses show that the public-private pay gap is, generally, negatively related to income quantiles. JEL classification: J31, J45, J48

Keywords: Pay gap; Public; Private sector; Decompositions; Quantiles
\end{abstract}

\section{Introduction}

Wage determination in the public sector has been a matter of considerable interest, given that the competitive paradigm and a number of other wage determination models are not directly applicable or appropriate. This hiatus has energized attempts to establish (i) how wages in the public sector are determined and (ii) what possible differences there may exist between wage determination outcomes in the public and private sectors and why.

In the context of the $\mathrm{EU}$, this issue attracts additional interest, given that its various integration policies involve convergence not only across Member States (MSs) but also within each MS. In Programme Countries (PCs) which have had to resort to Troika support (Cyprus, Greece, Ireland and Portugal), a major issue has been the public-private pay gap: In part, this is due to the fact that public sector wages amount to a large portion of national government expenditures which themselves need to be reduced. In addition, public servants have been easy targets, precisely because (at least in the short-run) the competitive paradigm does not apply and governments can often proceed to cut public sector wages unilaterally. But, more relevant to this endeavour, public sector pay has attracted attention because it is often thought to be excessive, particularly when working conditions and retirement provisions are taken into account. In PCs within the euro area, competitiveness is often an issue and strengthening it may require internal devaluations and wage decreases which can start in the public sector by edict, but may spread to and further encourage private sector wage reductions.

(C) 2013 Christofides and Michael; licensee Springer. This is an Open Access article distributed under the terms of the Creative Commons Attribution License (http://creativecommons.org/licenses/by/2.0), which permits unrestricted use, distribution, and reproduction in any medium, provided the original work is properly cited. 
Thus, the public-private wage differential is of critical importance to public policy, EU convergence and the welfare of MSs. Official documents often refer to the unconditional gap, implicitly assuming that none of it can be explained by measurable productivity characteristics. Yet, one of the most successful empirical regularities in labour economics is the Mincer equation which conditions earnings on variables such as education and experience, among others. Applied to public and private sector earnings, they often reduce the unconditional wage differential substantially and should shift the focus of attention to the unexplained wage gap. The unexplained gap varies considerably between countries; despite important contributions, this cross-sectional dimension has not been adequately explored and charted for a large enough number of countries.

This paper provides estimates of the public-private sector pay gap for 27 European countries, using comparable data and estimation methods for all countries. We establish what part of the gap can be explained by individual and job characteristics using Oaxaca and Ransom (1994), henceforth OR, decompositions. This is a necessary first step to a better understanding of why the unexplained gap varies across countries and how it might be further reduced once country-specific characteristics and policies are understood and taken into account. Cross-country comparisons complement country-specific examinations of 'natural experiments'; well-designed experiments are not always available or conclusive.

For this analysis, we use micro data from the 2008 European Union Statistics on Income and Living Conditions ${ }^{1}$ (EU SILC), which includes information on 27 countries: all 2008 MSs except France and Malta, plus Iceland and Norway. We address definitional issues, creating (given the possibilities offered by the data) samples of public servants and private sector employees which are comparable across countries. We study the influence of important factors (e.g. education and experience) on the wage determination processes of sectors (public and private) and countries, isolating the unexplained public-private wage gap in each country. In doing so, we also consider relevant sample selection issues. We also consider how the public-private wage gap may vary along country wage distributions.

We define the public sector as NACE Code L, which is "Public Administration and defence, compulsory social security" (Public Administration for short). The remaining NACE categories are defined as private and we conduct most of our analysis in these terms. However, in light of the fact that, in some countries, some portion of the health and education sectors is public, we pay special attention to NACE categories M (Education), and $\mathrm{N}$ (Health, social work). There is no public sector indicator in the data and it is, therefore, impossible to define and analyse the broader public sector with precision. In our sample, for most countries, the health and education sectors have a pay disadvantage, suggesting that policy concern should be focused on Public Administration relative to the remaining sectors.

In the sections that follow, we briefly review the international literature with emphasis on cross-country studies (Section 2), and comment on the sample construction protocol and data features (Section 3). In Section 4, we present unconditional differentials, the coefficients of conditional public sector controls and OR decompositions into the explained and unexplained components of the gap. For these models we also present quantile analyses of the relation between the public-private pay gap and the level of the hourly wage. For the OR approach, we explore the 'offered' wage gap that would prevail in the population at large following selection correction. We summarise our findings in Section 5. 


\section{Literature review}

The literature on public- private wage differentials has been quite extensive. This section does not aim to describe the current state of art. Rather, we refer to some of the classic papers that have informed our work and make more extensive reference to papers which examine a cross section of countries. A thorough review of the literature on public sector labour markets until 1998 can be found in Gregory and Borland (1999).

The first studies in this area are mainly for the United States, Canada and the United Kingdom. For Europe, a number of studies chart and explain the public-private sector pay gap. These include (Petersen et al. 1990) for Denmark, Hartog and Oosterbeek (1993) and Van Ophem (1993) for the Netherlands, Dustmann and Van Soest (1998) and Melly (2005) for Germany, Christofides and Pashardes (2002) for Cyprus, Bargain and Melly (2008) for France, Adamchik and Bedi (2000) and Fallaris (2004) for transition economies, and numerous authors for the UK (e.g. Rees and Shah (1995), Blackaby et al. (1999), and Heitmueller (2006)).

There are very few cross country studies that attempt to explain the public-private wage gap. Lucifora and Meurs (2006), measure and decompose the gap for three different countries (Italy, France and the UK), but using different data sources for each country. They use quantile regression to analyse the distribution of wages across sectors and conclude that wage differentials depend on the choice of quantile of the wage distribution; this conclusion also varies by gender and skill. In France and Italy the public-private sector wage gap is smaller than in the UK. This is related to the more decentralized wage setting in the UK; in France and Italy collective bargaining and union presence result in lower returns to productive characteristics.

Giordano et al. (2011) use EU SILC data from 2004-2007 for ten EU countries. They report results based on OLS regressions with a dummy variable for the public sector and also comment extensively on the institutional settings of each country. They find a conditional pay differential in favour of the public sector, especially for Spain, Greece, Ireland, Portugal and Italy (compared to Austria, Belgium, France, Germany and Slovenia). In separate regression analyses, the gap is generally higher for women at the low end of the wage distribution. In terms of institutional settings, the authors observe some positive correlation between low-gap countries and more decentralized wage setting. However, they do not see any relation between the size of the gap and union power.

Our work extends this paper in a number of directions. Since a public sector indicator is not available, we focus on a narrow definition of the public sector (Public Administration), while also reporting results for Education and Health. In unreported results, Giordano et al. (2011) allow the coefficients on characteristics to vary across sectors, while we report separate equations and make the calculation of the unexplained component of OR decompositions our central point because this is the puzzle that needs to be explored (Mincer equations explain the balance). We estimate and report quantiles because separate OLS regressions by income level may be open to selection biases. We deal with selection into the paid work sample that we analyse from the larger sample that includes the unemployed and non-participants, reporting and analysing not only 'measured' public-private wage gaps but those that would prevail in the larger, random, sample - the 'offered 'gap. Finally, we cover 27 rather than 10 countries, thereby opening the possibility of further study of the cross-country features that may explain the public-private pay gap. 
The majority of the more recent empirical studies describe and comment on the institutional background of the labour market under study, since it is believed that these institutional, country, characteristics influence labour market outcomes and the gap between public and private sector wages. Such characteristics include wage setting procedures, the level of centralization of the public sector, differences in recruitment procedures, union power, minimum wage laws and coverage, the wage indexation system, employment protection legislation, etc.

From a methodological point of view, a variety of approaches have been used to study wage differentials. Some studies, using micro data, tried to check for the existence of a positive wage premium in the public sector by including a dummy variable in the wage equation, indicating whether an employee belonged to the public or private sector - see Gregory and Borland (1999). Other studies applied decomposition methods, often that of OR. The main idea was to account, not only for differences in the intercept between the two sectors (the dummy variable approach), but also to take into account differences in the returns of worker characteristics and job attributes between the two sectors. A third wave of studies tried to take into account the selection effect caused by unobserved individual characteristics (which determines entry into the samples studied) and correct the bias using the two-step Heckman selection methods.

Gyourko and Tracy (1988) estimate a more general selection model in which workers decide not only the sector (public or private), but also whether they will become a member of a trade union or not. Christofides and Pashardes (2002) use a Bivariate Probit to account for selection into sector (public, private) and type of employment (paid, self-employment) and then examine public-private wage gaps for paid employees. Other attempts to take account of selection into the public sector, or at least explain the incidence of employment by sector, include Anghel et al. (2011), Glinskaya and Lokshin (2007), Heitmueller (2006), Kanellopoulos (1997), and Van der Gaag and Vijverberg (1988), to name but a few. Central to these efforts is the availability of instruments that explain the choice of sector but are not relevant to the wage determination process. Thus, Christofides and Pashardes (2002) use life insurance expenditures as a proxy for risk aversion and whether other household members are employed in the public sector as a proxy for the 'transaction' costs involved in gaining employment in the public sector. In general, these efforts are circumscribed by the availability of suitable instruments in the data set used and the EU SILC is not particularly rich in such instruments: Parental education, for example (a possible determinant of parental employment in the public sector), is only available if parents live in the same household. A number of size-related house variables, while available, are not clearly related to the decision to seek employment in the public sector. We have, therefore, not attempted to control for selection by sector.

Finally, recent studies use quantile regression techniques to examine differences in the wage distribution among the two sectors (Poterba and Rueben (1994)), while Machado and Mata (2005) propose a quantile regression decomposition technique, which allows decomposition at different quantiles. The Machado and Mata conditional quantile regression technique combines a decomposition procedure and a bootstrap approach. In particular, they analyse the changes in the wage density among the two groups. They decompose differences in the quantiles of the two groups into a portion which is due to the coefficients and one which is due to the covariates. Chernozhukov et al. (2013) break new ground, but Nõpo (2008), Melly (2005), and Van Kerm (2012) have also 
made important methodological contributions. Fortin et al. (2011) offer an excellent treatment of a variety of decomposition methods and related issues. We explore the possibility of analysing the public-private wage gap by the wage level in Section 4.4.

\section{Data issues}

We use micro data from the Cross-Sectional European Union Statistics on Income and Living Conditions (EU SILC) for 2008, which includes information on 27 countries; 25 MSs except France and Malta plus Iceland and Norway. The EU SILC data are collected by Eurostat, via the national statistical agencies, following common definitions and methodologies for all countries. Information is provided on the individual's personal and family characteristics, the number of children and child-minding arrangements, working status and type of employment, occupation, annual income and hours of work, the industry of employment, and income from non-employment. In the main body of the paper, we focus on the hourly wages defined as Annual Income/(Number of Months Worked times 4.2 times weekly hours of work). In Section 4.3.5, we check the sensitivity of our results to the use of monthly data, defined as Annual Income/ Number of Months Worked. The natural logarithm of wages is always used on the lefthand side and, for small differences, ln wage gaps can be viewed as percentage differences.

Since our main objective here is to compare public and private sector pay, it is important to select samples of individuals in jobs in the two sectors which are comparable along a number of dimensions. With that in mind, we exclude from the working sample: (i) individuals working part-time or below 30 hours per week, (ii) students, (iii) those retired or disabled, and (iv) soldiers. We do not exclude individuals who worked for part of the year (e.g. new starts and individuals who retired at some point through the year). We do exclude individuals below 25 and above 60 in order to avoid the possibly unusual patterns of work at the beginning and end of careers. It is also advisable to exclude the self-employed and family workers because it is widely felt that, in a number of countries, self-employment incomes are not truthfully reported. The total sample includes the unemployed and the inactive and endogenous selection behaviour into paid work (the sample of public and private employees that we analyse) is taken into account for the OR decompositions.

Beyond these restrictions, it was also necessary to 'clean' the data. Observations with missing information on important issues such as labour force status, employment status, the number of months worked, weekly hours worked, and annual income had to be dropped. Finally, we dropped, on a country-by-country basis, observations containing inconsistencies or possible mistakes, such as zero or very low income for those working. With similar reasons in mind, we dropped observations with hourly wages below the 1st percentile of the hourly wage distribution and above 3 times the 99th percentile.

In the final sample, we have 171,108 individuals (roughly equally divided between men and women) in 27 countries of whom 137,085 were full time employees, 12,284 were unemployed and 21,739 were inactive - see Table 3 in the Appendix. The number of observations ranges from 2,524 in Iceland to 15,688 in Italy. The number of observations in the public sector is smallest in Norway (125) and largest in Italy (1229). Breakdowns for key variables are available on request. 
Table 4 in the Appendix presents the unconditional mean hourly wage by country and by NACE industry. We observe significant variation among the 27 countries. The lowest average hourly wages are found in Bulgaria $(€ 1.58)$ and Romania $(€ 1.95)$ and the highest in Norway (€26.79) and Iceland (€25.26). This incredibly large range, unadjusted though it is for local cost of living, taxes, and other local peculiarities and amenities, points to the immense incentives for migration that already exist and will intensify as flows are liberalised further. In the public sector, the hourly wages in Bulgaria and Romania are $€ 1.81$ and $€ 2.68$ respectively, while in Norway and Iceland they are $€ 24.63$ and $€ 27.89$. From Table 4 in the Appendix one can also infer the unconditional wage levels in and implied wage differentials between the bolded public (NACE L) and components of the private sector in the 27 countries. Conditional public-private wage differentials are examined in the next section.

\section{Econometric analysis}

\subsection{Preliminaries}

Before proceeding to the main part of our econometric analysis, it is important to pause on the matter of the definition of the public sector alluded to in the introduction and, at the same time, to offer some insights into the structure of wages in the broader public sector in Europe. An easy method to explore this issue that also has some interesting properties ${ }^{2}$ is to introduce controls for NACE L, M and N and Other in standard Mincer equations, estimated with Ordinary Least Squares (OLS), for each country separately. The controls for industry (see Table 4 in the Appendix for definitions) and other categorical variables are entered so that all group coefficients are normalised to zero - though we do not discuss the individual contribution of regressors to the unexplained component (see Jann (2008) and Yun (2005)), this is a 'best practice' procedure that avoids identification errors when the unexplained component (which includes the intercept) is decomposed and helps us assess the results immediately below more easily. The wage equations also include seven controls for age, three controls for education ( $\mathrm{L}=$ less than secondary, $\mathrm{S}=$ secondary, and $\mathrm{H}=$ higher education), two for gender, two for temporary or permanent forms of employment, and four for occupations ${ }^{3}$, as well as a constant. Table 5 in the Appendix provides full results, with the coefficients on the important industry controls summarised in Figure 1.

As shown in Figure 1, wages differ substantially across the three sectors and the 27 countries. Coefficients, expressed as deviations from the grand mean, for the Education sector are either not significantly different from zero (at the 10\% level, unless otherwise stated), as in Lithuania, Slovenia, Finland, Austria, Luxembourg, and Germany, or are negative for most countries with six exceptions, viz. Cyprus, Spain, Ireland, Greece, Portugal and Poland. Wages for the education sector in Cyprus are particularly high compared to the grand mean of zero. Along the same lines, the coefficient for the Health sector is positive and significantly different from zero only for Italy. In all other countries, it is either not significantly different from zero or significantly negative - see Figure 1. By contrast, the Public Administration sector coefficient is either above zero or insignificant for all countries. Among the highest coefficients for this sector relative to the industry grand mean of each country are Hungary, Luxembourg, and Bulgaria. The graph for Other Industries in Figure 1, shows the sum (times minus one) of the coefficients for NACE L, $\mathrm{M}$ and $\mathrm{N}$ which, of course add up to zero across NACE L, M, N, and Other. 


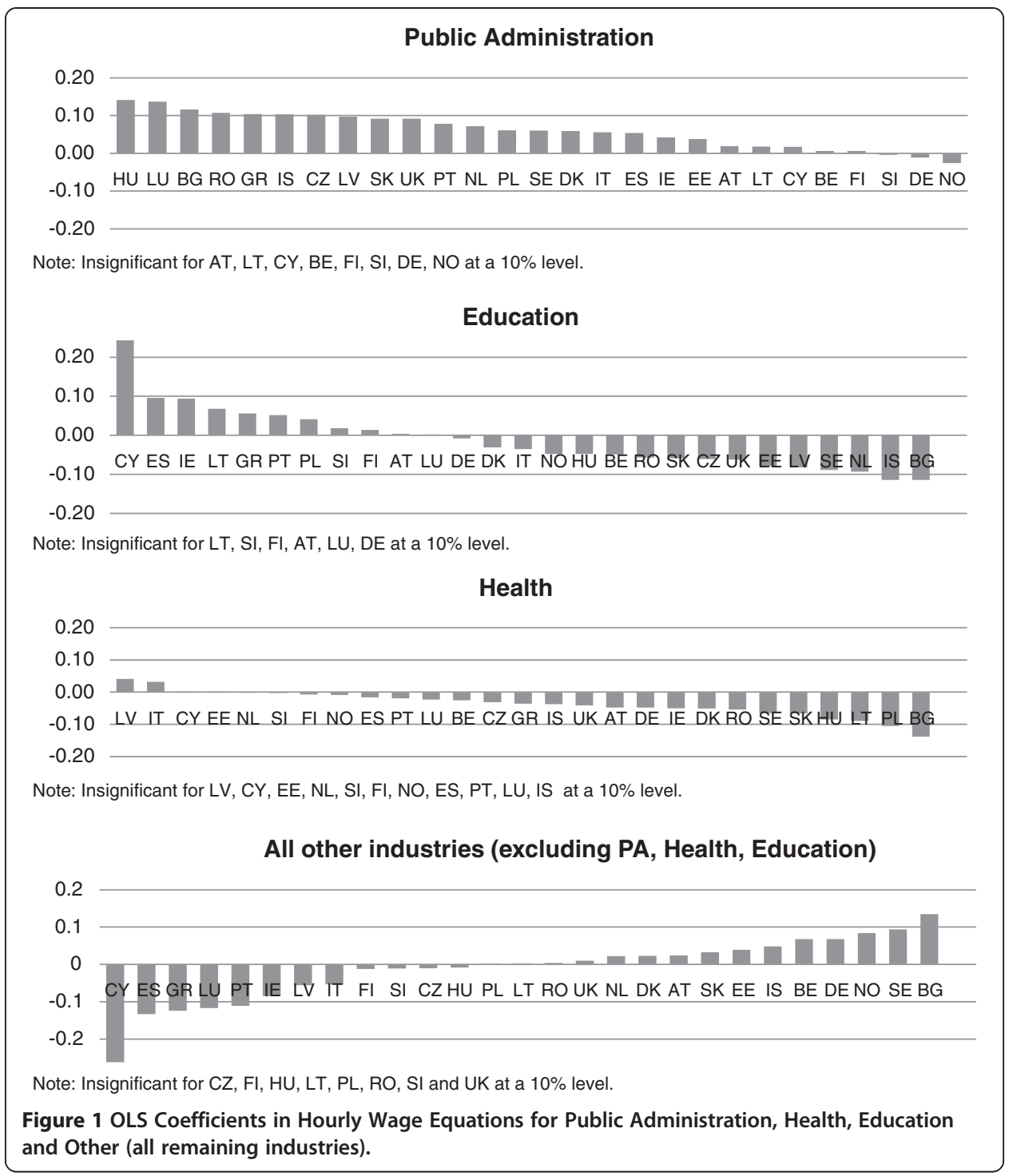

Figure 1 shows that it is the Public Administration sector that merits particular attention; this keeping in mind that, without a public sector identifier, observations in education and health cannot be reliably classified into the public and private sector. Table 6 in the Appendix and Figure 2 provide the OLS deviation from the grand mean for Public Administration, when Other now includes Education and Health. Luxembourg, Cyprus, and Greece have coefficients of the order of $10 \%$, with countries all the way down the graph to Bulgaria having coefficients which are significantly positive. Beginning with Bulgaria and for the next six countries in Figure 2, the coefficient on Public Administration is not significantly different from zero, while for Belgium, Germany and Norway, it is significantly lower than zero. The complete regression results are presented in Table 6 in the Appendix. The range of public-private sector ln wage gaps ( 0.121 for Luxembourg to -0.038 for Norway) is substantial and indicates quite different attitudes and practices across the 27 countries.

In order to examine the nature of these gaps across the 27 countries more closely, we turn now to the OR decompositions which are based on separate regressions for the 


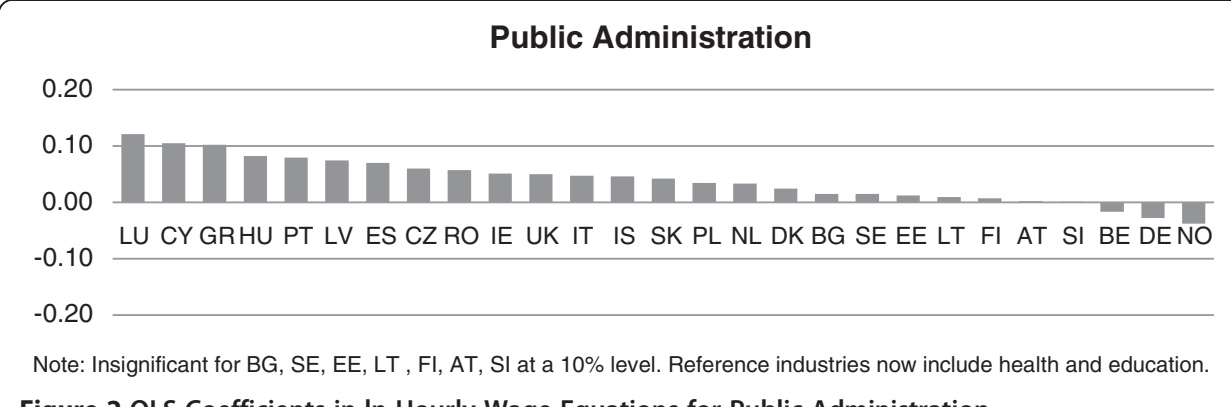

Figure 2 OLS Coefficients in In Hourly Wage Equations for Public Administration.

public and private sectors of each country, thus removing the restriction that variable coefficients must be the same across sectors and offering the possibility to arrive at an unexplained component which is based on differences in coefficients beyond those on the constant terms.

\subsection{OR decompositions}

In light of the discussion above, we use the OR decomposition ${ }^{4}$ to investigate the $\ln$ hourly wage gap between the public sector (defined as NACE=L) and the private sector (defined as all other NACE categories). We estimate the total ln wage differential and decompose it into (i) the part explained by individual characteristics (age, education, and gender) and job attributes (type of contract and occupation), (ii) the public sector advantage (unexplained higher returns to the various characteristics for public sector employees) and (iii) the private sector disadvantage (unexplained lower returns to individual characteristics for private sector employees). Items (ii) plus (iii) constitute the unexplained component. In effect, these are equations such as those in Table 6 in the Appendix but without the public sector dummy and estimated separately by sector; they are not reported to conserve space. We present normalised coefficients. Our main results concern hourly wages and the working sample.

Table 1 presents, in summary form, the results of the decompositions both in ln wage points (top part for each country) and in percentages (bottom part). The bolded row is the $\ln$ wage gap between the public and private sector (the left-hand side of the equation in endnote 4). There is a significant (three stars indicate the 1\% level, two stars the 5\% level and one star the $10 \%$ level) hourly wage differential between the public and private sector for almost all countries. The size of the total ln wage gap ranges from essentially zero in Belgium and Norway to 0.38 in Latvia. A number of interesting patterns exist. The lowest gaps are to be found in Belgium and in Scandinavian countries; indeed, in Norway the gap is actually negative (though not significantly different from zero). Gaps in excess of 30\% are to be found in Greece, Luxembourg and Latvia. PCs have gaps around 30\%, with the exception of Ireland where the gap is $0.157 \%$.

As noted earlier, it is the unexplained public-private wage gap that is of possible policy interest. Table 1 suggests that a substantial part of the conditional gap is actually explained. Indeed, in the case of Belgium, Germany and Norway, the personal and job characteristics of public sector employees are so good that they would justify more pay and, by implication, the unexplained components are negative. ${ }^{5}$ Other countries, where the explained component is larger than the unexplained (though not as extreme cases 
Table 1 OR Decompositions (In hourly wage, full sample, public sector defined as NACE L=Public Administration)

\begin{tabular}{|c|c|c|c|c|c|c|c|c|c|c|c|c|c|c|}
\hline & AT & $\mathrm{BE}$ & BG & $\mathrm{CY}$ & $\mathrm{CZ}$ & $\mathrm{DE}$ & DK & $\mathrm{EE}$ & ES & $\mathrm{FI}$ & GR & $\mathrm{HU}$ & IE & IS \\
\hline \multicolumn{15}{|c|}{ HOURLY WAGE } \\
\hline public & $2.847^{* * *}$ & $2.842^{* * *}$ & $0.428^{* * *}$ & $2.538^{* * *}$ & $1.539^{* * *}$ & $2.829^{* * *}$ & $3.211^{* * *}$ & $1.399^{* * *}$ & $2.536^{* * *}$ & $2.933^{* * *}$ & $2.507^{* * *}$ & $1.389^{* * *}$ & $3.180^{* * *}$ & $3.235^{* * *}$ \\
\hline private & $2.753^{* * *}$ & $2.839^{* * *}$ & $0.311^{* * *}$ & $2.242^{* * *}$ & $1.333^{* * *}$ & $2.794^{* * *}$ & $3.162^{* * *}$ & $1.266^{* * *}$ & $2.253^{* * *}$ & $2.805^{* * *}$ & $2.173^{* * *}$ & $1.098^{* * *}$ & $3.023^{* * *}$ & $3.082^{* * *}$ \\
\hline difference & $0.095^{* * *}$ & 0.004 & $0.117^{* * *}$ & $0.296^{* * *}$ & $0.206^{* * *}$ & $0.034^{* * *}$ & $0.049 * *$ & $0.133^{* * *}$ & $0.283^{* * *}$ & $0.128^{* * *}$ & $0.334^{* * *}$ & $0.291 * * *$ & $0.157^{* * *}$ & $0.153^{* * *}$ \\
\hline explained & $0.092^{* * *}$ & $0.036^{* * *}$ & $0.087^{* * *}$ & $0.097^{* * *}$ & $0.091^{* * *}$ & $0.087^{* * *}$ & 0.001 & $0.111^{* * *}$ & $0.151^{* * *}$ & $0.115^{* * *}$ & $0.144^{* * *}$ & $0.133^{* * *}$ & $0.061^{* * *}$ & $0.066^{* * *}$ \\
\hline pub. adv. & 0.003 & $-0.028^{* *}$ & 0.027 & $0.176^{* * *}$ & $0.108^{* * *}$ & $-0.045^{* * *}$ & $0.046^{* *}$ & 0.020 & $0.115^{* * *}$ & 0.012 & $0.159^{* * *}$ & $0.143^{* * *}$ & $0.081^{* * *}$ & $0.078^{* *}$ \\
\hline pri. disadv. & 0.000 & $-0.005^{* *}$ & 0.002 & $0.023^{* * *}$ & $0.007^{* * *}$ & $-0.007^{* * *}$ & $0.002^{* *}$ & 0.001 & $0.017^{* * *}$ & 0.001 & $0.031^{* * *}$ & $0.014^{* * *}$ & $0.014^{* * *}$ & $0.008^{* *}$ \\
\hline \multicolumn{15}{|l|}{ percent } \\
\hline explained & $96.84 \%$ & $900.00 \%$ & $74.36 \%$ & $32.77 \%$ & $44.17 \%$ & $255.88 \%$ & $15.87 \%$ & $83.46 \%$ & $53.36 \%$ & $89.84 \%$ & $43.11 \%$ & $45.70 \%$ & $38.85 \%$ & $43.14 \%$ \\
\hline pub. adv.. & $3.16 \%$ & $-700.00 \%$ & $23.08 \%$ & $59.46 \%$ & $52.43 \%$ & $-132.35 \%$ & $76.19 \%$ & $15.04 \%$ & $40.64 \%$ & $9.38 \%$ & $47.60 \%$ & $49.14 \%$ & $51.59 \%$ & $50.98 \%$ \\
\hline pri. disadv. & $0.00 \%$ & $-125.00 \%$ & $1.71 \%$ & $7.77 \%$ & $3.40 \%$ & $-20.59 \%$ & $6.35 \%$ & $0.75 \%$ & $6.01 \%$ & $0.78 \%$ & $9.28 \%$ & $4.81 \%$ & $8.92 \%$ & $5.23 \%$ \\
\hline \multirow[t]{2}{*}{ observ. } & 2,963 & 3,224 & 3,031 & 2,862 & 8,484 & 6,559 & 4,551 & 4,011 & 8,601 & 3,453 & 3,104 & 5,943 & 1,965 & 1,083 \\
\hline & IT & LT & LU & LV & NL & NO & $\mathrm{PL}$ & PT & RO & SE & $\mathrm{SI}$ & SK & UK & \\
\hline \multicolumn{15}{|c|}{ HOURLY WAGE } \\
\hline public & $2.719^{* * *}$ & $1.221^{* * *}$ & $3.297^{* * *}$ & $1.486^{* * *}$ & $3.227^{* * *}$ & $3.171^{* * *}$ & $1.451^{* * *}$ & $2.047^{* * * *}$ & $0.814^{* * *}$ & $2.928^{* * *}$ & $2.235^{* * *}$ & $1.185^{* * *}$ & $3.007^{* * *}$ & \\
\hline private & $2.489^{* * *}$ & $1.062^{* * *}$ & $2.962^{* * *}$ & $1.106^{* * *}$ & $3.092^{* * *}$ & $3.200^{* * *}$ & $1.178^{* * *}$ & $1.770^{* * *}$ & $0.520^{* * *}$ & $2.858^{* * *}$ & $2.009^{* * *}$ & $1.043^{* * *}$ & $2.909^{* * *}$ & \\
\hline difference & $0.230^{* * *}$ & $0.159^{* * *}$ & $0.335^{* * *}$ & $0.380^{* * *}$ & $0.134^{* * *}$ & -0.029 & $0.273^{* * *}$ & $0.277^{* * *}$ & $0.294^{* * *}$ & $0.070^{*}$ & $0.226^{* * *}$ & $0.142^{* * *}$ & $0.098^{* * *}$ & \\
\hline explained & $0.143^{* * *}$ & $0.142^{* * *}$ & $0.106^{* * *}$ & $0.241^{* * *}$ & $0.070^{* * *}$ & $0.044^{* * *}$ & $0.210^{* * *}$ & $0.124^{* * *}$ & $0.184^{* * *}$ & $0.042^{*}$ & $0.225^{* * *}$ & $0.063^{* * *}$ & 0.001 & \\
\hline pub. adv. & $0.077^{* * *}$ & 0.015 & $0.212^{* * *}$ & $0.124^{* * *}$ & $0.056^{* * *}$ & $-0.069^{* * *}$ & $0.058^{* * *}$ & $0.135^{* * *}$ & $0.104^{* * *}$ & 0.027 & 0.001 & $0.068^{* * *}$ & $0.086^{* * *}$ & \\
\hline priv. disadv. & $0.010^{* * *}$ & 0.001 & $0.017^{* * *}$ & $0.015^{* * *}$ & $0.008^{* * *}$ & $-0.004^{* * *}$ & $0.005^{* * *}$ & $0.017^{* * *}$ & $0.006^{* * *}$ & 0.001 & 0.000 & $0.011^{* * *}$ & $0.011^{* * *}$ & \\
\hline \multicolumn{15}{|l|}{ percent } \\
\hline explained & $62.17 \%$ & $89.31 \%$ & $31.64 \%$ & $63.42 \%$ & $52.24 \%$ & $-152.00 \%$ & $76.92 \%$ & $44.77 \%$ & $62.59 \%$ & $60.00 \%$ & $99.56 \%$ & $44.37 \%$ & $2.04 \%$ & \\
\hline pub. adv. & $33.48 \%$ & $9.43 \%$ & $63.28 \%$ & $32.63 \%$ & $41.79 \%$ & $238.00 \%$ & $21.25 \%$ & $48.74 \%$ & $35.37 \%$ & $38.57 \%$ & $0.44 \%$ & $47.89 \%$ & $93.88 \%$ & \\
\hline pri. disadv. & $4.35 \%$ & $0.63 \%$ & $5.07 \%$ & $3.95 \%$ & $5.97 \%$ & $14.00 \%$ & $1.83 \%$ & $6.14 \%$ & $2.04 \%$ & $1.43 \%$ & $0.00 \%$ & $7.75 \%$ & $4.08 \%$ & \\
\hline observ. & 10,219 & 3,575 & 2,912 & 3,726 & 2,485 & 2,128 & 8,586 & 2,777 & 4,588 & 2,493 & 3,365 & 5,521 & 4,439 & \\
\hline
\end{tabular}

Note: Three stars indicate significance at the $1 \%$, two stars at the $5 \%$ and one star at the $10 \%$ level. Pay gaps are Bolded. 
as Belgium, Germany and Norway), are Austria, Bulgaria, Estonia, Spain, Finland, Italy, Lithuania, Latvia, Netherlands, Poland, Romania, Sweden, and Slovenia. As the lower half of Table 1 shows, in the case of Austria and Slovenia, the explained part reaches $96.84 \%$ and $99.56 \%$ of the total gap respectively and, in some other countries (Bulgaria, Estonia, Finland, Lithuania, and Poland), the explained percentage is over $70 \%$. While eleven countries (Cyprus, the Czech Republic, Greece, Hungary, Ireland, Iceland, Luxembourg, Portugal, Slovakia, Denmark and the UK) have explained components which are lower than the unexplained components, the four PCs are all in this category, suggesting that the Troika's preoccupation with public pay reductions may be justified. The UK is a country with a middling ln wage gap (9.8\%) of which only $2.04 \%$ is explained by personal and job characteristics.

Figure 3 summarises these findings visually. The explained component (bottom of bars) is shown in very dark grey. The public sector advantage (middle of bars) is shown in light grey and the private sector disadvantage (top of bars) is shown in medium grey. The figure clearly shows the explained component which, in many countries, reduces the size of the public-private wage gap puzzle substantially. The unexplained component, the sum of the other two bars, is dominated by the public sector advantage. It is this amount which should be the subject of policy interest.

A number of important policy issues are buried into the results of Table 1 and Figure 3. These involve the contribution of age, education, gender, and occupation to the decompositions and we now proceed to consider these in greater depth. Most of these breakdowns are based on exogenous (age, gender) or largely predetermined in 2008 (occupation, education) decisions. We also examine the definitional issue of hourly versus monthly wages. The differentiation of the public-private wage gap by income level is examined through quantile analysis in Section 4.4.

\subsection{Sub-sample analysis}

The explained part of the decompositions presented above can be broken down into the contribution of each variable but, in light of the large number of variables and countries involved, this exercise would not have yielded transparent results. Instead, and in light of the exogeneity/predeterminateness noted earlier, we divide the sample into sub-groups of interest and repeat the ln hourly wage decompositions for all countries.

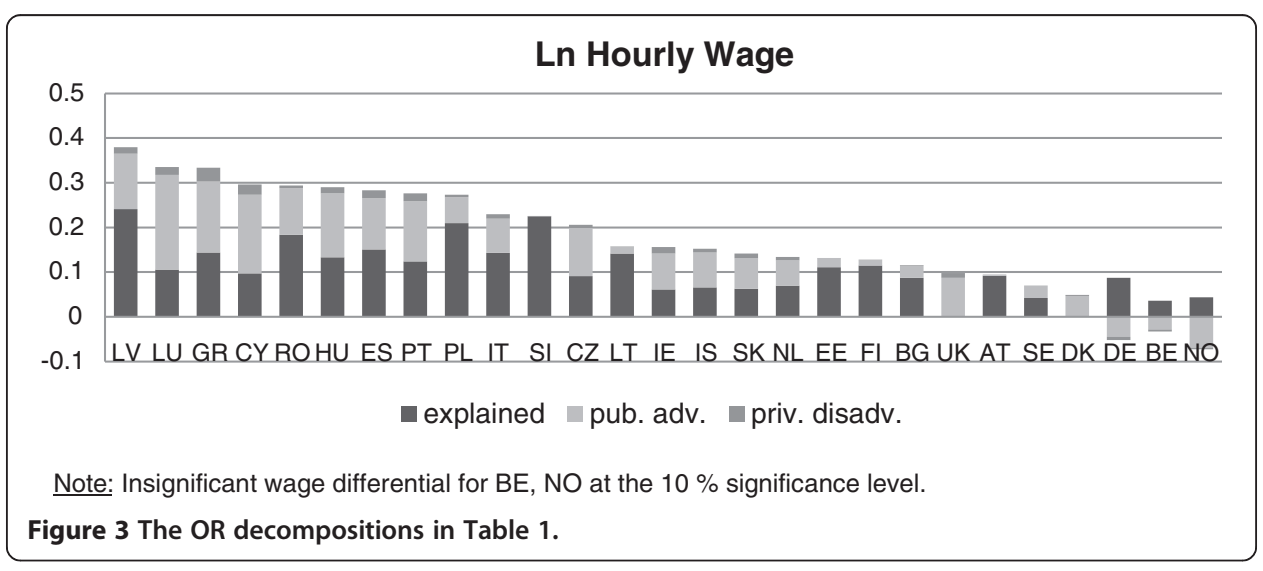




\subsubsection{Age}

As indicated in Figure 4, the ranking of countries by public-private pay gap changes substantially once we condition on age. In addition, the distinction between the explained and unexplained gap is important to keep in mind. Cyprus, for instance, seems to have double the wage gap for older workers compared to younger ones $(0.415$ compared to $0.202 \mathrm{ln}$ wage points). This might indicate that experience is valued more in the public sector, compared to the private. Indeed, a higher proportion of the gap is explained for older workers $(0.173 / 0.415=0.42)$ than for the young $(0.047 / 0.202=0.23)$ see Table 7 in the Appendix for full results. Slovenia also exhibits a much higher gap for older workers, compared to the young. However, for Slovenia most of the gap is explained, which suggests that among people aged 45 and over, public sector employees are more qualified. Some other examples of countries with slightly higher gaps for the older worker group are Austria, Finland, Ireland, Poland, and Slovakia.

On the other hand, there are countries where younger workers have a much higher wage differential, compared to the older-employee group. Romania for example has a wage differential of $0.363 \mathrm{ln}$ wage points for younger employees, but only 0.178 for older workers. Similarly, Bulgaria, Hungary, Latvia, Italy, Portugal and Luxembourg have higher gaps for the young. In the case of ex USSR countries, this might reflect a need to attract workers with new skills which might, at least soon after the breakdown of the USSR, be in short supply.

This kind of information might identify possible problems with public sector payment structures and identify structural reforms which might improve the efficiency of this sector.

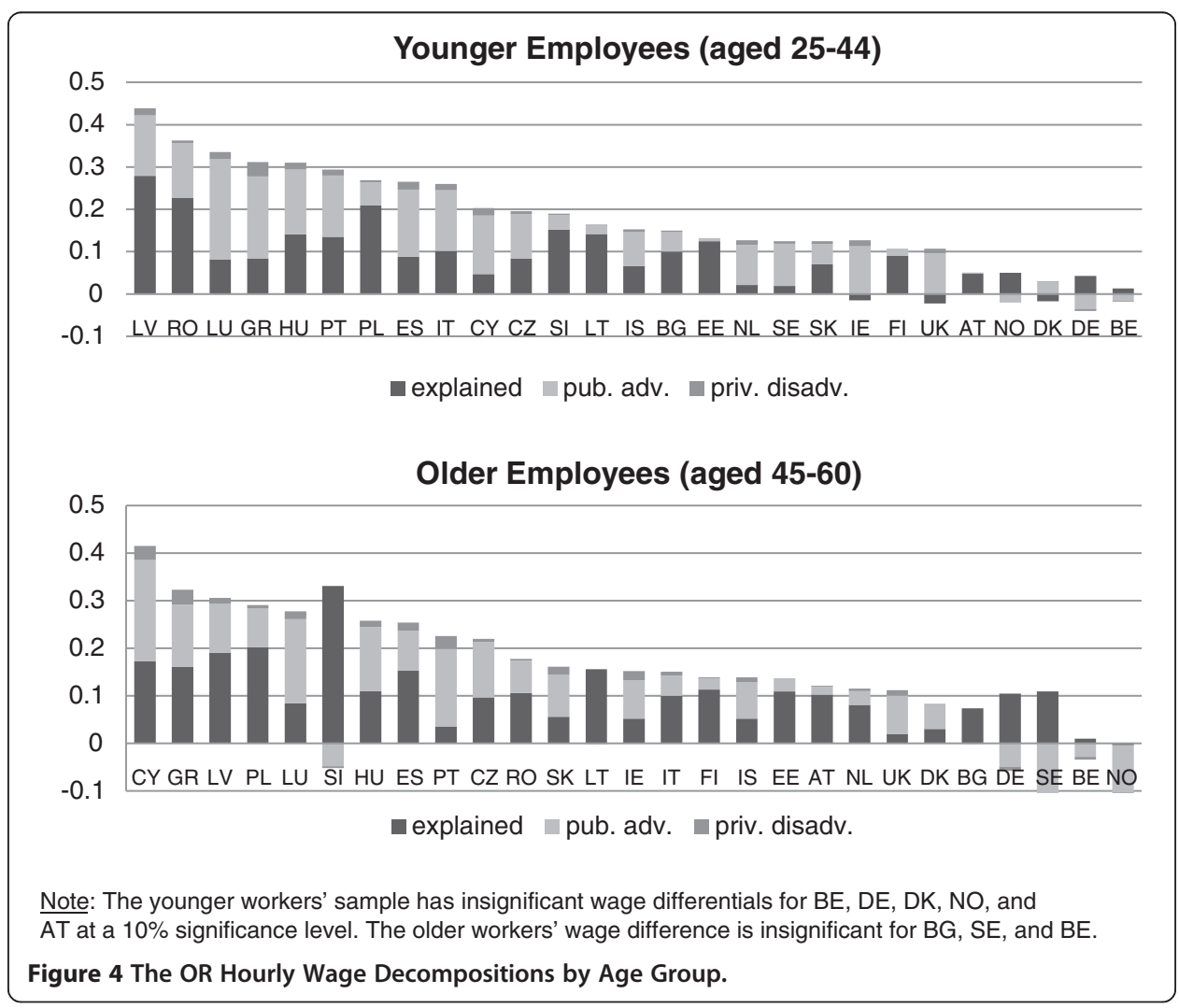


However, such analysis should be done with caution, since differences might be due to not just pay scales but also cohort differences and other unmeasured characteristics.

\subsubsection{By education}

We also divide the sample into tertiary educated and non-tertiary educated individuals. From Figure 5 and Table 8 in the Appendix, it is obvious that, in most countries, less educated workers are compensated much more in the public sector than in the private sector. Luxembourg for example, which has one of the highest ln wage differentials in total sample estimates, has an insignificant wage differential for tertiary educated employees, while for less educated individuals the differential is the highest among all countries (0.542 ln wage points). This pattern also holds for the unexplained gaps. In the case of Cyprus, the total gap for less educated workers is 0.428 ln wage points compared to 0.084 points for tertiary education graduates and the unexplained gap follows a similar pattern. This information is of critical importance to current efforts to reform the labour market in Cyprus. Indeed, it would appear that Troika-backed changes to the public-private wage gap in Cyprus may have stressed reductions to wages at the high end of the earnings distribution unduly.

Exceptions to the general pattern discussed above are found in the five new MSs, Estonia, Hungary, Lithuania, Bulgaria, Romania, where public-private wage gap is higher for tertiary education graduates both in total and at the unexplained level. As in the case of age, this may reflect shortages that may have emerged following the collapse of the USSR.

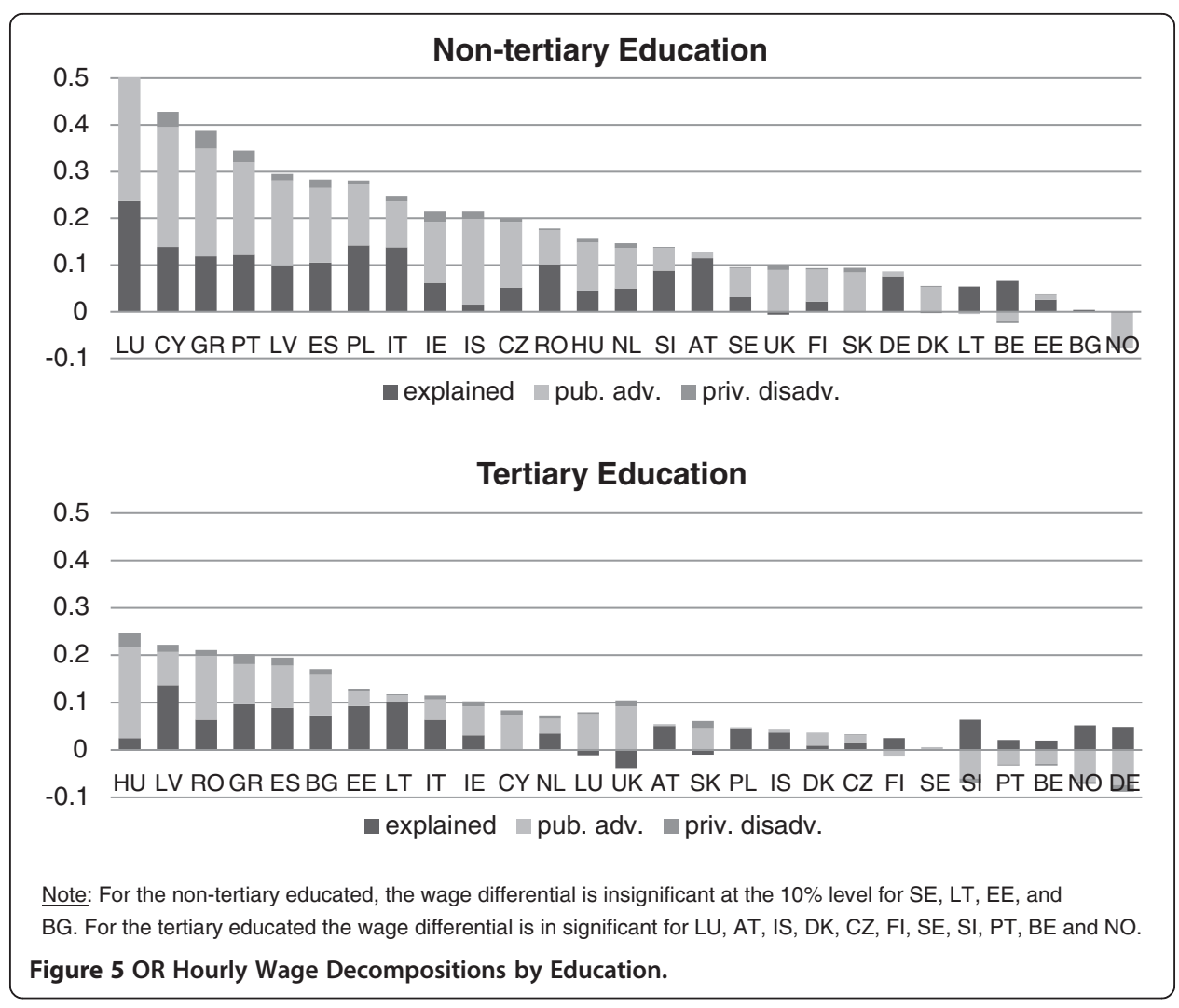




\subsubsection{By gender}

Wage differentials by gender are widely discussed in the literature - for an extensive treatment for OECD countries see Anghel et al. (2011). In the context of the publicprivate sector, some literature has reported evidence for higher public-private sector wage gaps for females than for males. In our estimates (Figure 6 and Table 9 in the Appendix), we obtain mixed results. The public-private sector ln wage gap is higher by more than 0.10 ln wage points for women in Latvia, Lithuania and Estonia, countries that in Christofides et al. (2013) were found to have relatively large gender wage gaps. A higher public-private sector pay gap for females may indicate considerable private sector disadvantage and/or progressive public sector pay policies but these effects do not fully remove the disadvantage that women have in these countries. Giordano et al. (2011) find that the pay gap is generally higher for women at the low end of the wage distribution. However, more than half of the 27 countries have higher public-private sector gaps for males. Low pay differences between men and women (about $0.02 \mathrm{ln}$ wage points) are observed in Bulgaria, Cyprus, Spain, Italy, Portugal, Slovenia and Slovakia, and high ones in Iceland, Poland, and Sweden (0.124, 0.073 and 0.099 respectively) - Figure 6 and Table 9 in the Appendix.

\subsubsection{Occupation: clerks}

We have singled out clerks for special attention because they are relatively low-paid and, in principle, similar across sectors; they are also a relatively numerous category of public sector employees. Results appear in Figure 7 and Table 10 in the Appendix. When clerks only are considered, the public-private ln wage differential is generally lower than in the total sample and insignificant for about half of the countries.

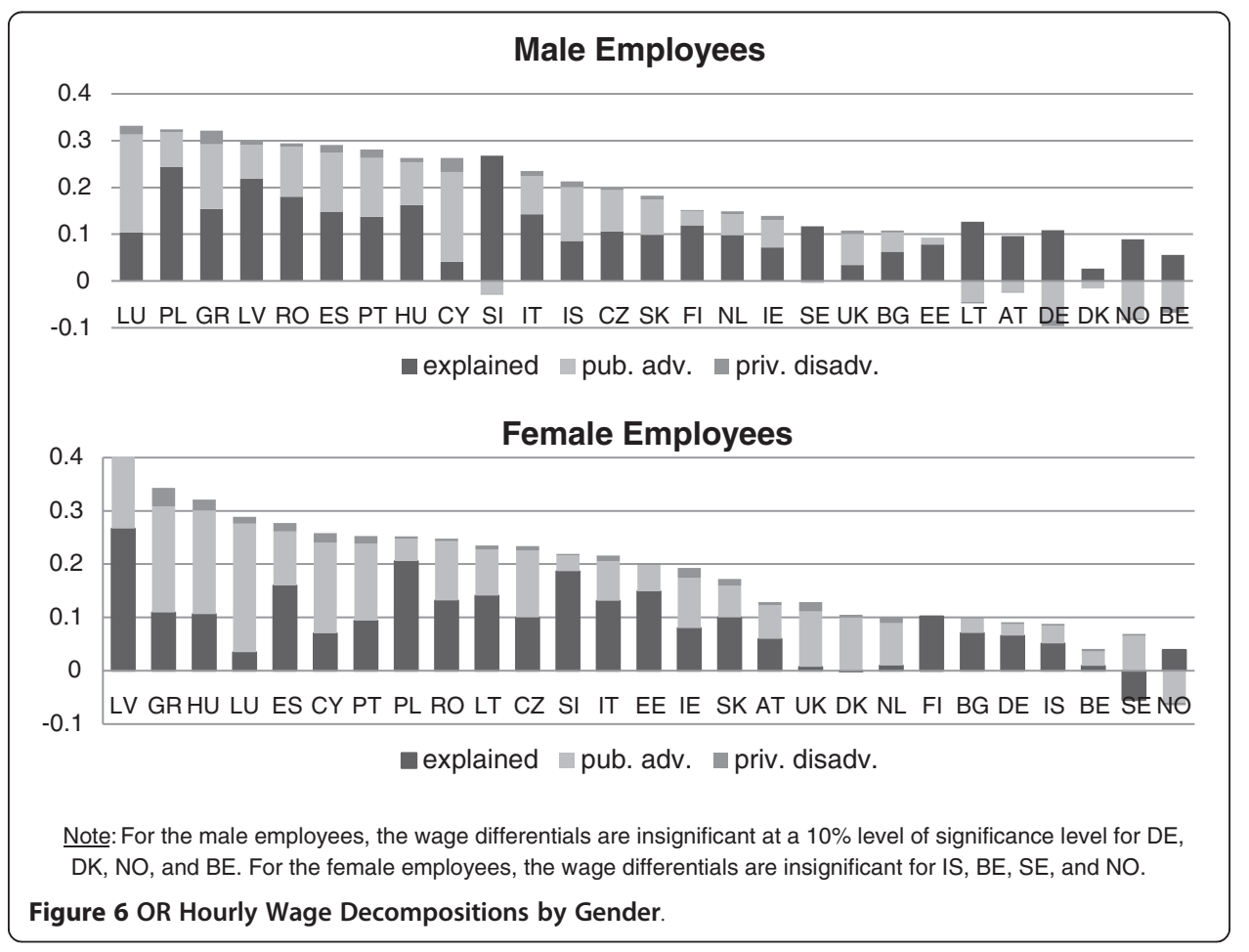




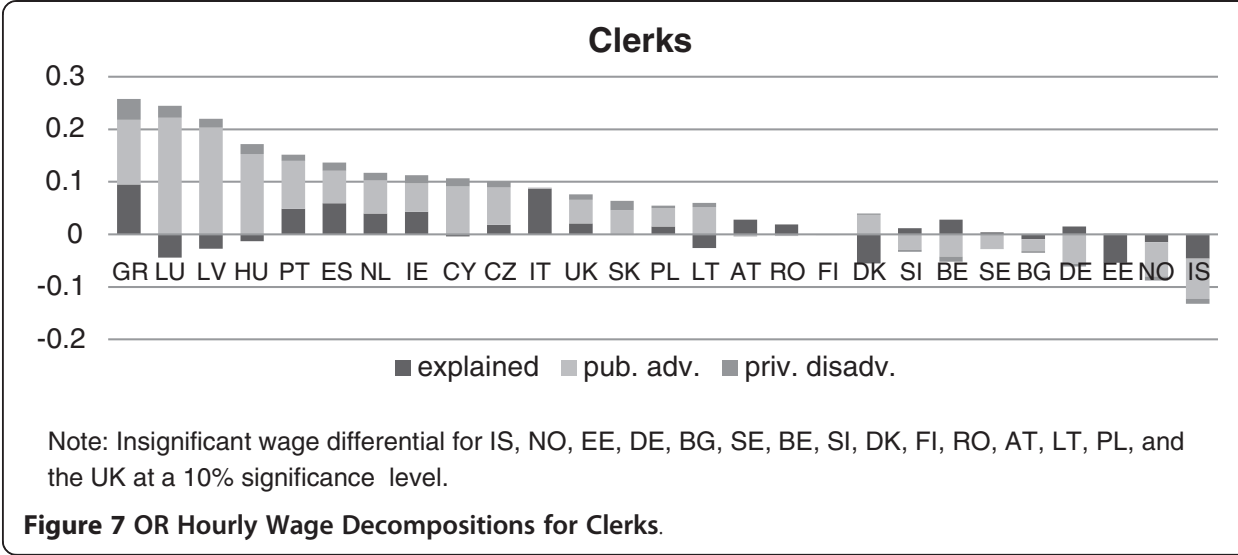

The highest public-private ln wage differential for clerks is observed for Greece, Luxembourg, Latvia, Hungary and Portugal. These countries also have among the highest total-sample public-private $\ln$ wage gaps. Cyprus and Romania have a significantly lower public-private ln wage differential for clerks compared to the one estimated for the total sample. This may reflect more heterogeneous occupations in the private sector of these countries, a fact which may not be adequately captured by the available occupation controls. For example, in Romania, an important part of the private sector is related to low-paid primary occupations (around 30\% of total employment, the highest in the EU) which are not present in the public sector. We may then find a large wage gap in the total sample whereas, in the clerks' sample, the gap may be insignificant if the remuneration of clerks in the two sectors is comparable. Unfortunately, we do not have enough observations in the sample to explore this issue further.

Though the total public-private ln wage gap is generally lower for clerks, for the majority of countries the gap is largely unexplained except for Italy and (partly) Spain, Greece and Portugal. This might reflect a larger degree of educational mismatch in these countries, i.e. educated people take unskilled jobs due to the inability to find a skilled job with a satisfactory wage. The $\mathrm{X}$ variables will then be comparable across sectors, placing a larger burden on the unexplained component.

\subsubsection{Monthly wage decompositions}

Because hours of work may differ in a systematic way between the public and private sectors, it is possible that public-private wage gaps may look different if based on hourly rates than if based on monthly rates. Accordingly, we check our main findings, which are generally based on hourly rates, using monthly wages.

Hours in the private sector are higher and, with the exception of a handful of countries, the public-private ln wage gap is generally higher when using hourly wages. This holds with both the OLS results (see Figure 14 in the Appendix and results in Table 11 in the Appendix) and the OR decomposition in Figure 8 (Table 12 in the Appendix). The ranking of countries is approximately the same, though, as that of hourly wage estimates. Note that Belgium and Norway have a slightly negative total public-private ln wage differential, significant at the $10 \%$ level; for these countries, the hourly gap was insignificant.

The proportion of the total gap that is explained is generally lower when hourly rates are used than is the case with the monthly data examined here (see Figures 3 and 8). 


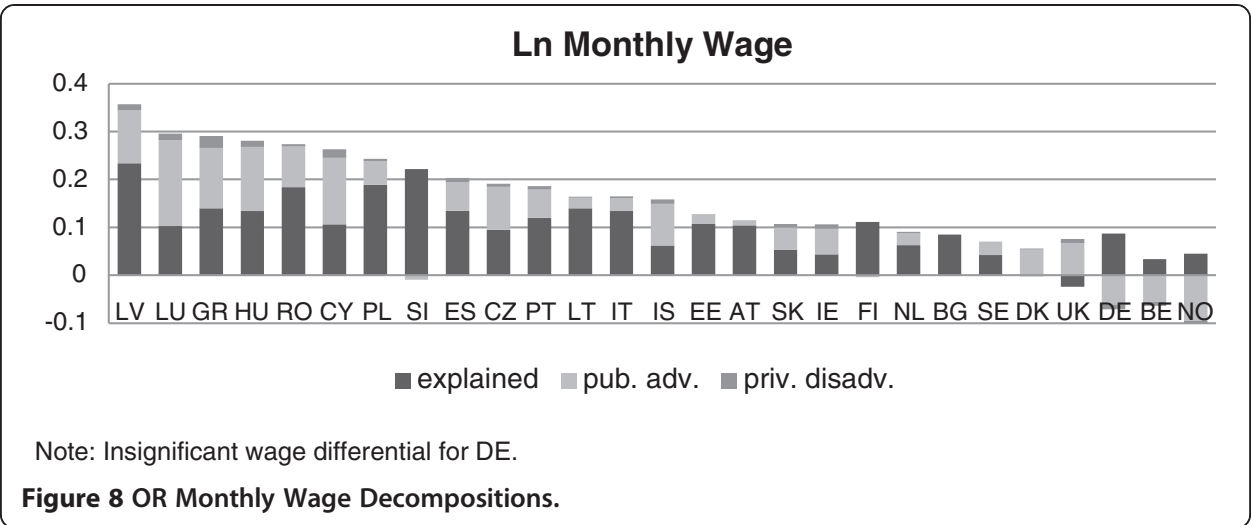

This suggests that the use of actual hours worked, far from contributing to further understanding of the gap, increases the unexplained public-private sector gap. This dimension of private sector disadvantage is brought to the surface, justifying the use of hourly rates.

Slovenia continues to have the entire public-private gap explained by characteristics and some countries (Finland and Bulgaria) now join that case. Germany continues to have an explained component which is larger than the total, suggesting that rewards in the public sector should either be larger or that there are features of public sector rewards, such as working conditions and retirement provisions, that are not captured by the data and which bring the remuneration package in the two sectors into closer alignment.

\subsection{Quantile analysis}

An unexplained public-private pay gap in a country raises questions about productive efficiency, the extent to which unwarranted public sector settlements might spill over into the private sector and affect competitiveness, and about public finances. It also raises questions about equity as most analysts would consider that, taking all factors into account, overall remuneration (including retirement and other working provisions) should be similar in the two sectors. Thus, a constant pay gap across income levels would raise questions along the lines just noted.

A number of further issues arise when the public-private pay gap is not constant across income levels. A large starting pay gap would attract more competent young entrants into the public service but also exacerbate queuing phenomena and early-career turnover. For a given overall pay gap, it would also mean that the public-private differential diminishes or becomes negative at higher levels of income, encouraging turnover at the more senior level or, worse still, discouragement and underperformance. On the other hand, steep profiles (relative to those prevailing in the private sector) may fail to attract liquidity-constrained but competent young entrants and those that do enter the public service may never wish to leave.

\subsubsection{Coefficient on public (specification of Table 6 in the Appendix)}

We begin by examining whether the coefficient for Public in the wage equation varies across quantiles ${ }^{6}$. Table 2 summarises our findings when the conditioning equation is that which lies behind Table 6 in the Appendix. We provide estimates only for the coefficient on Public, for five quantiles: the 10th, 25th, 50th (median), 75th and the 90th. 
Table 2 Quantile regression results for the coefficient on Public

\begin{tabular}{|c|c|c|c|c|c|c|c|c|}
\hline $\begin{array}{l}\text { Countries/ } \\
\text { Quantiles }\end{array}$ & $q 10$ & $q 25$ & q50 & $q 75$ & $q 90$ & $\begin{array}{l}\text { Mean } \\
\text { (OLS) }\end{array}$ & $\begin{array}{l}\text { F-Test for } \\
\text { q equality } \\
\text { (p-value) }\end{array}$ & Obs \\
\hline AT & 0.051 & 0.040 & 0.007 & -0.009 & -0.027 & 0.003 & 0.709 & 2,963 \\
\hline $\mathrm{BE}$ & -0.005 & -0.021 & $-0.046^{* * *}$ & $-0.056^{* *}$ & $-0.072^{* * *}$ & $-0.034^{* *}$ & 0.140 & 3,224 \\
\hline$B G$ & $0.084^{* *}$ & 0.015 & 0.010 & 0.009 & 0.006 & 0.031 & 0.298 & 3,031 \\
\hline $\mathrm{CY}$ & $0.416^{* * *}$ & $0.302^{* * *}$ & $0.197^{* * *}$ & $0.067^{* * *}$ & -0.009 & $0.210^{* * *}$ & 0.000 & 2,862 \\
\hline$C Z$ & $0.134^{* * *}$ & $0.143^{* * *}$ & $0.150^{* * *}$ & $0.109^{* * *}$ & $0.084^{* * *}$ & $0.119^{* * *}$ & 0.072 & 8,484 \\
\hline $\mathrm{DE}$ & $0.150^{* * *}$ & $0.023^{*}$ & $-0.063^{* * *}$ & $-0.138^{* * *}$ & $-0.195^{* * *}$ & $-0.055^{* * *}$ & 0.000 & 6,559 \\
\hline DK & $0.100^{* * *}$ & $0.040^{*}$ & 0.025 & 0.027 & 0.006 & $0.048^{* *}$ & 0.026 & 4,551 \\
\hline $\mathrm{EE}$ & $0.103^{* *}$ & $0.074^{* *}$ & 0.030 & -0.038 & $-0.122^{* *}$ & 0.023 & 0.003 & 4,011 \\
\hline ES & $0.226^{* * *}$ & $0.230^{* * *}$ & $0.144^{* * *}$ & $0.091^{* * *}$ & $0.053^{* *}$ & $0.141^{* * *}$ & 0.000 & 8,601 \\
\hline $\mathrm{FI}$ & $0.083^{* * *}$ & $0.064^{* *}$ & 0.020 & -0.018 & $-0.052^{* *}$ & 0.014 & 0.006 & 3,453 \\
\hline GR & $0.190^{* * *}$ & $0.263^{* * *}$ & $0.239 * * *$ & $0.194^{* * *}$ & $0.127^{* * *}$ & $0.203^{* * *}$ & 0.002 & 3,104 \\
\hline $\mathrm{HU}$ & $0.147^{* * *}$ & $0.155^{* * *}$ & $0.165^{* * *}$ & $0.191^{* * *}$ & $0.144^{* * *}$ & $0.165^{* * *}$ & 0.566 & 5,943 \\
\hline $\mathrm{IE}$ & $0.224^{* * *}$ & $0.215^{* * *}$ & $0.073^{* * *}$ & 0.037 & -0.015 & $0.102^{* * *}$ & 0.000 & 1,965 \\
\hline IS & $0.142^{* *}$ & 0.084 & $0.076^{* *}$ & 0.046 & 0.067 & $0.092^{* *}$ & 0.844 & 1,083 \\
\hline IT & $0.181^{* * *}$ & $0.147^{* * *}$ & $0.108^{* * *}$ & $0.064^{* * *}$ & 0.001 & $0.094^{* * *}$ & 0.000 & 10,219 \\
\hline LT & $0.086^{* *}$ & 0.021 & -0.001 & 0.051 & -0.026 & 0.017 & 0.033 & 3,575 \\
\hline LU & $0.264^{* * *}$ & $0.366^{* * *}$ & $0.277^{* * *}$ & $0.234^{* * *}$ & $0.166^{* * *}$ & $0.241^{* * *}$ & 0.011 & 2,912 \\
\hline LV & $0.270^{* * *}$ & $0.237^{* * *}$ & $0.133^{* * *}$ & $0.074^{*}$ & 0.011 & $0.148^{* * *}$ & 0.000 & 3,726 \\
\hline $\mathrm{NL}$ & $0.173^{* * *}$ & $0.129^{* * *}$ & $0.094^{* * *}$ & 0.035 & $-0.055^{* *}$ & $0.067 * * *$ & 0.000 & 2,485 \\
\hline NO & 0.042 & -0.026 & $-0.038^{*}$ & $-0.131^{* * *}$ & $-0.213^{* * *}$ & $-0.075^{* * *}$ & 0.000 & 2,128 \\
\hline$P L$ & $0.163^{* * *}$ & $0.117^{* * *}$ & $0.091 * * *$ & $0.051^{* *}$ & $-0.052^{*}$ & $0.068^{* * *}$ & 0.000 & 8,586 \\
\hline PT & $0.237^{* * *}$ & $0.242^{* * *}$ & $0.151^{* * *}$ & $0.088^{*}$ & 0.051 & $0.158^{* * *}$ & 0.000 & 2,777 \\
\hline $\mathrm{RO}$ & 0.035 & $0.114^{* * *}$ & $0.099 * * *$ & $0.133^{* * *}$ & $0.123^{* *}$ & $0.114^{* * *}$ & 0.700 & 4,588 \\
\hline SE & $0.117^{* * *}$ & 0.009 & 0.001 & -0.063 & -0.042 & 0.029 & 0.011 & 2,493 \\
\hline $\mathrm{SI}$ & $0.103^{* *}$ & -0.006 & -0.009 & 0.006 & -0.043 & 0.001 & 0.040 & 3,365 \\
\hline SK & $0.137^{* * *}$ & $0.115^{* * *}$ & $0.083^{* * *}$ & $0.087^{* * *}$ & 0.030 & $0.084^{* * *}$ & 0.001 & 5,521 \\
\hline UK & $0.181^{* * *}$ & $0.149 * * *$ & $0.107^{* * *}$ & $0.061^{* * *}$ & 0.054 & $0.101^{* * *}$ & 0.003 & 4,439 \\
\hline
\end{tabular}

Notes: (i) The OLS coefficients for Public differ from those in Table 6 in the Appendix because coefficients are not normalised (Other is omitted). The reference group is the private sector, age 25-29, lower education, female, and in occupation d. (ii) Bootstrap standard errors are based on 50 repetitions. (iii) Job permanency information is not available for Denmark and the UK. (iv) F-tests are for the joint equality of coefficients across the five quantiles.

The results are quite informative. The $\mathrm{F}$ test for the joint equality of the coefficients on Public in the five quantiles rejects equality in 21 out of the 27 cases. The joint equality of coefficients cannot be rejected for Austria, Belgium, Bulgaria, Hungary, Iceland, and Romania.

A number of patterns emerge. The relationship between the pay gap and the hourly wage quantiles is generally negative. This finding is also observed in previous studies, such as Mueller (1998) for Canada and Lucifora and Meurs (2006) for Italy, France and the UK. As shown in Table 2, interesting points of detail can be discerned. Many countries have individually significant and positive gaps at the lowest quantiles, which decline and turn insignificant or even negative at higher quantiles (Cyprus, Ireland, Iceland, Italy, Latvia, Netherlands, Poland, Slovakia, Denmark, and the UK). For Bulgaria, Finland, Lithuania, Sweden, Slovenia, and Denmark, the coefficient on Public is individually insignificant at all quantiles except at the lowest part of the distribution, where the public sector is shown 
to pay significantly more than the private sector. The pattern is more complex in some countries, where a positive and individually significant gap for all quantiles is higher in the middle of the distribution at q25 to q50 (Czech Republic, Spain, Greece, Hungary, Luxembourg, and Portugal). Belgium and Norway have negative or insignificant gaps for all quantiles, which become more negative and individually significantly different from zero at the highest quantiles. Austria has individually insignificant public sector coefficients at all points of the distribution. In the case of Austria and Belgium, the F test does not reject the equality of coefficients. Finally, Romania is the only country where the gap is smallest and insignificant at the lowest quantile, while positive and significant at higher quantiles; however, the F test accepts coefficient equality. Table 2 provides further details. It is not clear from our 2008 EU SILC snapshot whether these profiles are steady state ones or whether they are the result of cohort and other historical effects.

\subsubsection{Quantile decompositions}

In addition to the quantile analysis of the coefficient for Public administration presented above, we decompose differences in the distributions of the public and private sector based on Machato and Mata (2005) and Chernozukhov et al. (2013) ${ }^{7}$. Similar to the Oaxaca decomposition, this method can decompose the difference between the entire public and private wage distributions into a part attributed to the effects of characteristics (explained) and a part due to differences in coefficients or differences in the wage structure of the two groups (unexplained). To construct the conditional distribution of wages for private employees and hence, the counterfactual distribution necessary for the decomposition, we use linear quantile regression as in the previous section. We present the decomposition results estimated for nine quantiles (0.1 to 0.9) in Figures 9 and $10^{8}$.

The analysis described in this section is performed: (a) for each country separately in Figure 9 and (b) for two groups of countries: the four PCs and all remaining countries in the sample (Figure 10). In order to make Figure 9 more readable, the results are presented in groups which are roughly based on the patterns involved. The total and unexplained components are shown on the left and right-hand graphs respectively. In Groups A and B are countries with high total differences across quantiles and with a lower difference observed at the highest quantiles. The pattern for Group A (Cyprus, Germany, Ireland, Italy, Norway and the Netherlands) is roughly one of a straight negatively sloped line, while that for Group B (Greece, Portugal, Spain, the United Kingdom and Luxembourg) generally involves more complexity, with high differences between the 0.2 and 0.5 quantiles. In these two groups we observe all PCs (Cyprus and Ireland in group A and Greece and Portugal in Group B). We also see other Southern European countries, such as Italy and Spain, in groups A and B. Luxembourg, which is among the highest pay-gap countries, also has the biggest difference in distributions across quantiles (the difference at q20 is 0.51 ln wage points but only 0.07 at q90). However, we observe some low pay gap countries to also exhibit high differences across quantiles. For example, Germany has a maximum difference of 0.29 at q10 and a minimum one of -0.19 at q90. A similar comment holds for Norway and the United Kingdom.

Note that, the unexplained difference in distributions follows a similar pattern for most countries but at slightly lower levels than the total gap, with a couple of exceptions. For Cyprus the unexplained part is especially high and equals the total gap at $\mathrm{q} 10$, but it becomes lower than the total at the highest quantiles. For the UK, the 


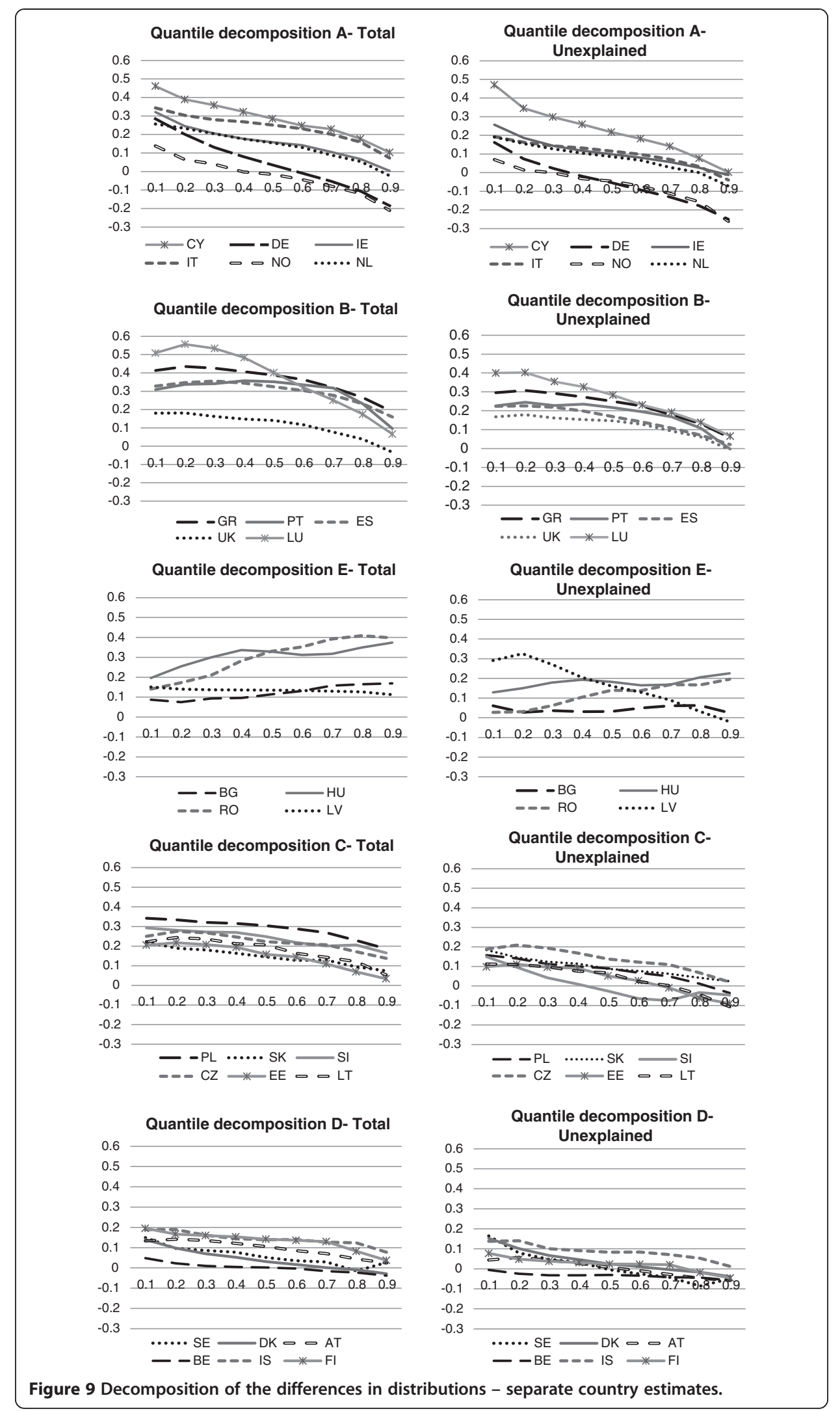




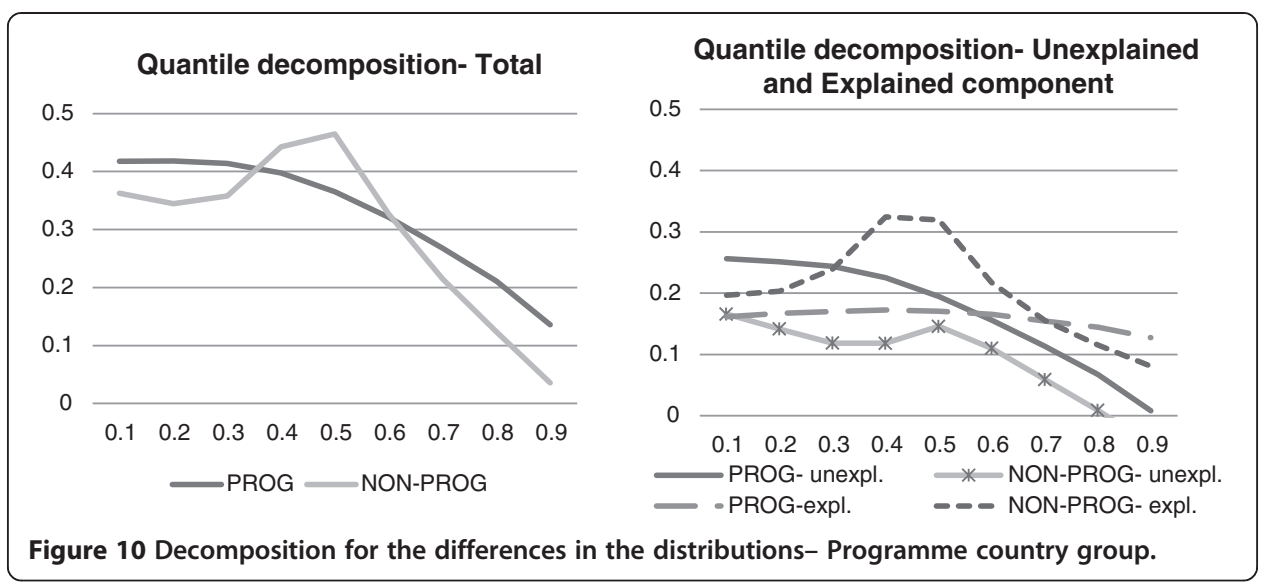

unexplained gap is almost identical to the total gap. This is a consistent finding for the UK across most of our approaches.

Groups C and D are countries with generally lower differences across quantiles; a lower gap at the higher relative to the low quantiles is still in evidence. Group $\mathrm{C}$ countries have somewhat higher gaps in levels compared to Group D, though they exhibit the same pattern. Note that countries in group C (Poland, Slovakia, Slovenia, the Czech Republic, Estonia, and Latvia) are all ex-USSR countries and new MSs, while countries in Group D (Sweden, Denmark, Austria, Belgium, Iceland, and Finland) include Scandinavian and other central European countries.

Finally, in Group E we present countries with a total difference which is roughly constant across quantiles (e.g. Latvia), or with a positive difference and a positive slope across quantiles (Bulgaria, Hungary, and Romania). Note that, these are also all exUSSR countries and new MSs. For Latvia, despite the constant difference across quantiles, the difference in coefficients (unexplained) is much higher at the lowest quantiles.

When the programme and non-programme countries are grouped (Figure 10), it is noteworthy that the unexplained component for the former lies uniformly above that for the latter - see the right-hand graph in Figure 10.

\subsection{Correcting for selection}

As noted in Section 3, a number of exclusions (e.g. part-timers, students, retired, disabled, soldiers and the self-employed) were imposed in order to focus on a sample of paid employees which is reasonably homogeneous and which could, in principle, be located in either the public or the private sector. The selected sample includes the unemployed and those inactive. It is conceivable that unobservables may steer individuals into the sample of paid employees and that these unobservables may not be independent of unobservables in the wage equations. This may be particularly the case with individuals who may, in time, withdraw from the labour force for family-formation reasons but will, until then, underperform in terms of earnings. In addition, some individuals with a strong preference for leisure, perhaps because of independent means, may exclude themselves from employment by specifying reservation wages which are unrealistically high. It would, therefore, be useful to check the sample of paid employees used so far for selection. 
One way of proceeding is to re-estimate Table 6 in the Appendix taking care of selection as well. We do so using the Maximum Likelihood (ML) version of the Heckman correction in Stata. In the implied first-stage Probit equation we include, in addition to the age, education, and gender variables that appear in the standard wage equations, marital status, the number of children (childn), whether paid childcare is used (paidc), whether childcare is provided by relatives (relativec), and net exogenous income (exog inc=rents, dividends and unincorporated profits). These are reasonable instruments, in addition to the non-linearity of Probit, for determining paid employment.

Table 13 in the Appendix ${ }^{9}$ parallels Table 6 in the Appendix which was discussed earlier. The explanatory variables behave as expected in the Mincer equations. The extent to which the selection correction is warranted can be judged from the significance of the correlation coefficient between the error term in the Probit and the wage equation, which Stata reports in the row 'athrho' of Table 13 in the Appendix. In one third of the 27 countries this correlation is not significantly different from zero, suggesting that selection is not important ${ }^{10}$. But in the large majority of the countries it is significantly positive or negative and sometimes quite large in absolute value. It is, therefore, necessary to take selection into account and to explore how different the coefficients on 'Public' (always defined as NACE=L) are between Tables 6 and 13 of the Appendix.

Table 14 in the Appendix reports the Probit equation, estimated as part of the ML approach which produces Table 13 in the Appendix, where unity indicates paid employment, and zero unemployment or inactivity. Early and late stages of life are associated with reduced propensity, while high levels of education with increased likelihood of paid employment (relative to the unemployed and inactive). Males are more prone to paid employment, marital status has mixed coefficients, and those with more children generally have lower probability of paid employment. Other variables of special interest generally behave as expected. The availability of child care by relatives is associated with higher probability of paid work in almost all countries. Paid child care is associated with a lower probability of paid work in about two thirds of the countries studied. The ambiguity of sign may indicate some endogeneity. Finally, outside income is clearly associated with reduced proclivity for paid work.

Figure 11, reports the coefficients on the dummy variable signifying the public sector. The dark bars correspond to Figure 2 and the numbers in Table 6 in the Appendix, while the light grey ones correspond to the selection-corrected ones in Table 13 in the Appendix. As can be seen, the coefficients on the variable Public are very similar across the two tables. This suggests that selection does not influence in a quantitatively

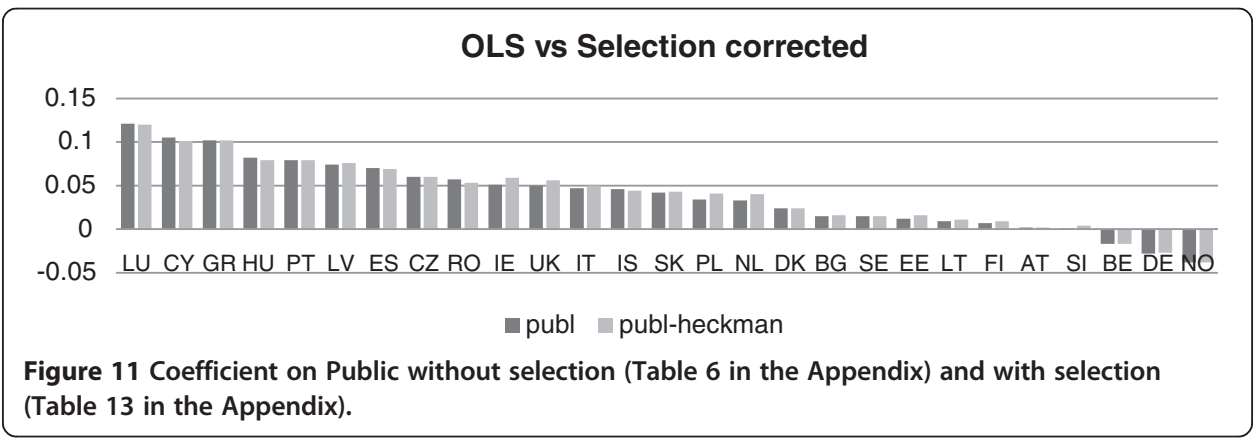


important way the coefficient estimate of the public sector dummy variable. However, selection must be taken into account, since the evidence in Table 13 in the Appendix suggests that it is a statistically important force. The modest differences between the dark and light grey bars in Figure 11 may not tell the whole story in that quantitatively important effects may materialise with respect to the coefficients on other variables, affecting OR decompositions.

The selection approach adopted above is clean but potentially limited in scope. One can imagine a more complete approach where, having excluded soldiers, students and the retired, observations are selected into self or paid employment and, if the latter, into the public or private sector with controls in the wage equation for part-time status and disability. However, this procedure is too ambitious given the availability of observations ${ }^{11}$.

As a check on the selection procedure first reported, we have carried out OR decompositions, having run a first-stage Probit equation that sorts observations into paid employment (out of the entire sample that also includes the unemployed and the inactive). The estimate of the inverse Mills ratio $\hat{\lambda}_{i}, i=(P, R)$, from this equation was included as a variable with an estimated coefficient $\hat{\theta}_{P}$ in the public and $\hat{\theta}_{R}$ in the private sector wage equations that feed into the OR decompositions ${ }^{12}$. The Probit specification (Table 16 in the Appendix) is the same as that outlined in the ML, system, procedure above but, of course, the results are not identical to those in Table 14 in the Appendix due to the difference in estimation procedure adopted (Heckit rather than ML). Note that, although the number of observations in Tables 14 and 16 in the Appendix are generally the same, the small differences in the number of observations for Denmark, Iceland and Romania arise because the Stata routine for Probit drops the childcare variable for these three countries where there is almost no cross-sectional variation. The implied decompositions appear in Table 15 in the Appendix and in Figure 12, similar to Figure 3.

The difference in the selection terms (item four on the right-hand-side of the equation in endnote 12) is significant at the 10\% level in 10 of the 27 countries (Cyprus, Denmark, Finland, Germany, Netherlands, Poland, Portugal, Slovenia, Spain, and the UK). Figures 3 and 12 have the same general setup; however, Figure 3 decomposes the 'measured' and Figure 12 the 'offered' wage gap. The ranking of countries by the size of the offered gap

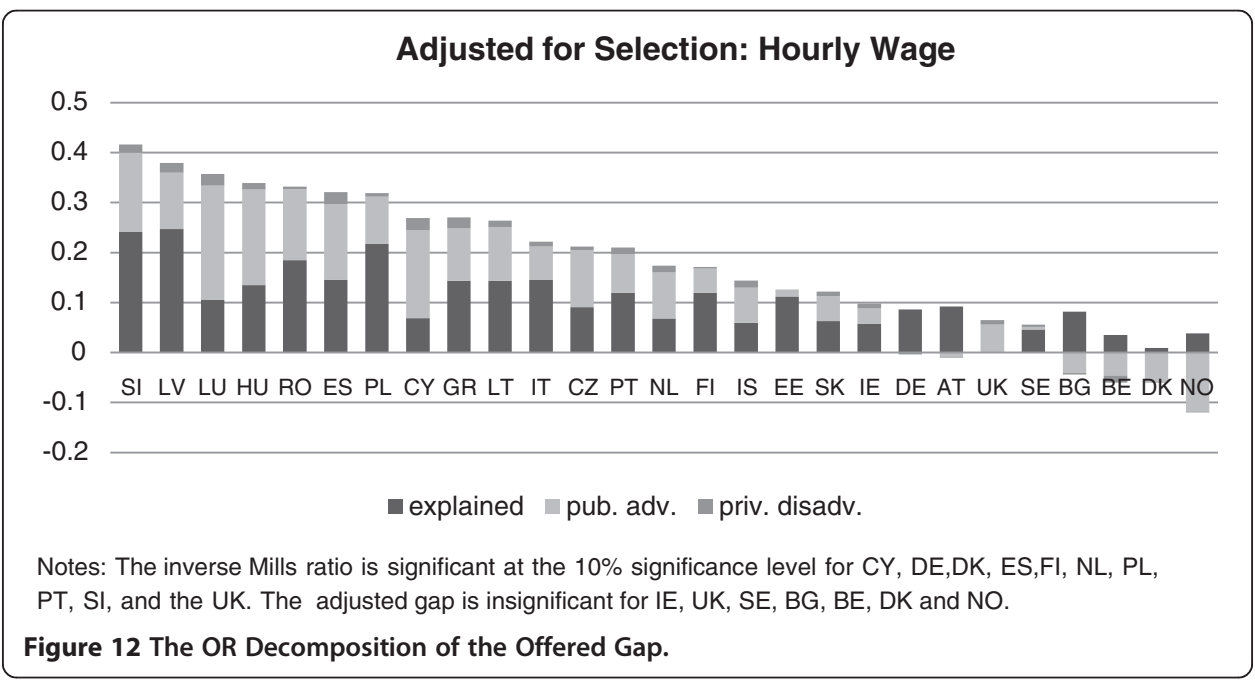


changes somewhat. Some noteworthy changes also occur in the nature of the decompositions, especially for Bulgaria, Denmark, Germany, Latvia, Slovenia, and Sweden. Only a fraction of the offered gap in Figure 12 is explained by characteristics and it is the unexplained gap that should be the subject of policy initiatives.

Figure 13 compares the unexplained gaps in the 'measured' and 'offered' publicprivate ln wage gaps of the 27 countries; the former are obtained from the sum of rows 5 and 6 in Table 1, while the latter are based on the sum of rows 8 and 9 in Table 15 in the Appendix. Luxembourg, Cyprus, Greece and Hungary have the highest unexplained component, while Belgium, Germany and Norway have the lowest unexplained components; indeed, the latter are negative, suggesting that productive characteristics would justify higher public-private wage gaps in these countries. In the case of Bulgaria, Lithuania, Slovenia, and Sweden, large differences between the unadjusted and selection-adjusted unexplained gaps can be discerned, but it should be remembered that, for these countries, the inverse Mills expressions are not significant. In the case of Denmark, where the inverse Mills expression is significant, there is also a change of sign in the (small) unexplained component.

\section{Conclusions}

Using comparable data drawn from the 2008 cross-sectional EU SILC and a common econometric protocol, this paper provides estimates of the public-private sector hourly pay gap for 27 European countries based on a narrow definition of the public sector (NACE L = Public Administration and Defence, Compulsory Social Security).

In the context of OLS, we first present conditional (age, education, gender, job permanency, and occupation are controlled for) public-private sector pay gaps using a 'Public' categorical variable. Complexity is added by exploring the extent to which the public-private pay gap is not constant (as implied in Table 6 in the Appendix) but varies with the quantiles of the hourly wage. Allowing for complexity in a different direction, we check and correct for endogenous selection and its effects on the estimated pay gaps. We find that Luxembourg, Cyprus, Greece, Hungary, and Portugal are at the top of the public-private pay gap country list, while Austria, Slovenia, Belgium, Germany and Norway have the lowest gaps. This holds without and with selection corrections. In the quantile analysis, the modal pattern is a negative one, where the pay gap is higher and often highest at low hourly wages. Whether this is a feature of

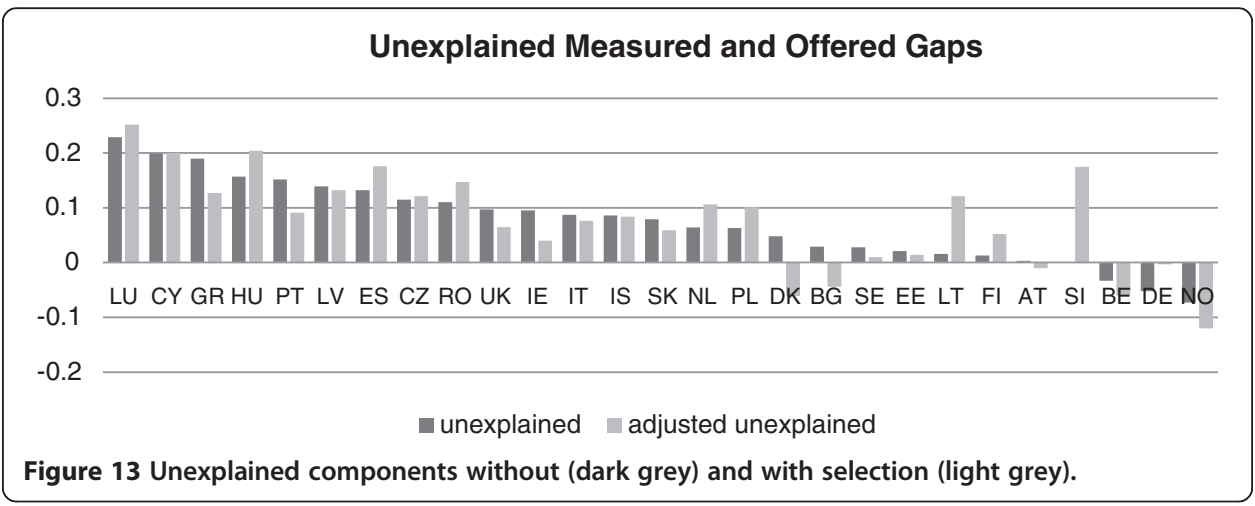


the 2008 EU SILC snapshot or a steady state one is an issue on which we cannot as yet shed light; further work is pending.

More complexity is also achieved by allowing the coefficients on all the controls mentioned above to differ by sector, making possible decompositions along the lines of Oaxaca and Ransom (1994) into the explained and unexplained components of the gap (with and without selection corrections). Without selection, the OR decompositions focus on the 'measured' gap while, with selection, it is possible to report the 'offered' gap that would have prevailed in the population at large (rather than in the selected sample) and its decompositions. In either case, the Mincer equations explain substantial portions of the gap, in some countries completely or even suggesting 'underpayment' of public sector employees, given their characteristics. This fact alone suggests that the unconditional approach that is typically followed in official EU and other documents can be very misleading. It is a strength of these decompositions that they allow analysts to focus on the unexplained component of the public-private pay gap, the concept on which policy should focus.

When separate regressions in the two sectors are allowed for, the measured pay gap is topped by Latvia, Luxembourg, Greece, Cyprus, and Romania, while Sweden, Denmark, Germany, Belgium and Norway are at the bottom of the list. Luxembourg and Cyprus have the highest unexplained gaps, while those for Germany, Belgium and Norway are actually negative. These gaps are examined separately for (i) young and old employees, (ii) those with tertiary and no tertiary education, (iii) males and females and (iv) clerks relative to the whole sample. These breakdowns provide interesting insight into the pay structure of the public sector. For instance, Luxembourg has high unexplained components for both young and old, those without tertiary education, males and females and clerks but not especially so for those with tertiary education. A variety of patterns can be identified across countries and rankings can change substantially. In general, less educated workers tend to have larger unexplained gaps; a variety of patterns exist across countries with respect to the other breakdowns that were carried out. Clerks were examined because it is a populous category that may be similar across the two sectors. The results suggest that the pay gap is lower for clerks than in general but that this gap is largely unexplained.

Quantile estimations which allow for decompositions support the decreasing relationship with the hourly wage reported earlier in the context of the intercept-shift model. In addition, this pattern generally holds for the unexplained component. These results suggest that the public-private pay gap is highest at low hourly wages. We noted earlier that it is highest for the less educated and, in some countries, for women. At one level, this picture suggests that the public sector is a vehicle for greater equality. But, at another level, this propensity is coming under closer scrutiny, particularly in programme countries which need to enhance their competitiveness, suggesting that social policy should be more targeted and separate from the remuneration practices of the public sector.

Having established in a number of alternative ways the public-private sector ln wage gaps in the 27 countries, it is of course important to explore why these patterns exist. The structure of the labour market might affect the size and nature of the gap (percentage of employees in primary sector, percentage in self-employment, percentage of employees in small firms, etc.). Other factors related to wage setting procedures, entry procedures, the level of centralization of the public sector, minimum wages and wage indexation might also affect the public-private wage gap. Exploring the reasons for the crosssectional differences is an enormous task, beyond the scope of the current paper. 


\section{Endnotes}

${ }^{1}$ Eurostat has no responsibility for the results and conclusions of this paper.

${ }^{2}$ See Elder et al. (2010).

3 The four occupation dummies are: a =legislators, senior officials, managers (11-13); $\mathrm{b}=$ professionals (21-24), technicians and associate professionals (31-34), skilled agricultural and fishery workers (61), and armed forces (01); c = clerks (41-42), and service and shop sales workers $(51-52)$; and $d=$ craft and related trade workers (71-74), plant and machine operators and assemblers (81-83), and elementary occupations (91-93).

4 A simple decomposition among two groups Public (P) and Private (R) can be described by the following equation:

$$
\overline{\ln W}_{P}-\overline{\ln W}_{R}=\left(\bar{X}_{P}-\bar{X}_{R}\right) b_{P}+\bar{X}_{R}\left(b_{P}-b_{R}\right)
$$

where the left-hand side is the difference between the average natural logarithms of hourly wages in group $\mathrm{P}$ and group $\mathrm{R}$, and $b_{P}$ and $b_{R}$ correspond to estimated coefficients from separate OLS regression equations for groups $P$ and $R$ respectively. The first right-hand side term describes the portion of the wage-gap which is explained by differences in personal characteristics and job attributes included in X, while the second term is the unexplained part of the log wage difference which corresponds to differences in returns to individual characteristics. The size of the explained part depends on $b_{P}$ and the size of the unexplained part on $\bar{X}_{R}$, and to avoid this arbitrary dependence the OR decomposition proposes:

$$
\overline{\ln W}_{P}-\overline{\ln W}_{R}=\left(\bar{X}_{P}-\bar{X}_{R}\right) b_{N}+\bar{X}_{P}\left(b_{P}-b_{N}\right)+\bar{X}_{R}\left(b_{N}-b_{R}\right)
$$

where $b_{N}$ is a non-discriminatory structure estimated using a pooled regression - the no-sector dummy option in Stata is used for the implementation of this decomposition, see Jann (2008). The first term is now the explained part, the second the public sector advantage and the third term the private sector disadvantage.

${ }^{5}$ In the case of Belgium and Germany the public-private sector gap is still positive but could have been larger, given the superior measurable characteristics of public sector employees. In the case of Norway where public sector employees earn less than their private sector equivalents, the pay gap is actually negative $(-0.029)$ and the explained gap positive (0.044); this suggests that a public-private sector pay gap of approximately $7 \%$ would have been justified. The unexplained component is -0.073 (the sum of the negative public sector advantage and the also negative private sector disadvantage). The large and unusual percentage changes in the lower part of the table reflect these circumstances.

${ }^{6}$ The estimator for quantile q minimizes by choice of $\beta_{q}$ the weighted sum of the absolute deviations

$$
Q\left(\beta_{q}\right)=\sum_{i: y_{i} \geq x_{i} \beta}^{N} q\left|y_{i}-x_{i}^{\prime} \beta_{q}\right|+\sum_{i: y_{i}<x_{i} \beta}^{N}(1-q)\left|y_{i}-x_{i}^{\prime} \beta_{q}\right|
$$

This non-differentiable function is minimized using linear programming techniques. Standard errors are calculated using the bootstrap (50 repetitions). 
${ }^{7}$ The difference between the observed wage distribution for the private sector $F_{w(R / R)}$ and that of the public $F_{w(P / P)}$ is decomposed as follows:

$$
F_{w(P / P)}-F_{w(R / R)}=\left[F_{w(P / P)}-F_{w(R / P)}\right]+\left[F_{w(R / P)}-F_{w(R / R)}\right] \text {, }
$$

Where $F_{w(R / P)}$ is the counterfactual distribution that would have prevailed for public employees if they faced the private wage schedule. This distribution is constructed by integrating the conditional distribution of wages for the private sector with respect to the distribution of characteristics for the public sector. This quantity is well defined if the support of the private sector's characteristics includes the support of the public sector characteristics. The conditional distribution is estimated using linear quantile regression (100 regressions are estimated). Bootstrap standard errors are estimated using 50 repetitions.

${ }^{8}$ Due to the large volume of estimation results, we do not provide the full decomposition estimates from the quantile regression analysis. Stata routine cdeco was used for the estimation.

${ }^{9}$ The total number of observations (including the unemployed and inactive) in Table 13 in the Appendix differs somewhat from those in Table 3 in the Appendix because some observations were lost when data on important explanatory variables (such as occupation and industry) were missing for some individuals in the sample.

${ }^{10}$ A positive (negative) correlation suggests that an unobservable entering the Probit equation through the error term affects selection into the paid employee sample in the same (in the opposite) direction that it affects hourly wages through the error term in the wage equation.

11 The papers by Kanellopoulos (1997), Heitmueller (2006), Van der Gaag and Vijverberg (1988) and Glinskaya and Lokshin (2007), as well as those noted earlier, explore selection in to the public sector.

${ }^{12}$ The OR decomposition with selection is discussed in Neuman and Oaxaca (2004):

$$
\overline{\ln W}_{P}-\overline{\ln W}_{R}=\left(\bar{X}_{P}-\bar{X}_{R}\right) b_{N}+\bar{X}_{P}\left(b_{P}-b_{N}\right)+\bar{X}_{R}\left(b_{N}-b_{R}\right)+\left(\hat{\theta}_{P} \hat{\lambda}_{P}-\hat{\theta}_{R} \hat{\lambda}_{R}\right)
$$

where the $b$ terms indicate estimates of relevant coefficients on the explanatory variables $X$ in the wage equations and overbars indicate means. The subscript $\mathrm{N}$ refers to the non-discriminatory structure which is normally based on the combined public and private sector regression in each country. It is a matter of preference and purpose how the decomposition results are presented. The left-hand side of the above equation refers to the 'measured' public-private gap in the paid worker sample. But since this procedure corrects for selection bias, it is possible to refer to the public-private pay gap that would have prevailed in the population at large (which includes in addition to the paid workers, the unemployed and the inactive). This is referred to as the 'offered' pay gap. Neuman and Oaxaca (2004) note the inherent complexity involved in decomposing the fourth term in the above equation into further explained and unexplained components. The estimates below transfer the entire last term to the left hand side (this is one of the options discussed in the literature) to define the 'offered' gap. These estimates complement and extend the information supplied by the earlier estimates of the 'measured' pay gap. 


\section{Appendix}

This appendix provides full results on the figures and issues raised in the main body of the paper. Three broad categories are relevant, viz. Descriptive statistics, OLS regressions and Sample decompositions and selection corrections.

\section{Descriptive statistics}

Table 3 shows the number of individuals that were full time employees, unemployed and inactive in 27 countries. Table 4 presents the unconditional mean hourly wage by country and by NACE industry.

\section{OLS regressions}

Table 5 provides full results, with the coefficients on the important industry controls summarised in Figure 1. Table 6 provides the OLS deviation from the grand mean for Public Administration, when Other now includes Education and Health - see also Figure 2.

Table 3 Number of observations by labour force status

\begin{tabular}{|c|c|c|c|c|}
\hline Country & Full- time employees & Unemployed & Total inactive & Total \\
\hline Austria (AT) & 3,130 & 236 & 687 & 4,053 \\
\hline Belgium (BE) & 3,292 & 503 & 724 & 4,519 \\
\hline Bulgaria (BG) & 3,249 & 637 & 193 & 4,079 \\
\hline Cyprus (CY) & 2,865 & 98 & 544 & 3,507 \\
\hline Czech Rep (CZ) & 8,494 & 412 & 790 & 9,696 \\
\hline Germany (DE) & 6,641 & 945 & 1,258 & 8,844 \\
\hline Denmark (DK) & 4,718 & 108 & 122 & 4,948 \\
\hline Estonia (EE) & 4,061 & 199 & 349 & 4,609 \\
\hline Spain (ES) & 8,704 & 1,207 & 2,355 & 12,266 \\
\hline Finland (FI) & 7,062 & 650 & 566 & 8,278 \\
\hline Greece (GR) & 3,113 & 383 & 1,070 & 4,566 \\
\hline Hungary (HU) & 6,062 & 701 & 959 & 7,722 \\
\hline Ireland (IE) & 2,017 & 314 & 848 & 3,179 \\
\hline Iceland (IS) & 2,385 & 9 & 130 & 2,524 \\
\hline Italy (IT) & 10,228 & 1,344 & 4,116 & 15,688 \\
\hline Lithuania (LT) & 3,602 & 278 & 220 & 4,100 \\
\hline Luxembourg (LU) & 2,953 & 207 & 702 & 3,862 \\
\hline Latvia (LV) & 3,727 & 338 & 418 & 4,483 \\
\hline Netherlands (NL) & 5,241 & 90 & 1,172 & 6,503 \\
\hline Norway (NO) & 4,331 & 78 & 123 & 4,532 \\
\hline Poland (PL) & 8,666 & 1,027 & 1,505 & 11,198 \\
\hline Portugal (PT) & 2,831 & 307 & 483 & 3,621 \\
\hline Romania (RO) & 4,693 & 179 & 919 & 5,791 \\
\hline Sweden (SE) & 5,146 & 270 & 104 & 5,520 \\
\hline Slovenia (SI) & 9,847 & 1,144 & 461 & 11,452 \\
\hline Slovakia (SK) & 5,574 & 445 & 193 & 6,212 \\
\hline United Kingdom (UK) & 4,453 & 175 & 728 & 5,356 \\
\hline Total & 137,085 & 12,284 & 21,739 & 171,108 \\
\hline
\end{tabular}


Table 4 Hourly mean wage in euro by industry (NACE categories)

\begin{tabular}{|c|c|c|c|c|c|c|c|c|c|c|c|c|c|}
\hline Coun & $+B$ & $\mathrm{D}+\mathrm{E}$ & $F$ & G & $\mathrm{H}$ & 1 & $\mathrm{~J}$ & $\mathrm{~K}$ & $\mathbf{L}$ & $M$ & $\mathrm{~N}$ & $\mathrm{O}+\mathrm{P}+\mathrm{Q}$ & Total \\
\hline $\mathrm{T}$ & .66 & 586 & 16.16 & 5.80 & 12.16 & 16.38 & 23.34 & 19.70 & 18.70 & 20.81 & 16.10 & 6.19 & 17.44 \\
\hline BE & 16.05 & 18.68 & 5 & 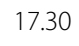 & 13.19 & 17.30 & 24.63 & 19.51 & 18.29 & 9 & 17.70 & 8 & 3 \\
\hline BG & 1.15 & 67 & 6 & 1.44 & 6 & 1.69 & 2.39 & 1.74 & 1.81 & 1.38 & 1. & 35 & 58 \\
\hline 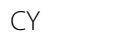 & .90 & 18 & 11.23 & 8.96 & 7.97 & 12.99 & 16.84 & 11.02 & 13.98 & 19.64 & 13.9 & 9 & 70 \\
\hline$C Z$ & 3.37 & 2 & & 3.71 & 4 & 4.48 & 56 & 2 & & 35 & s & 39 & 18 \\
\hline DE & 12.23 & 20 & 14.59 & 566 & 10.21 & 7.32 & 24.18 & 1 & 7.73 & 18.85 & 16 & .13 & 21 \\
\hline n & 17.54 & 77 & 23 & 82 & 14 & 24.59 & .45 & 2 & 26.04 & 4 & 22.40 & 2 & 95 \\
\hline $\mathrm{EE}$ & 3.44 & 75 & 5.38 & 3.84 & 2.94 & 4.82 & 7.13 & 5.07 & 4.54 & 3.61 & 3.69 & 3.47 & .16 \\
\hline & 7.58 & 10.70 & & 8.72 & 8.13 & 6 & 16.31 & 1 & 13.77 & 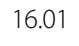 & 12.74 & 9 & 11.13 \\
\hline $\mathrm{FI}$ & 13.60 & 20.31 & 16.00 & 17.96 & 13.53 & 17.65 & 23.64 & 19.73 & 19.81 & 19.43 & 16.17 & 5.53 & 18.34 \\
\hline GR & 5.73 & 10.33 & 7.90 & 8.36 & 4 & 12.90 & 3.94 & 10.59 & 13.52 & 5 & 11.46 & 4 & 63 \\
\hline U & 2.82 & 37 & 2.84 & 2.99 & 8 & 3.72 & 5.56 & 4.00 & 4.65 & 4.02 & 3. & 3.74 & .56 \\
\hline IE & 17.04 & 23.15 & 21.07 & 0 & 7 & 4 & 02 & 9 & 9 & 2 & 23.89 & 21.31 & 96 \\
\hline IS & 20.3 & 66 & 21.49 & 6 & 18.02 & 27.42 & 35.24 & 6 & 27.89 & 23 & 2 & 19 & 25.31 \\
\hline IT & 9.72 & 12.89 & 11.01 & 11.67 & 10.00 & 13.89 & 19.98 & 13.55 & 16.07 & 14.46 & 16.42 & 1.70 & 13.58 \\
\hline 1 & 2 & 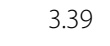 & 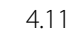 & 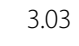 & 1.95 & 3.66 & 5.31 & T. & 3.87 & 4.05 & 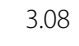 & 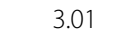 & 48 \\
\hline U & 17.10 & 24.34 & 13.39 & 14.51 & 11.77 & 24.78 & 33.97 & 21.43 & 29.65 & 30.81 & 23.43 & 33.37 & 23.46 \\
\hline LV & 2.83 & 3.55 & 3.87 & 3.18 & 2.45 & 4.12 & 2 & 5.08 & 5.21 & 3.96 & 4.22 & 3.71 & 3.92 \\
\hline $\mathrm{NL}$ & 21.34 & 24.32 & 20.48 & 21.67 & 16.21 & 21.31 & 30.60 & 25.85 & 26.16 & 24.72 & 24.95 & 22.60 & 24.23 \\
\hline 0 & 20.32 & 29.76 & 25.24 & 25.35 & 18.06 & 27.39 & 36.43 & 30.07 & 24.63 & 25.15 & 23.80 & 1.67 & 26.79 \\
\hline PL & 3.28 & 3.87 & 3.29 & 3.11 & 0 & 4.10 & 6.46 & 4.13 & 2 & 7 & + & 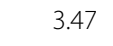 & 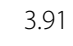 \\
\hline T & 4.72 & 6.08 & 5.61 & 5.71 & 4.77 & 8.38 & 15.18 & 7.27 & 8.85 & 12.31 & 87 & .53 & 38 \\
\hline RO & 1.49 & 02 & 2 & 1. & 1.33 & 2 & 76 & 2.22 & 2.68 & 2.14 & 2.07 & 9 & 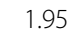 \\
\hline SE & 18.08 & 20.38 & 19.44 & 19.47 & 13.60 & 18.80 & 32.06 & 21.66 & 20.46 & 17.10 & 17.55 & 8.07 & 9.56 \\
\hline SI & 7 & 7.70 & 7 & 7.76 & 6 & 8 & 12.03 & 9.40 & 4 & 3 & 9.12 & 7 & 5 \\
\hline $5 K$ & 2.73 & 3.17 & 3.16 & 2.79 & 2.38 & 3.31 & 4.06 & 3.58 & 3.52 & 3.00 & 2.75 & 2.94 & 3.15 \\
\hline UK & 13.90 & 21.05 & 20.90 & 17.30 & 18.51 & 20.25 & 31.26 & 24.81 & 22.52 & 21.72 & 21.43 & 17.56 & 51 \\
\hline Total & 6.12 & 10.03 & 9.56 & 9.43 & 7.35 & 10.86 & 20.22 & 14.91 & 13.22 & 12.51 & 13.10 & 11.82 & 11.39 \\
\hline
\end{tabular}

Note: $A=$ Agriculture, hunting, forestry; $B=$ Fishing; $C=$ Mining; $D=$ Manufacturing; $E=$ Electricity, gas, water; $F=$ Construction; $\mathrm{G}=$ Wholesale, retail trade, repair of vehicles, motorcycles, personal and household goods; $\mathrm{H}=$ Hotels, restaurants; I= Transport, storage, communications; $\mathrm{J}=$ Financial intermediation; $\mathrm{K}=$ Real estate etc.; $\mathrm{L}=$ Public Administration and defence, compulsory social security; $\mathrm{M}=$ Education; $\mathrm{N}=$ Health and social work; $\mathrm{O}+\mathrm{P}+\mathrm{Q}=$ Remaining industries.

The Bolded column L=Public.

\section{Sample decompositions and selection corrections}

Tables 7 to 16 and Figure 14 provide full results for the decompositions and sample selection corrections that were discussed in the main body of the paper.

Table 13 parallels Table 6 which was discussed in Section 4. Table 14 reports the Probit equation, estimated as part of the ML approach which produces Table 13, where unity indicates paid employment, and zero unemployment or inactivity.

The implied decompositions appear in Table 15. The Probit specification (Table 16) is the same as that outlined in the ML, system, procedure above but, of course, the results are not identical to those in Table 14 due to the difference in estimation procedure adopted (Heckit rather than ML). 
Table 5 OLS Regression with Public (L), Education (M), Health (N) and Other (all other NACE categories) industries shown in the bolded rows

\begin{tabular}{|c|c|c|c|c|c|c|c|c|c|c|c|c|c|c|}
\hline & AT & BE & BG & $\mathrm{CY}$ & $C Z$ & $\mathrm{DE}$ & DK & $\mathrm{EE}$ & ES & $\mathrm{FI}$ & GR & $\mathrm{HU}$ & IE & IS \\
\hline public & 0.019 & 0.006 & $0.116^{* * *}$ & 0.017 & $0.102^{* * *}$ & -0.011 & $0.059^{* * *}$ & $0.038^{*}$ & $0.054^{* * *}$ & 0.006 & $0.104 * * *$ & $0.141 * * *$ & $0.042^{* *}$ & $0.103^{* * *}$ \\
\hline education & 0.004 & $-0.049 * * *$ & $-0.114^{* * *}$ & $0.243^{* * *}$ & $-0.061 * * *$ & -0.008 & $-0.031^{* *}$ & $-0.079 * * *$ & $0.096^{* * *}$ & 0.014 & $0.056^{*}$ & $-0.048^{* * *}$ & $0.094^{* * *}$ & $-0.114^{* * *}$ \\
\hline health & $-0.048^{* * *}$ & $-0.025^{*}$ & $-0.138^{* * *}$ & 0.002 & $-0.031 * * *$ & $-0.048^{* * *}$ & $-0.051^{* * *}$ & 0.002 & -0.016 & -0.007 & $-0.036^{*}$ & $-0.085^{* * *}$ & $-0.050^{* *}$ & -0.037 \\
\hline other & $0.024^{*}$ & $0.068^{* * *}$ & $0.135^{* * *}$ & $-0.262^{* * *}$ & -0.010 & $0.068^{* * *}$ & $0.023^{* *}$ & $0.039^{* * *}$ & $-0.133^{* * *}$ & -0.012 & $-0.124^{* * *}$ & -0.008 & $-0.085^{* * *}$ & $0.048^{* *}$ \\
\hline age25_29 & $-0.196^{* * *}$ & $-0.222^{* * *}$ & -0.025 & $-0.237^{* * *}$ & $-0.051^{* * *}$ & $-0.222^{* * *}$ & $-0.201^{* * *}$ & $0.076^{* * *}$ & $-0.175^{* * *}$ & $-0.119^{* * *}$ & $-0.338^{* * *}$ & $-0.130^{* * *}$ & $-0.282^{* * *}$ & $-0.201^{* * *}$ \\
\hline age30_34 & $-0.063^{* * *}$ & $-0.111^{* * *}$ & -0.025 & $-0.099^{* * *}$ & $0.020^{* *}$ & $-0.080^{* * *}$ & $-0.038^{* * *}$ & $0.094^{* * *}$ & $-0.111^{* * *}$ & $-0.061^{* * *}$ & $-0.167^{* * *}$ & -0.017 & $-0.149^{* * *}$ & $-0.113^{* * * *}$ \\
\hline age35_39 & -0.014 & -0.009 & 0.019 & $-0.063^{* * * *}$ & $0.033^{* * *}$ & 0.017 & $0.020^{*}$ & $0.049^{* * * *}$ & -0.011 & $-0.027^{*}$ & $-0.052^{* * * *}$ & $0.031^{* *}$ & 0.025 & 0.013 \\
\hline age40_44 & -0.006 & $0.052^{* * *}$ & 0.014 & $0.033^{*}$ & 0.002 & $0.034^{* * *}$ & $0.059^{* * * *}$ & $0.033^{* *}$ & $0.025^{* *}$ & 0.023 & $0.056^{* * *}$ & $0.024^{*}$ & $0.062^{* * *}$ & $0.071^{* * *}$ \\
\hline age45_49 & $0.057^{* * *}$ & $0.087^{* * *}$ & $0.037^{*}$ & $0.068^{* * *}$ & $0.024^{* * *}$ & $0.083^{* * *}$ & $0.068^{* * *}$ & -0.016 & $0.064^{* * *}$ & $0.046^{* * *}$ & $0.138^{* * *}$ & 0.004 & $0.146^{* * *}$ & $0.097^{* * *}$ \\
\hline age50_54 & $0.078^{* * *}$ & $0.099^{* * *}$ & -0.004 & $0.145^{* * *}$ & 0.002 & $0.102^{* * *}$ & $0.043^{* * *}$ & $-0.053^{* * *}$ & $0.095^{* * *}$ & $0.062^{* * *}$ & $0.193^{* * *}$ & $0.060^{* * *}$ & $0.088^{* * *}$ & $0.059^{* *}$ \\
\hline age55_60 & $0.144^{* * *}$ & $0.104^{* * *}$ & -0.015 & $0.152^{* * *}$ & $-0.030^{* * *}$ & $0.065^{* * *}$ & $0.050^{* * * *}$ & $-0.183^{* * *}$ & $0.114^{* * *}$ & $0.076^{* * *}$ & $0.171^{* * *}$ & $0.028^{*}$ & $0.110^{* * *}$ & $0.075^{* * *}$ \\
\hline edL & $-0.207^{* * *}$ & $-0.109 * * *$ & $-0.170^{* * * *}$ & $-0.088^{* * *}$ & $-0.215^{* * *}$ & $-0.092^{* * * *}$ & $-0.077^{* * *}$ & $-0.151^{* * *}$ & $-0.139 * * *$ & $-0.118^{* * *}$ & $-0.142^{* * *}$ & $-0.236^{* * *}$ & $-0.157^{* * *}$ & $-0.153^{* * *}$ \\
\hline edS & 0.004 & $-0.014^{*}$ & $-0.059^{* * * *}$ & $-0.043^{* * *}$ & $-0.029^{* * *}$ & $-0.036^{* * *}$ & -0.005 & -0.017 & 0.001 & $-0.028^{* * *}$ & -0.013 & $-0.065^{* * *}$ & -0.014 & -0.018 \\
\hline edH & $0.203^{* * *}$ & $0.123^{* * *}$ & $0.229^{* * *}$ & $0.131^{* * *}$ & $0.243^{* * *}$ & $0.128^{* * *}$ & $0.081^{* * *}$ & $0.169^{* * *}$ & $0.138^{* * *}$ & $0.146^{* * *}$ & $0.156^{* * *}$ & $0.301^{* * *}$ & $0.171^{* * *}$ & $0.171^{* * *}$ \\
\hline female & $-0.100^{* * *}$ & $-0.033^{* * *}$ & $-0.129 * * *$ & $-0.176^{* * *}$ & $-0.132^{* * *}$ & $-0.091^{* * *}$ & $-0.093^{* * *}$ & $-0.203^{* * *}$ & $-0.085^{* * *}$ & $-0.108^{* * *}$ & $-0.102^{* * *}$ & $-0.084^{* * *}$ & $-0.073^{* * *}$ & $-0.082^{* * *}$ \\
\hline male & $0.100^{* * *}$ & $0.033^{* * *}$ & $0.129^{* * *}$ & $0.176^{* * *}$ & $0.132^{* * *}$ & $0.091^{* * *}$ & $0.093^{* * *}$ & $0.203^{* * *}$ & $0.085^{* * *}$ & $0.108^{* * *}$ & $0.102^{* * *}$ & $0.084^{* * *}$ & $0.073^{* * *}$ & $0.082^{* * * *}$ \\
\hline temporary & $-0.071^{* * *}$ & $-0.065^{* * * *}$ & $-0.070^{* * * *}$ & $-0.291^{* * * *}$ & $-0.025^{* * *}$ & $-0.102^{* * *}$ & na. & -0.051 & $-0.084^{* * * *}$ & $-0.083^{* * *}$ & $-0.087^{* * *}$ & $-0.079 * * *$ & -0.038 & $-0.097^{* * * *}$ \\
\hline permanent & $0.071^{* * *}$ & $0.065^{* * *}$ & $0.070^{* * *}$ & $0.291^{* * *}$ & $0.025^{* * *}$ & $0.102^{* * *}$ & na. & 0.051 & $0.084^{* * *}$ & $0.083^{* * *}$ & $0.087^{* * *}$ & $0.079^{* * *}$ & 0.038 & $0.097^{* * *}$ \\
\hline occup_d & $-0.189^{* * *}$ & $-0.145^{* * *}$ & $-0.113^{* * *}$ & $-0.305^{* * *}$ & $-0.162^{* * *}$ & $-0.231^{* * *}$ & $-0.125^{* * *}$ & $-0.148^{* * *}$ & $-0.161^{* * *}$ & $-0.173^{* * *}$ & $-0.201^{* * *}$ & $-0.201^{* * *}$ & $-0.170^{* * *}$ & $-0.128^{* * *}$ \\
\hline occup_c & $-0.063^{* * *}$ & $-0.071^{* * *}$ & $-0.141^{* * * *}$ & $-0.149^{* * *}$ & $-0.120^{* * *}$ & $-0.087^{* * *}$ & $-0.120^{* * *}$ & $-0.236^{* * *}$ & $-0.126^{* * *}$ & $-0.160^{* * *}$ & $-0.122^{* * *}$ & $-0.170^{* * *}$ & $-0.152^{* * *}$ & $-0.093^{* * *}$ \\
\hline occup_b & $0.102^{* * *}$ & $0.047^{* * *}$ & $0.065^{* * *}$ & $0.099^{* * *}$ & $0.067^{* * *}$ & $0.116^{* * *}$ & $0.067^{* * *}$ & $0.147^{* * *}$ & $0.090^{* * *}$ & $0.028^{* * *}$ & 0.020 & $0.088^{* * *}$ & $0.139^{* * *}$ & $0.082^{* * *}$ \\
\hline occup_a & $0.150^{* * *}$ & $0.169^{* * *}$ & $0.189^{* * *}$ & $0.355^{* * *}$ & $0.216^{* * *}$ & $0.202^{* * *}$ & $0.178^{* * *}$ & $0.237^{* * *}$ & $0.198^{* * *}$ & $0.305^{* * *}$ & $0.304^{* * *}$ & $0.283^{* * *}$ & $0.183^{* * *}$ & $0.140^{* * *}$ \\
\hline Constant & $2.628^{* * *}$ & $2.730^{* * *}$ & $0.221^{* * *}$ & $2.286^{* * *}$ & $1.369^{* * *}$ & $2.561^{* * *}$ & $3.114^{* * *}$ & $1.206^{* * *}$ & $2.374^{* * *}$ & $2.725^{* * *}$ & $2.335^{* * *}$ & $1.108^{* * *}$ & $2.987^{* * *}$ & $2.905^{* * *}$ \\
\hline Observations & 2,963 & 3,224 & 3,031 & 2,862 & 8,484 & 6,559 & 4,551 & 4,011 & 8,601 & 3,453 & 3,104 & 5,943 & 1,965 & 1,083 \\
\hline R-squared & 0.326 & 0.268 & 0.216 & 0.528 & 0.341 & 0.266 & 0.262 & 0.334 & 0.366 & 0.400 & 0.392 & 0.381 & 0.351 & 0.274 \\
\hline
\end{tabular}


Table 5 OLS Regression with Public (L), Education (M), Health (N) and Other (all other NACE categories) industries shown in the bolded rows (Continued)

\begin{tabular}{|c|c|c|c|c|c|c|c|c|c|c|c|c|c|}
\hline & IT & LT & LU & LV & $\mathrm{NL}$ & NO & $\mathrm{PL}$ & PT & RO & SE & SI & SK & UK \\
\hline public & $0.056^{* * *}$ & 0.018 & $0.137^{* * *}$ & $0.097^{* * *}$ & $0.072 * * *$ & -0.026 & $0.061^{* * *}$ & $0.078^{* * *}$ & $0.107^{* * *}$ & $0.060^{* *}$ & -0.004 & $0.092^{* * *}$ & $0.092 * * *$ \\
\hline education & $-0.035^{* * *}$ & $0.068^{* * *}$ & 0.002 & $-0.082^{* * *}$ & $-0.093^{* * *}$ & $-0.048^{* * *}$ & $0.041^{* * *}$ & $0.052^{* * *}$ & $-0.057^{* * *}$ & $-0.089 * * *$ & 0.018 & $-0.059 * * *$ & $-0.062^{* * *}$ \\
\hline health & $0.032^{* * *}$ & $-0.089 * * *$ & -0.023 & 0.041 & -0.002 & -0.009 & $-0.105^{* * *}$ & -0.019 & $-0.054^{* * *}$ & $-0.065^{* * *}$ & -0.003 & $-0.066^{* * *}$ & $-0.041^{* *}$ \\
\hline other & $-0.053^{* * *}$ & 0.003 & $-0.117^{* * *}$ & $-0.056^{* * *}$ & $0.022^{* *}$ & $0.084 * * *$ & 0.002 & $-0.111^{* * *}$ & 0.004 & $0.094^{* * *}$ & -0.011 & $0.033^{* * *}$ & 0.010 \\
\hline age25_29 & $-0.205^{* * *}$ & 0.011 & $-0.250^{* * *}$ & 0.029 & $-0.264^{* * *}$ & $-0.151^{* * *}$ & $-0.163^{* * *}$ & $-0.219^{* * *}$ & $-0.137^{* * * *}$ & $-0.187^{* * *}$ & $-0.159^{* * *}$ & $-0.049^{* * *}$ & $-0.180^{* * *}$ \\
\hline age30_34 & $-0.111^{* * *}$ & $0.075^{* * *}$ & $-0.176^{* * *}$ & $0.059^{* *}$ & $-0.113^{* * *}$ & $-0.071^{* * *}$ & $-0.089 * * *$ & $-0.112^{* * *}$ & -0.023 & $-0.122^{* * *}$ & $-0.109 * * *$ & $-0.038^{* * *}$ & 0.002 \\
\hline age35_39 & $-0.040^{* * *}$ & $-0.043^{* *}$ & $-0.091^{* * *}$ & 0.015 & 0.007 & 0.024 & $0.027^{* *}$ & -0.011 & -0.003 & -0.015 & -0.008 & $0.026^{* *}$ & $0.042^{* *}$ \\
\hline age40_44 & $0.021^{* * *}$ & 0.017 & -0.005 & -0.014 & $0.066^{* * *}$ & $0.043^{* *}$ & $0.067^{* * *}$ & $0.032^{*}$ & $0.063^{* * *}$ & $0.037^{*}$ & $0.031^{* *}$ & $0.028^{* *}$ & $0.043^{* * *}$ \\
\hline age45_49 & $0.077^{* * *}$ & 0.008 & $0.085^{* * *}$ & -0.004 & $0.087^{* * *}$ & $0.080^{* * *}$ & $0.054^{* * *}$ & $0.082^{* * *}$ & $0.040^{* * *}$ & $0.080^{* * *}$ & $0.094^{* * *}$ & $0.024^{* *}$ & $0.043^{* * *}$ \\
\hline age50_54 & $0.113^{* * *}$ & -0.030 & $0.176^{* * *}$ & $-0.050^{* *}$ & $0.108^{* * *}$ & $0.055^{* * *}$ & $0.048^{* * *}$ & $0.104^{* * * *}$ & $0.041^{* * *}$ & $0.099^{* * *}$ & $0.079^{* * *}$ & $0.026^{* *}$ & 0.021 \\
\hline age55_60 & $0.145^{* * *}$ & $-0.038^{*}$ & $0.261^{* * *}$ & -0.034 & $0.109^{* * *}$ & 0.020 & $0.056^{* * *}$ & $0.125^{* * *}$ & 0.019 & $0.108^{* * *}$ & $0.071^{* * *}$ & -0.017 & $0.030^{*}$ \\
\hline edL & $-0.139 * * *$ & $-0.121^{* * *}$ & $-0.192^{* * *}$ & $-0.207^{* * *}$ & $-0.140^{* * *}$ & $-0.118^{* * *}$ & $-0.179^{* * *}$ & $-0.352^{* * *}$ & $-0.240^{* * *}$ & $-0.039^{*}$ & $-0.246^{* * *}$ & $-0.209^{* * *}$ & $-0.204^{* * *}$ \\
\hline edS & -0.001 & $-0.031^{*}$ & -0.015 & $-0.076^{* * *}$ & $-0.058^{* * *}$ & -0.001 & $-0.032^{* * *}$ & $-0.048^{* * *}$ & $-0.050^{* * *}$ & $-0.021^{*}$ & $-0.057^{* * *}$ & -0.006 & -0.011 \\
\hline $\mathrm{edH}$ & $0.139^{* * *}$ & $0.152^{* * *}$ & $0.207^{* * *}$ & $0.283^{* * *}$ & $0.198^{* * *}$ & $0.119^{* * *}$ & $0.212^{* * *}$ & $0.401^{* * *}$ & $0.290^{* * *}$ & $0.060^{* * *}$ & $0.303^{* * *}$ & $0.215^{* * *}$ & $0.215^{* * *}$ \\
\hline female & $-0.076^{* * *}$ & $-0.187^{* * *}$ & $-0.088^{* * *}$ & $-0.170^{* * *}$ & $-0.063^{* * *}$ & $-0.088^{* * *}$ & $-0.116^{* * *}$ & $-0.135^{* * *}$ & $-0.091^{* * *}$ & $-0.084^{* * *}$ & $-0.076^{* * *}$ & $-0.114^{* * *}$ & $-0.082^{* * *}$ \\
\hline male & $0.076^{* * *}$ & $0.187^{* * *}$ & $0.088^{* * *}$ & $0.170^{* * *}$ & $0.063^{* * *}$ & $0.088^{* * *}$ & $0.116^{* * *}$ & $0.135^{* * *}$ & $0.091^{* * *}$ & $0.084^{* * *}$ & $0.076^{* * *}$ & $0.114^{* * *}$ & $0.082^{* * *}$ \\
\hline temporary & $-0.115^{* * *}$ & $-0.049^{* *}$ & $-0.107^{* * *}$ & $-0.056^{*}$ & $-0.057^{* * *}$ & $-0.062^{* *}$ & $-0.096^{* * *}$ & $-0.079^{* * * *}$ & $-0.071^{* * *}$ & $-0.130^{* * *}$ & $-0.097^{* * *}$ & $-0.050^{* * *}$ & na \\
\hline permanent & $0.115^{* * *}$ & $0.049^{* *}$ & $0.107^{* * *}$ & $0.056^{*}$ & $0.057^{* * *}$ & $0.062^{* *}$ & $0.096^{* * *}$ & $0.079^{* * *}$ & $0.071^{* * *}$ & $0.130^{* * *}$ & $0.097^{* * *}$ & $0.050^{* * *}$ & na \\
\hline occup_d & $-0.182^{* * *}$ & $-0.237^{* * *}$ & $-0.283^{* * *}$ & $-0.220^{* * *}$ & $-0.157^{* * *}$ & $-0.086^{* * *}$ & $-0.202^{* * *}$ & $-0.186^{* * *}$ & $-0.204^{* * *}$ & $-0.209^{* * * *}$ & $-0.234^{* * *}$ & $-0.131^{* * *}$ & $-0.226^{* * *}$ \\
\hline occup_c & $-0.088^{* * *}$ & $-0.255^{* * *}$ & $-0.150^{* * *}$ & $-0.215^{* * *}$ & $-0.083^{* * *}$ & $-0.093^{* * *}$ & $-0.210^{* * *}$ & $-0.091^{* * *}$ & $-0.212^{* * *}$ & $-0.134^{* * *}$ & $-0.120^{* * *}$ & $-0.137^{* * *}$ & $-0.120^{* * *}$ \\
\hline occup_b & $0.025^{* *}$ & $0.170^{* * *}$ & $0.138^{* * *}$ & $0.140^{* * *}$ & $0.063^{* * *}$ & $0.058^{* * *}$ & $0.128^{* * *}$ & $0.177^{* * *}$ & $0.104^{* * *}$ & $0.037^{* *}$ & $0.083^{* * *}$ & $0.060^{* * *}$ & $0.111^{* * *}$ \\
\hline occup_a & $0.246^{* * *}$ & $0.322^{* * *}$ & $0.295^{* * *}$ & $0.296^{* * *}$ & $0.177^{* * *}$ & $0.120^{* * *}$ & $0.284^{* * *}$ & 0.100 & $0.312^{* * *}$ & $0.307^{* * *}$ & $0.271^{* * *}$ & $0.209^{* * *}$ & $0.235^{* * *}$ \\
\hline Constant & $2.528^{* * *}$ & $1.004^{* * *}$ & $3.042^{* * *}$ & $1.176^{* * *}$ & $2.943^{* * *}$ & $3.017^{* * *}$ & $1.185^{* * *}$ & $2.046^{* * *}$ & $0.530^{* * *}$ & $2.721^{* * *}$ & $2.000^{* * *}$ & $0.995^{* * *}$ & $2.819^{* * *}$ \\
\hline Observations & 10,219 & 3,575 & 2,912 & 3,726 & 2,485 & 2,128 & 8,586 & 2,777 & 4,588 & 2,493 & 3,365 & 5,521 & 4,439 \\
\hline R-squared & 0.313 & 0.282 & 0.537 & 0.293 & 0.417 & 0.182 & 0.303 & 0.514 & 0.387 & 0.224 & 0.442 & 0.284 & 0.294 \\
\hline
\end{tabular}


Table 6 OLS Regressions with dummy variables for Public administration (bolded row) and Other; Other now includes all other NACE categories

\begin{tabular}{|c|c|c|c|c|c|c|c|c|c|c|c|c|c|c|}
\hline & AT & $\mathrm{BE}$ & BG & $\mathrm{CY}$ & $C Z$ & $\mathrm{DE}$ & DK & $\mathrm{EE}$ & ES & $\mathrm{FI}$ & GR & $\mathrm{HU}$ & IE & IS \\
\hline public & 0.002 & $-0.017^{* *}$ & 0.015 & $0.105^{* * * *}$ & $0.060^{* * *}$ & $-0.028^{* * *}$ & $0.024^{* *}$ & 0.012 & $0.070^{* * *}$ & 0.007 & $0.102^{* * *}$ & $0.082^{* * * *}$ & $0.051 * * *$ & $0.046^{* *}$ \\
\hline other & -0.002 & $0.017^{* *}$ & -0.015 & $-0.105^{* * *}$ & $-0.060^{* * *}$ & $0.028^{* * *}$ & $-0.024^{* *}$ & -0.012 & $-0.070^{* * *}$ & -0.007 & $-0.102^{* * *}$ & $-0.082^{* * *}$ & $-0.051^{* * *}$ & $-0.046^{* *}$ \\
\hline age25_29 & $-0.195^{* * *}$ & $-0.215^{* * *}$ & -0.008 & $-0.258^{* * *}$ & $-0.049^{* * *}$ & $-0.216^{* * *}$ & $-0.201^{* * *}$ & $0.080^{* * *}$ & $-0.189^{* * *}$ & $-0.120^{* * *}$ & $-0.349^{* * *}$ & $-0.126^{* * *}$ & $-0.290^{* * *}$ & $-0.194^{* * *}$ \\
\hline age30_34 & $-0.063^{* * *}$ & $-0.106^{* * *}$ & -0.014 & $-0.111^{* * *}$ & $0.020^{* *}$ & $-0.080^{* * *}$ & $-0.038^{* * *}$ & $0.097^{* * *}$ & $-0.124^{* * *}$ & $-0.062^{* * *}$ & $-0.172^{* * *}$ & -0.015 & $-0.157^{* * *}$ & $-0.106^{* * *}$ \\
\hline age35_39 & -0.013 & -0.006 & 0.023 & $-0.072^{* * *}$ & $0.032^{* * *}$ & 0.018 & $0.021^{*}$ & $0.050^{* * *}$ & $-0.019^{*}$ & $-0.027^{*}$ & $-0.056^{* * *}$ & $0.031^{* *}$ & 0.022 & 0.021 \\
\hline age40_44 & -0.005 & $0.052^{* * *}$ & 0.010 & 0.030 & 0.002 & $0.035^{* * *}$ & $0.060^{* * *}$ & $0.032^{*}$ & $0.026^{* * *}$ & $0.023^{*}$ & $0.059^{* * *}$ & $0.023^{*}$ & $0.061^{* * *}$ & $0.072^{* * *}$ \\
\hline age45_49 & $0.056^{* * *}$ & $0.084^{* * *}$ & 0.027 & $0.077^{* * *}$ & $0.023^{* *}$ & $0.082^{* * *}$ & $0.069^{* * *}$ & -0.016 & $0.070^{* * *}$ & $0.046^{* * *}$ & $0.138^{* * *}$ & 0.003 & $0.149^{* * *}$ & $0.092^{* * *}$ \\
\hline age50_54 & $0.077^{* * *}$ & $0.093^{* * *}$ & -0.008 & $0.157^{* * *}$ & 0.001 & $0.100^{* * *}$ & $0.042^{* * *}$ & $-0.055^{* * *}$ & $0.108^{* * *}$ & $0.063^{* * *}$ & $0.199 * * *$ & $0.058^{* * *}$ & $0.096^{* * *}$ & $0.048^{*}$ \\
\hline age55_60 & $0.143^{* * *}$ & $0.099^{* * *}$ & -0.030 & $0.176^{* * *}$ & $-0.030^{* * *}$ & $0.060^{* * *}$ & $0.047^{* * *}$ & $-0.188^{* * *}$ & $0.128^{* * *}$ & $0.077^{* * *}$ & $0.182^{* * *}$ & $0.025^{*}$ & $0.118^{* * *}$ & $0.068^{* *}$ \\
\hline edL & $-0.204^{* * *}$ & $-0.107^{* * *}$ & $-0.164^{* * *}$ & $-0.105^{* * *}$ & $-0.212^{* * *}$ & $-0.086^{* * *}$ & $-0.075^{* * *}$ & $-0.150^{* * *}$ & $-0.147^{* * *}$ & $-0.119^{* * *}$ & $-0.145^{* * *}$ & $-0.234^{* * *}$ & $-0.160^{* * *}$ & $-0.145^{* * *}$ \\
\hline eds & 0.006 & -0.009 & $-0.045^{* * *}$ & $-0.063^{* * *}$ & $-0.026^{* * *}$ & $-0.035^{* * *}$ & -0.002 & -0.014 & -0.006 & $-0.029 * * *$ & $-0.017^{*}$ & $-0.064^{* * *}$ & -0.018 & -0.013 \\
\hline edH & $0.199^{* * *}$ & $0.116^{* * *}$ & $0.209^{* * *}$ & $0.168^{* * *}$ & $0.238^{* * *}$ & $0.121^{* * *}$ & $0.077^{* * *}$ & $0.164^{* * *}$ & $0.152^{* * *}$ & $0.148^{* * *}$ & $0.162^{* * *}$ & $0.298^{* * *}$ & $0.177^{* * *}$ & $0.157^{* * *}$ \\
\hline female & $-0.104^{* * *}$ & $-0.045^{* * *}$ & $-0.142^{* * *}$ & $-0.152^{* * *}$ & $-0.135^{* * *}$ & $-0.102^{* * *}$ & $-0.099 * * *$ & $-0.209^{* * *}$ & $-0.073^{* * *}$ & $-0.107^{* * *}$ & $-0.098^{* * *}$ & $-0.090^{* * *}$ & $-0.066^{* * *}$ & $-0.092^{* * *}$ \\
\hline male & $0.104^{* * *}$ & $0.045^{* * *}$ & $0.142^{* * *}$ & $0.152^{* * *}$ & $0.135^{* * *}$ & $0.102^{* * *}$ & $0.099^{* * *}$ & $0.209^{* * *}$ & $0.073^{* * *}$ & $0.107^{* * *}$ & $0.098^{* * *}$ & $0.090^{* * *}$ & $0.066^{* * *}$ & $0.092^{* * *}$ \\
\hline temporary & $-0.073^{* * *}$ & $-0.072^{* * *}$ & $-0.071^{* * *}$ & $-0.278^{* * *}$ & $-0.026^{* * *}$ & $-0.106^{* * *}$ & na & -0.049 & $-0.080^{* * *}$ & $-0.081^{* * *}$ & $-0.087^{* * *}$ & $-0.080^{* * *}$ & -0.025 & $-0.112^{* * *}$ \\
\hline permanent & $0.073^{* * *}$ & $0.072^{* * *}$ & $0.071^{* * *}$ & $0.278^{* * *}$ & $0.026^{* * *}$ & $0.106^{* * *}$ & na & 0.049 & $0.080^{* * *}$ & $0.081^{* * *}$ & $0.087^{* * *}$ & $0.080^{* * *}$ & 0.025 & $0.112^{* * *}$ \\
\hline occup_d & $-0.188^{* * *}$ & $-0.138^{* * *}$ & $-0.097^{* * *}$ & $-0.315^{* * *}$ & $-0.162^{* * *}$ & $-0.226^{* * *}$ & $-0.122^{* * *}$ & $-0.140^{* * *}$ & $-0.174^{* * *}$ & $-0.173^{* * *}$ & $-0.208^{* * *}$ & $-0.197^{* * *}$ & $-0.177^{* * *}$ & $-0.120^{* * *}$ \\
\hline occup_c & $-0.065^{* * *}$ & $-0.064^{* * *}$ & $-0.152^{* * *}$ & $-0.167^{* * *}$ & $-0.119^{* * *}$ & $-0.087^{* * *}$ & $-0.123^{* * *}$ & $-0.233^{* * *}$ & $-0.135^{* * *}$ & $-0.159^{* * *}$ & $-0.124^{* * *}$ & $-0.168^{* * *}$ & $-0.152^{* * *}$ & $-0.094^{* * *}$ \\
\hline occup_b & $0.099^{* * *}$ & $0.028^{* * *}$ & $0.038^{*}$ & $0.172^{* * *}$ & $0.063^{* * *}$ & $0.104^{* * *}$ & $0.066^{* * *}$ & $0.132^{* * *}$ & $0.128^{* * *}$ & $0.029^{* * *}$ & $0.041^{* *}$ & $0.079^{* * *}$ & $0.155^{* * *}$ & $0.070^{* * *}$ \\
\hline occup_a & $0.154^{* * *}$ & $0.174^{* * *}$ & $0.211^{* * *}$ & $0.311^{* * *}$ & $0.218^{* * *}$ & $0.208^{* * *}$ & $0.180^{* * *}$ & $0.241^{* * *}$ & $0.180^{* * *}$ & $0.304^{* * *}$ & $0.290^{* * *}$ & $0.286^{* * *}$ & $0.173^{* * *}$ & $0.144^{* * *}$ \\
\hline Constant & $2.643^{* * *}$ & $2.749^{* * *}$ & $0.330^{* * *}$ & $2.184^{* * *}$ & $1.413^{* * *}$ & $2.582^{* * *}$ & $3.152^{* * *}$ & $1.243^{* * *}$ & $2.345^{* * *}$ & $2.723^{* * *}$ & $2.330^{* * *}$ & $1.170^{* * *}$ & $2.982^{* * *}$ & $2.962^{* * *}$ \\
\hline Observations & 2,963 & 3,224 & 3,031 & 2,862 & 8,484 & 6,559 & 4,551 & 4,011 & 8,601 & 3,453 & 3,104 & 5,943 & 1,965 & 1,083 \\
\hline R-squared & 0.324 & 0.259 & 0.194 & 0.483 & 0.340 & 0.261 & 0.258 & 0.330 & 0.353 & 0.399 & 0.387 & 0.380 & 0.344 & 0.263 \\
\hline
\end{tabular}


Table 6 OLS Regressions with dummy variables for Public administration (bolded row) and Other; Other now includes all other NACE categories (Continued)

\begin{tabular}{|c|c|c|c|c|c|c|c|c|c|c|c|c|c|}
\hline & IT & LT & LU & LV & $\mathrm{NL}$ & NO & $\mathrm{PL}$ & PT & RO & SE & $\mathrm{SI}$ & SK & UK \\
\hline public & $0.047^{* * *}$ & 0.009 & $0.121 * * *$ & $0.074^{* * *}$ & $0.033^{* * *}$ & $-0.038^{* * *}$ & $0.034^{* * *}$ & $0.079 * * *$ & $0.057^{* * *}$ & 0.015 & 0.001 & $0.042^{* * *}$ & $0.050 * * *$ \\
\hline other & $-0.047^{* * *}$ & -0.009 & $-0.121^{* * *}$ & $-0.074^{* * *}$ & $-0.033^{* * *}$ & $0.038^{* * *}$ & $-0.034^{* * *}$ & $-0.079 * * *$ & $-0.057^{* * *}$ & -0.015 & -0.001 & $-0.042^{* * *}$ & $-0.050^{* * *}$ \\
\hline age25_29 & $-0.210^{* * *}$ & 0.011 & $-0.251^{* * *}$ & 0.026 & $-0.263^{* * *}$ & $-0.137^{* * *}$ & $-0.163^{* * *}$ & $-0.236^{* * *}$ & $-0.134^{* * *}$ & $-0.172^{* * *}$ & $-0.161^{* * *}$ & $-0.043^{* * *}$ & $-0.175^{* * *}$ \\
\hline age30_34 & $-0.115^{* * *}$ & $0.077^{* * *}$ & $-0.178^{* * *}$ & $0.056^{* *}$ & $-0.107^{* * *}$ & $-0.068^{* * *}$ & $-0.088^{* * *}$ & $-0.120^{* * *}$ & -0.022 & $-0.109^{* * *}$ & $-0.110^{* * *}$ & $-0.035^{* * *}$ & 0.004 \\
\hline age35_39 & $-0.042^{* * *}$ & $-0.047^{* *}$ & $-0.091^{* * *}$ & 0.015 & 0.012 & 0.027 & $0.026^{* *}$ & -0.017 & -0.002 & -0.004 & -0.008 & $0.030^{* *}$ & $0.044^{* * *}$ \\
\hline age40_44 & $0.022^{* * *}$ & 0.016 & -0.007 & -0.012 & $0.067^{* * *}$ & $0.043^{* *}$ & $0.069^{* * *}$ & $0.032^{*}$ & $0.065^{* * *}$ & $0.038^{*}$ & $0.032^{* *}$ & $0.029 * * *$ & $0.041^{* * *}$ \\
\hline age45_49 & $0.079^{* * *}$ & 0.011 & $0.083^{* * *}$ & -0.003 & $0.084^{* * *}$ & $0.077^{* * *}$ & $0.053^{* * *}$ & $0.089^{* * *}$ & $0.040^{* * *}$ & $0.068^{* * *}$ & $0.094^{* * *}$ & $0.022^{* *}$ & $0.041^{* * *}$ \\
\hline age50_54 & $0.116^{* * *}$ & -0.030 & $0.180^{* * *}$ & $-0.050^{* *}$ & $0.101^{* * *}$ & $0.050^{* *}$ & $0.046^{* * *}$ & $0.112^{* * *}$ & $0.039 * * *$ & $0.083^{* * *}$ & $0.079 * * *$ & $0.023^{* *}$ & 0.018 \\
\hline age55_60 & $0.150^{* * *}$ & $-0.040^{* *}$ & $0.264^{* * *}$ & -0.031 & $0.106^{* * *}$ & 0.008 & $0.057^{* * *}$ & $0.138^{* * *}$ & 0.013 & $0.095^{* * *}$ & $0.074 * * *$ & $-0.025^{*}$ & 0.026 \\
\hline edL & $-0.141^{* * *}$ & $-0.119^{* * *}$ & $-0.194^{* * *}$ & $-0.206^{* * *}$ & $-0.135^{* * *}$ & $-0.112^{* * *}$ & $-0.181^{* * *}$ & $-0.374^{* * *}$ & $-0.241^{* * *}$ & -0.023 & $-0.248^{* * *}$ & $-0.207^{* * *}$ & $-0.200^{* * *}$ \\
\hline edS & -0.004 & $-0.033^{* *}$ & -0.014 & $-0.075^{* * *}$ & $-0.054^{* * *}$ & 0.006 & $-0.035^{* * *}$ & $-0.062^{* * *}$ & $-0.049 * * *$ & -0.017 & $-0.058^{* * *}$ & -0.001 & -0.008 \\
\hline edH & $0.144^{* * *}$ & $0.152^{* * *}$ & $0.208^{* * *}$ & $0.281^{* * *}$ & $0.190^{* * *}$ & $0.106^{* * *}$ & $0.216^{* * *}$ & $0.436^{* * *}$ & $0.290^{* * *}$ & $0.040^{* *}$ & $0.305^{* * *}$ & $0.208^{* * *}$ & $0.208^{* * *}$ \\
\hline female & $-0.072^{* * *}$ & $-0.189^{* * *}$ & $-0.081^{* * *}$ & $-0.169^{* * *}$ & $-0.068^{* * *}$ & $-0.101 * * *$ & $-0.119^{* * *}$ & $-0.121^{* * *}$ & $-0.094^{* * *}$ & $-0.107^{* * *}$ & $-0.075^{* * *}$ & $-0.123^{* * *}$ & $-0.089 * * *$ \\
\hline male & $0.072^{* * *}$ & $0.189^{* * *}$ & $0.081^{* * *}$ & $0.169^{* * *}$ & $0.068^{* * *}$ & $0.101^{* * *}$ & $0.119^{* * *}$ & $0.121^{* * *}$ & $0.094^{* * *}$ & $0.107^{* * *}$ & $0.075^{* * *}$ & $0.123^{* * *}$ & $0.089^{* * *}$ \\
\hline temporary & $-0.116^{* * *}$ & $-0.046^{*}$ & $-0.103^{* * *}$ & $-0.056^{*}$ & $-0.057^{* * *}$ & $-0.065^{* * *}$ & $-0.096^{* * *}$ & $-0.078^{* * *}$ & $-0.071^{* * *}$ & $-0.136^{* * *}$ & $-0.097^{* * *}$ & $-0.049^{* * *}$ & na \\
\hline permanent & $0.116^{* * *}$ & $0.046^{*}$ & $0.103^{* * *}$ & $0.056^{*}$ & $0.057^{* * *}$ & $0.065^{* * *}$ & $0.096^{* * *}$ & $0.078^{* * *}$ & $0.071^{* * *}$ & $0.136^{* * *}$ & $0.097^{* * *}$ & $0.049 * * *$ & na \\
\hline occup_d & $-0.186^{* * *}$ & $-0.237^{* * *}$ & $-0.286^{* * *}$ & $-0.225^{* * *}$ & $-0.154^{* * *}$ & $-0.081^{* * *}$ & $-0.197^{* * *}$ & $-0.182^{* * *}$ & $-0.200^{* * *}$ & $-0.193^{* * *}$ & $-0.234^{* * *}$ & $-0.128^{* * *}$ & $-0.221^{* * *}$ \\
\hline occup_c & $-0.089^{* * *}$ & $-0.256^{* * *}$ & $-0.153^{* * *}$ & $-0.213^{* * *}$ & $-0.080^{* * *}$ & $-0.098^{* * *}$ & $-0.208^{* * *}$ & $-0.083^{* * *}$ & $-0.210^{* * *}$ & $-0.154^{* * *}$ & $-0.120^{* * *}$ & $-0.134^{* * *}$ & $-0.123^{* * *}$ \\
\hline occup_b & $0.035^{* * *}$ & $0.167^{* * *}$ & $0.147^{* * *}$ & $0.144^{* * *}$ & $0.056^{* * *}$ & $0.050^{* * *}$ & $0.120^{* * *}$ & $0.193^{* * *}$ & $0.096^{* * *}$ & 0.024 & $0.086^{* * *}$ & $0.050^{* * *}$ & $0.102^{* * *}$ \\
\hline occup_a & $0.241^{* * *}$ & $0.327^{* * *}$ & $0.291^{* * *}$ & $0.293^{* * *}$ & $0.178^{* * *}$ & $0.129 * * *$ & $0.285^{* * *}$ & 0.072 & $0.314^{* * *}$ & $0.323^{* * *}$ & $0.268^{* * *}$ & $0.212^{* * *}$ & $0.242^{* * *}$ \\
\hline Constant & $2.534^{* * *}$ & $1.017^{* * *}$ & $3.061 * * *$ & $1.198^{* * *}$ & $2.986^{* * *}$ & $3.036^{* * *}$ & $1.216^{* * *}$ & $2.048^{* * *}$ & $0.582^{* * *}$ & $2.779^{* * *}$ & $1.993^{* * *}$ & $1.053^{* * *}$ & $2.866^{* * *}$ \\
\hline Observations & 10,219 & 3,575 & 2,912 & 3,726 & 2,485 & 2,128 & 8,586 & 2,777 & 4,588 & 2,493 & 3,365 & 5,521 & 4,439 \\
\hline R-squared & 0.310 & 0.278 & 0.534 & 0.291 & 0.411 & 0.172 & 0.300 & 0.508 & 0.386 & 0.206 & 0.441 & 0.279 & 0.292 \\
\hline
\end{tabular}


Table 7 Decompositions for subsamples of younger and older employees (aged 25-44, 45-60) with pay gap rows bolded

\begin{tabular}{|c|c|c|c|c|c|c|c|c|c|c|c|c|c|c|}
\hline & AT & $\mathrm{BE}$ & BG & $\mathrm{CY}$ & $\mathrm{CZ}$ & $\mathrm{DE}$ & DK & $\mathrm{EE}$ & ES & $\mathrm{FI}$ & GR & $\mathrm{HU}$ & IE & IS \\
\hline \multicolumn{15}{|c|}{ FULL SAMPLE } \\
\hline public & $2.847^{* * *}$ & $2.842^{* * *}$ & $0.428^{* * *}$ & $2.538^{* * *}$ & $1.539^{* * *}$ & $2.829^{* * *}$ & $3.211^{* * *}$ & $1.399 * * *$ & $2.536^{* * *}$ & $2.933^{* * *}$ & $2.507^{* * *}$ & $1.389^{* * *}$ & $3.180^{* * *}$ & $3.235^{* * *}$ \\
\hline private & $2.753^{* * *}$ & $2.839^{* * *}$ & $0.311^{* * *}$ & $2.242^{* * *}$ & $1.333^{* * *}$ & $2.794^{* * *}$ & $3.162^{* * *}$ & $1.266^{* * *}$ & $2.253^{* * *}$ & $2.805^{* * *}$ & $2.173^{* * *}$ & $1.098^{* * *}$ & $3.023^{* * *}$ & $3.082^{* * *}$ \\
\hline difference & $0.095^{* * *}$ & 0.004 & $0.117^{* * *}$ & $0.296^{* * *}$ & $0.206^{* * *}$ & $0.034^{* * *}$ & $0.049 * *$ & $0.133^{* * *}$ & $0.283^{* * *}$ & $0.128^{* * *}$ & $0.334^{* * *}$ & $0.291^{* * *}$ & $0.157^{* * *}$ & $0.153^{* * *}$ \\
\hline explained & $0.092^{* * *}$ & $0.036^{* * *}$ & $0.087^{* * *}$ & $0.097^{* * *}$ & $0.091^{* * *}$ & $0.087^{* * *}$ & 0.001 & $0.111^{* * *}$ & $0.151^{* * *}$ & $0.115^{* * *}$ & $0.144^{* * *}$ & $0.133^{* * *}$ & $0.061^{* * *}$ & $0.066^{* * *}$ \\
\hline pub. adv. & 0.003 & $-0.028^{* *}$ & 0.027 & $0.176^{* * *}$ & $0.108^{* * *}$ & $-0.045^{* * *}$ & $0.046^{* *}$ & 0.020 & $0.115^{* * *}$ & 0.012 & $0.159^{* * *}$ & $0.143^{* * *}$ & $0.081^{* * *}$ & $0.078^{* *}$ \\
\hline pri. disadv. & 0.000 & $-0.005^{* *}$ & 0.002 & $0.023^{* * *}$ & $0.007^{* * *}$ & $-0.007^{* * *}$ & $0.002^{* *}$ & 0.001 & $0.017^{* * *}$ & 0.001 & $0.031^{* * *}$ & $0.014^{* * *}$ & $0.014^{* * *}$ & $0.008^{* *}$ \\
\hline Obs. & 2,963 & 3,224 & 3,031 & 2,862 & 8,484 & 6,559 & 4,551 & 4,011 & 8,601 & 3,453 & 3,104 & 5,943 & 1,965 & 1,083 \\
\hline \multicolumn{15}{|l|}{ OLDER } \\
\hline public & $2.931^{* * *}$ & $2.917^{* * *}$ & $0.383^{* * *}$ & $2.777^{* * *}$ & $1.535^{* * *}$ & $2.891^{* * *}$ & $3.274^{* * *}$ & $1.321^{* * *}$ & $2.619 * * *$ & $2.982^{* * *}$ & $2.682^{* * *}$ & $1.364^{* * *}$ & $3.255^{* * *}$ & $3.270^{* * *}$ \\
\hline private & $2.810^{* * *}$ & $2.941 * * *$ & $0.310^{* * *}$ & $2.362^{* * *}$ & $1.315^{* * *}$ & $2.844^{* * *}$ & $3.191^{* * *}$ & $1.185^{* * *}$ & $2.365^{* * *}$ & $2.843^{* * *}$ & $2.359^{* * *}$ & $1.106^{* * *}$ & $3.103^{* * *}$ & $3.131^{* * *}$ \\
\hline difference & $0.121 * * *$ & -0.025 & 0.073 & $0.415^{* * *}$ & $0.220^{* * *}$ & $0.047^{* * *}$ & $0.083^{* *}$ & $0.136^{* * *}$ & $0.254^{* * *}$ & $0.139 * * *$ & $0.323^{* * *}$ & $0.258^{* * *}$ & $0.152^{* * *}$ & $0.138^{* *}$ \\
\hline explained & $0.103^{* * *}$ & 0.010 & $0.074^{* *}$ & $0.173^{* * *}$ & $0.097^{* * *}$ & $0.105^{* * *}$ & $0.030^{*}$ & $0.109^{* * *}$ & $0.153^{* * *}$ & $0.113^{* * *}$ & $0.161^{* * *}$ & $0.110^{* * *}$ & $0.052^{* *}$ & 0.052 \\
\hline pub. adv. & 0.016 & -0.028 & -0.001 & $0.213^{* * *}$ & $0.116^{* * *}$ & $-0.049 * * *$ & $0.051^{*}$ & 0.025 & $0.084^{* * *}$ & 0.024 & $0.131^{* * *}$ & $0.135^{* * *}$ & $0.081^{* * *}$ & $0.077^{*}$ \\
\hline pri. disadv. & 0.002 & -0.006 & -0.000 & $0.029 * * *$ & $0.007^{* * *}$ & $-0.009 * * *$ & $0.002^{*}$ & 0.002 & $0.017^{* * *}$ & 0.002 & $0.031^{* * *}$ & $0.013^{* * *}$ & $0.019^{* * *}$ & 0.010 \\
\hline Obs. & 1,207 & 1,096 & 1,389 & 1,194 & 3,736 & 3,167 & 2,202 & 1,892 & 3,213 & 1,688 & 1,032 & 2,367 & 879 & 477 \\
\hline \multicolumn{15}{|l|}{ YOUNGER } \\
\hline public & $2.766^{* * *}$ & $2.784^{* * *}$ & $0.464^{* * *}$ & $2.358^{* * *}$ & $1.542^{* * *}$ & $2.753^{* * *}$ & $3.149^{* * *}$ & $1.470^{* * *}$ & $2.456^{* * *}$ & $2.876^{* * *}$ & $2.396^{* * *}$ & $1.404^{* * *}$ & $3.077^{* * *}$ & $3.198^{* * *}$ \\
\hline private & $2.715^{* * *}$ & $2.789^{* * *}$ & $0.313^{* * *}$ & $2.156^{* * *}$ & $1.346^{* * *}$ & $2.750^{* * *}$ & $3.135^{* * *}$ & $1.338^{* * *}$ & $2.191^{* * *}$ & $2.768^{* * *}$ & $2.084^{* * *}$ & $1.094^{* * *}$ & $2.964^{* * *}$ & $3.045^{* * *}$ \\
\hline difference & 0.051 & -0.005 & $0.151^{* * *}$ & $0.202^{* * *}$ & $0.195^{* * *}$ & 0.003 & 0.014 & $0.132^{* * *}$ & $0.265^{* * *}$ & $0.108^{* * *}$ & $0.312^{* * *}$ & $0.311^{* * *}$ & $0.113^{* * *}$ & $0.152^{* *}$ \\
\hline explained & $0.048^{* * *}$ & 0.013 & $0.100^{* * *}$ & $0.047^{*}$ & $0.084^{* * *}$ & $0.043^{* * *}$ & -0.017 & $0.125^{* * *}$ & $0.088^{* * *}$ & $0.091^{* * *}$ & $0.084^{* * *}$ & $0.141^{* * *}$ & -0.015 & $0.066^{* *}$ \\
\hline pub. adv. & 0.003 & -0.016 & 0.046 & $0.138^{* * *}$ & $0.105^{* * *}$ & $-0.035^{* *}$ & 0.029 & 0.007 & $0.159 * * *$ & 0.015 & $0.194^{* * *}$ & $0.153^{* * *}$ & $0.113^{* * *}$ & 0.080 \\
\hline pri. disadv. & 0.000 & -0.002 & 0.004 & $0.018^{* * *}$ & $0.007^{* * *}$ & $-0.005^{* *}$ & 0.001 & 0.000 & $0.018^{* * *}$ & 0.001 & $0.034^{* * *}$ & $0.016^{* * *}$ & $0.014^{* * *}$ & 0.007 \\
\hline Obs. & 1,756 & 2,128 & 1,642 & 1,668 & 4,748 & 3,392 & 2,349 & 2,119 & 5,388 & 1,765 & 2,072 & 3,576 & 1,086 & 606 \\
\hline
\end{tabular}


Table 7 Decompositions for subsamples of younger and older employees (aged 25-44, 45-60) with pay gap rows bolded (Continued)

\begin{tabular}{|c|c|c|c|c|c|c|c|c|c|c|c|c|c|}
\hline & IT & LT & LU & LV & $\mathrm{NL}$ & NO & $\mathrm{PL}$ & PT & RO & $\mathrm{SE}$ & SI & SK & UK \\
\hline \multicolumn{14}{|c|}{ FULL SAMPLE } \\
\hline public & $2.719^{* * *}$ & $1.221^{* * *}$ & $3.297^{* * *}$ & $1.486^{* * *}$ & $3.227^{* * *}$ & $3.171^{* * *}$ & $1.451^{* * *}$ & $2.047^{* * *}$ & $0.814^{* * *}$ & $2.928^{* * *}$ & $2.235^{* * *}$ & $1.185^{* * *}$ & $3.007^{* * *}$ \\
\hline private & $2.489^{* * *}$ & $1.062^{* * *}$ & $2.962^{* * *}$ & $1.106^{* * *}$ & $3.092^{* * *}$ & $3.200^{* * *}$ & $1.178^{* * *}$ & $1.770^{* * *}$ & $0.520^{* * *}$ & $2.858^{* * *}$ & $2.009^{* * *}$ & $1.043^{* * *}$ & $2.909^{* * *}$ \\
\hline difference & $0.230^{* * *}$ & $0.159 * * *$ & $0.335^{* * *}$ & $0.380^{* * *}$ & $0.134^{* * *}$ & -0.029 & $0.273^{* * *}$ & $0.277^{* * *}$ & $0.294^{* * *}$ & $0.070^{*}$ & $0.226^{* * *}$ & $0.142^{* * *}$ & $0.098^{* * *}$ \\
\hline explained & $0.143^{* * *}$ & $0.142^{* * *}$ & $0.106^{* * *}$ & $0.241^{* * *}$ & $0.070^{* * *}$ & $0.044^{* * *}$ & $0.210^{* * *}$ & $0.124^{* * *}$ & $0.184^{* * *}$ & $0.042^{*}$ & $0.225^{* * *}$ & $0.063^{* * *}$ & 0.001 \\
\hline pub. adv. & $0.077^{* * *}$ & 0.015 & $0.212^{* * *}$ & $0.124^{* * *}$ & $0.056^{* * *}$ & $-0.069^{* * *}$ & $0.058^{* * *}$ & $0.135^{* * *}$ & $0.104^{* * *}$ & 0.027 & 0.001 & $0.068^{* * *}$ & $0.086^{* * *}$ \\
\hline pri. disadv. & $0.010^{* * *}$ & 0.001 & $0.017^{* * *}$ & $0.015^{* * *}$ & $0.008^{* * *}$ & $-0.004^{* * *}$ & $0.005^{* * *}$ & $0.017^{* * *}$ & $0.006^{* * *}$ & 0.001 & 0.000 & $0.011^{* * *}$ & $0.011^{* * *}$ \\
\hline Obs. & 10,219 & 3,575 & 2,912 & 3,726 & 2,485 & 2,128 & 8,586 & 2,777 & 4,588 & 2,493 & 3,365 & 5,521 & 4,439 \\
\hline \multicolumn{14}{|l|}{ OLDER } \\
\hline public & $2.758^{* * *}$ & $1.215^{* * *}$ & $3.481^{* * *}$ & $1.369^{* * *}$ & $3.294^{* * *}$ & $3.145^{* * *}$ & $1.512^{* * *}$ & $2.086^{* * *}$ & $0.749^{* * *}$ & $2.934^{* * *}$ & $2.354^{* * *}$ & $1.199^{* * *}$ & $3.016^{* * *}$ \\
\hline private & $2.607^{* * *}$ & $1.061^{* * *}$ & $3.203^{* * *}$ & $1.063^{* * *}$ & $3.179^{* * *}$ & $3.255^{* * *}$ & $1.222^{* * *}$ & $1.860^{* * *}$ & $0.571^{* * *}$ & $2.940^{* * *}$ & $2.076^{* * *}$ & $1.039^{* * *}$ & $2.904^{* * *}$ \\
\hline difference & $0.151 * * *$ & $0.154^{* * *}$ & $0.278^{* * *}$ & $0.305^{* * *}$ & $0.115^{* * *}$ & $-0.110^{* * *}$ & $0.291^{* * *}$ & $0.226^{* * *}$ & $0.178^{* * *}$ & -0.007 & $0.278^{* * *}$ & $0.161^{* * *}$ & $0.112^{* * *}$ \\
\hline explained & $0.100^{* * *}$ & $0.156^{* * *}$ & $0.084^{*}$ & $0.191^{* * *}$ & $0.081^{* * *}$ & -0.004 & $0.202^{* * *}$ & 0.035 & $0.106^{* *}$ & $0.109^{* * *}$ & $0.331^{* * *}$ & $0.056^{* * *}$ & 0.019 \\
\hline pub. adv. & $0.043^{* * *}$ & -0.002 & $0.177^{* * *}$ & $0.103^{* * *}$ & 0.029 & $-0.099^{* * *}$ & $0.082^{* * *}$ & $0.164^{* * *}$ & 0.068 & $-0.111^{* * *}$ & $-0.048^{*}$ & $0.089^{* * *}$ & $0.082^{* * *}$ \\
\hline pri. disadv. & $0.008^{* * *}$ & -0.000 & $0.017^{* * *}$ & $0.012^{* * *}$ & 0.005 & $-0.007^{* * *}$ & $0.007^{* * *}$ & $0.027^{* * *}$ & 0.004 & $-0.005^{* * *}$ & $-0.004^{*}$ & $0.016^{* * *}$ & $0.011^{* * *}$ \\
\hline Obs. & 3,989 & 1,842 & 805 & 1,715 & 1,012 & 867 & 3,294 & 1,185 & 1,730 & 1,004 & 1,317 & 2,415 & 2,012 \\
\hline \multicolumn{14}{|l|}{ YOUNGER } \\
\hline public & $2.678^{* * *}$ & $1.226^{* * *}$ & $3.207^{* * *}$ & $1.583^{* * *}$ & $3.162^{* * *}$ & $3.193^{* * *}$ & $1.419^{* * *}$ & $2.001^{* * *}$ & $0.852^{* * *}$ & $2.925^{* * *}$ & $2.156^{* * *}$ & $1.172^{* * *}$ & $2.999 * * *$ \\
\hline private & $2.419^{* * *}$ & $1.063^{* * *}$ & $2.872^{* * *}$ & $1.143^{* * *}$ & $3.036^{* * *}$ & $3.162^{* * *}$ & $1.150^{* * *}$ & $1.707^{* * *}$ & $0.489^{* * *}$ & $2.801^{* * *}$ & $1.966^{* * *}$ & $1.046^{* * *}$ & $2.913^{* * *}$ \\
\hline difference & $0.260 * * *$ & $0.164^{* * *}$ & $0.335^{* * *}$ & $0.440^{* * *}$ & $0.127^{* * *}$ & 0.031 & $0.269 * * *$ & $0.294^{* * *}$ & $0.363^{* * *}$ & $0.125^{* *}$ & $0.190 * * *$ & $0.125^{* * *}$ & $0.085^{* * *}$ \\
\hline explained & $0.102^{* * *}$ & $0.142^{* * *}$ & $0.082^{* * *}$ & $0.279^{* * *}$ & 0.021 & $0.050^{* *}$ & $0.209^{* * *}$ & $0.135^{* * *}$ & $0.227^{* * *}$ & 0.019 & $0.152^{* * *}$ & $0.070^{* * *}$ & -0.022 \\
\hline pub. adv. & $0.143^{* * *}$ & 0.020 & $0.236^{* * *}$ & $0.143^{* * *}$ & $0.095^{* * *}$ & -0.019 & $0.055^{* * *}$ & $0.145^{* * *}$ & $0.129^{* * *}$ & $0.100^{* *}$ & 0.035 & $0.048^{* * *}$ & $0.096^{* * *}$ \\
\hline pri. disadv. & $0.015^{* * *}$ & 0.002 & $0.017^{* * *}$ & $0.017^{* * *}$ & $0.011^{* * *}$ & -0.001 & $0.005^{* * *}$ & $0.014^{* * *}$ & $0.007^{* * *}$ & $0.006^{* *}$ & 0.003 & $0.007^{* * *}$ & $0.011^{* * *}$ \\
\hline Obs. & 6,230 & 1,733 & 2,107 & 2,011 & 1,473 & 1,261 & 5,292 & 1,592 & 2,858 & 1,489 & 2,048 & 3,106 & 2,427 \\
\hline
\end{tabular}


Table 8 Decompositions for subsamples of tertiary and non-tertiary educated with pay gap rows bolded

\begin{tabular}{|c|c|c|c|c|c|c|c|c|c|c|c|c|c|c|}
\hline & AT & $\mathrm{BE}$ & BG & $\mathrm{CY}$ & $\mathrm{CZ}$ & $\mathrm{DE}$ & DK & $\mathrm{EE}$ & ES & $\mathrm{FI}$ & GR & $\mathrm{HU}$ & IE & IS \\
\hline \multicolumn{15}{|c|}{ FULL SAMPLE } \\
\hline public & $2.847^{* * *}$ & $2.842^{* * *}$ & $0.428^{* * *}$ & $2.538^{* * *}$ & $1.539^{* * *}$ & $2.829^{* * *}$ & $3.211^{* * *}$ & $1.399^{* * *}$ & $2.536^{* * *}$ & $2.933^{* * *}$ & $2.507^{* * *}$ & $1.389^{* * *}$ & $3.180^{* * *}$ & $3.235^{* * *}$ \\
\hline private & $2.753^{* * *}$ & $2.839^{* * *}$ & $0.311^{* * *}$ & $2.242^{* * *}$ & $1.333^{* * *}$ & $2.794^{* * *}$ & $3.162^{* * *}$ & $1.266^{* * *}$ & $2.253^{* * *}$ & $2.805^{* * *}$ & $2.173^{* * *}$ & $1.098^{* * *}$ & $3.023^{* * *}$ & $3.082^{* * *}$ \\
\hline difference & $0.095^{* * *}$ & 0.004 & $0.117^{* * *}$ & $0.296^{* * *}$ & $0.206^{* * *}$ & $0.034^{* * *}$ & $0.049 * *$ & $0.133^{* * *}$ & $0.283^{* * *}$ & $0.128^{* * *}$ & $0.334^{* * *}$ & $0.291^{* * *}$ & $0.157^{* * *}$ & $0.153^{* * *}$ \\
\hline explained & $0.092^{* * *}$ & $0.036^{* * *}$ & $0.087^{* * *}$ & $0.097^{* * *}$ & $0.091^{* * *}$ & $0.087^{* * *}$ & 0.001 & $0.111^{* * *}$ & $0.151^{* * *}$ & $0.115^{* * *}$ & $0.144^{* * *}$ & $0.133^{* * *}$ & $0.061^{* * *}$ & $0.066^{* * *}$ \\
\hline pub. adv. & 0.003 & $-0.028^{* *}$ & 0.027 & $0.176^{* * *}$ & $0.108^{* * *}$ & $-0.045^{* * *}$ & $0.046^{* *}$ & 0.020 & $0.115^{* * *}$ & 0.012 & $0.159^{* * *}$ & $0.143^{* * *}$ & $0.081^{* * *}$ & $0.078^{* *}$ \\
\hline pri. disadv. & 0.000 & $-0.005^{* *}$ & 0.002 & $0.023^{* * *}$ & $0.007^{* * *}$ & $-0.007^{* * *}$ & $0.002^{* *}$ & 0.001 & $0.017^{* * *}$ & 0.001 & $0.031^{* * *}$ & $0.014^{* * *}$ & $0.014^{* * *}$ & $0.008^{* *}$ \\
\hline Obs. & 2,963 & 3,224 & 3,031 & 2,862 & 8,484 & 6,559 & 4,551 & 4,011 & 8,601 & 3,453 & 3,104 & 5,943 & 1,965 & 1,083 \\
\hline \multicolumn{15}{|l|}{ TERTIARY } \\
\hline public & $3.014^{* * *}$ & $2.936^{* * *}$ & $0.731^{* * *}$ & $2.600^{* * *}$ & $1.733^{* * *}$ & $2.894^{* * *}$ & $3.310^{* * *}$ & $1.550^{* * *}$ & $2.668^{* * *}$ & $2.999^{* * *}$ & $2.579^{* * *}$ & $1.734^{* * *}$ & $3.289 * * *$ & $3.291^{* * *}$ \\
\hline private & $2.959^{* * *}$ & $2.950^{* * *}$ & $0.560^{* * *}$ & $2.516^{* * *}$ & $1.700^{* * *}$ & $2.934^{* * *}$ & $3.274 * *$ & $1.422^{* * *}$ & $2.473^{* * *}$ & $2.988^{* * *}$ & $2.376^{* * *}$ & $1.487^{* * *}$ & $3.187^{* * *}$ & $3.248^{* * *}$ \\
\hline difference & 0.055 & -0.014 & $0.171^{* * *}$ & $0.084^{*}$ & 0.033 & $-0.039 * *$ & 0.036 & $0.128^{* * *}$ & $0.194^{* * *}$ & 0.011 & $0.202^{* * *}$ & $0.246^{* * *}$ & $0.103^{* * *}$ & 0.043 \\
\hline explained & $0.051^{* *}$ & 0.020 & $0.071^{* * *}$ & 0.002 & 0.014 & $0.049^{* * *}$ & 0.009 & $0.093^{* * *}$ & $0.089^{* * *}$ & 0.025 & $0.097^{* * *}$ & $0.025^{*}$ & 0.031 & 0.037 \\
\hline pub. adv. & 0.004 & -0.029 & $0.087^{*}$ & $0.072^{* * *}$ & 0.017 & $-0.074^{* * *}$ & 0.026 & 0.031 & $0.089^{* * *}$ & -0.012 & $0.084^{* * *}$ & $0.191^{* * *}$ & $0.061^{* *}$ & 0.005 \\
\hline pri. disadv. & 0.000 & -0.004 & $0.013^{*}$ & $0.010^{* * *}$ & 0.002 & $-0.014^{* * *}$ & 0.001 & 0.004 & $0.017^{* * *}$ & -0.002 & $0.021^{* * *}$ & $0.031^{* * *}$ & $0.011^{* *}$ & 0.001 \\
\hline Obs. & 1,051 & 1,583 & 739 & 1,124 & 1,452 & 3,563 & 1,816 & 1,398 & 3,538 & 1,667 & 1,157 & 1,764 & 1,058 & 507 \\
\hline \multicolumn{15}{|c|}{ NON- TERTIARY } \\
\hline public & $2.767^{* * *}$ & $2.770^{* * *}$ & $0.240^{* * *}$ & $2.494^{* * *}$ & $1.460^{* * *}$ & $2.722^{* * *}$ & $3.140^{* * *}$ & $1.224^{* * *}$ & $2.393^{* * *}$ & $2.740^{* * *}$ & $2.447^{* * *}$ & $1.102^{* * *}$ & $3.048^{* * *}$ & $3.158^{* * *}$ \\
\hline private & $2.638^{* * *}$ & $2.727^{* * *}$ & $0.237^{* * *}$ & $2.066^{* * *}$ & $1.261^{* * *}$ & $2.637^{* * *}$ & $3.088^{* * *}$ & $1.187^{* * *}$ & $2.109^{* * *}$ & $2.647^{* * *}$ & $2.060^{* * *}$ & $0.946^{* * *}$ & $2.834^{* * *}$ & $2.944^{* * *}$ \\
\hline difference & $0.129 * * *$ & $0.043^{* *}$ & 0.003 & $0.428^{* * *}$ & $0.199 * * *$ & $0.086^{* * *}$ & $0.052^{* *}$ & 0.037 & $0.284^{* * *}$ & $0.093^{* * *}$ & $0.388^{* * *}$ & $0.156^{* * *}$ & $0.214^{* * *}$ & $0.214^{* * *}$ \\
\hline explained & $0.115^{* * *}$ & $0.066^{* * *}$ & 0.004 & $0.139 * * *$ & $0.052^{* * *}$ & $0.076^{* * *}$ & -0.003 & 0.026 & $0.105^{* * *}$ & 0.022 & $0.119^{* * *}$ & $0.045^{* * *}$ & $0.062^{* * *}$ & 0.015 \\
\hline pub. adv. & 0.013 & -0.020 & -0.000 & $0.256^{* * *}$ & $0.140^{* * *}$ & 0.009 & $0.053^{* *}$ & 0.010 & $0.160^{* * *}$ & $0.068^{* * *}$ & $0.230^{* * *}$ & $0.103^{* * *}$ & $0.130^{* * *}$ & $0.184^{* * *}$ \\
\hline pri. disadv. & 0.001 & -0.004 & -0.000 & $0.033^{* * *}$ & $0.008^{* * *}$ & 0.001 & $0.002^{* *}$ & 0.001 & $0.018^{* * *}$ & $0.003^{* * *}$ & $0.038^{* * *}$ & $0.008^{* * *}$ & $0.022^{* * *}$ & $0.015^{* * *}$ \\
\hline Obs. & 1,912 & 1,641 & 2,292 & 1,738 & 7,032 & 2,996 & 2,735 & 2,613 & 5,063 & 1,786 & 1,947 & 4,179 & 907 & 576 \\
\hline
\end{tabular}


Table 8 Decompositions for subsamples of tertiary and non-tertiary educated with pay gap rows bolded (Continued)

\begin{tabular}{|c|c|c|c|c|c|c|c|c|c|c|c|c|c|}
\hline & IT & LT & LU & LV & $\mathrm{NL}$ & NO & $\mathrm{PL}$ & PT & RO & SE & SI & SK & UK \\
\hline \multicolumn{14}{|c|}{ FULL SAMPLE } \\
\hline public & $2.719^{* * *}$ & $1.221^{* * *}$ & $3.297^{* * *}$ & $1.486^{* * *}$ & $3.227^{* * *}$ & $3.171^{* * *}$ & $1.451^{* * *}$ & $2.047^{* * *}$ & $0.814^{* * *}$ & $2.928^{* * *}$ & $2.235^{* * *}$ & $1.185^{* * *}$ & $3.007^{* * *}$ \\
\hline private & $2.489^{* * *}$ & $1.062^{* * *}$ & $2.962^{* * *}$ & $1.106^{* * *}$ & $3.092^{* * *}$ & $3.200^{* * *}$ & $1.178^{* * *}$ & $1.770^{* * *}$ & $0.520^{* * *}$ & $2.858^{* * *}$ & $2.009^{* * *}$ & $1.043^{* * *}$ & $2.909^{* * *}$ \\
\hline difference & $0.230^{* * *}$ & $0.159 * * *$ & $0.335^{* * *}$ & $0.380 * * *$ & $0.134^{* * *}$ & -0.029 & $0.273^{* * *}$ & $0.277^{* * *}$ & $0.294 * * *$ & $0.070^{*}$ & $0.226^{* * *}$ & $0.142^{* * *}$ & $0.098^{* * *}$ \\
\hline explained & $0.143^{* * *}$ & $0.142^{* * *}$ & $0.106^{* * *}$ & $0.241^{* * *}$ & $0.070^{* * *}$ & $0.044^{* * *}$ & $0.210^{* * *}$ & $0.124^{* * *}$ & $0.184^{* * *}$ & $0.042^{*}$ & $0.225^{* * *}$ & $0.063^{* * *}$ & 0.001 \\
\hline pub. adv. & $0.077^{* * *}$ & 0.015 & $0.212^{* * *}$ & $0.124^{* * *}$ & $0.056^{* * *}$ & $-0.069^{* * *}$ & $0.058^{* * *}$ & $0.135^{* * *}$ & $0.104^{* * *}$ & 0.027 & 0.001 & $0.068^{* * *}$ & $0.086^{* * *}$ \\
\hline pri. disadv. & $0.010^{* * *}$ & 0.001 & $0.017^{* * *}$ & $0.015^{* * *}$ & $0.008^{* * *}$ & $-0.004^{* * *}$ & $0.005^{* * *}$ & $0.017^{* * *}$ & $0.006^{* * *}$ & 0.001 & 0.000 & $0.011^{* * *}$ & $0.011^{* * *}$ \\
\hline Obs. & 10,219 & 3,575 & 2,912 & 3,726 & 2,485 & 2,128 & 8,586 & 2,777 & 4,588 & 2,493 & 3,365 & 5,521 & 4,439 \\
\hline \multicolumn{14}{|l|}{ TERTIARY } \\
\hline public & $2.822^{* * *}$ & $1.288^{* * *}$ & $3.398^{* * *}$ & $1.679 * * *$ & $3.349^{* * *}$ & $3.264^{* * *}$ & $1.541^{* * *}$ & $2.552^{* * *}$ & $1.155^{* * *}$ & $2.945^{* * *}$ & $2.430^{* * *}$ & $1.362^{* * *}$ & $3.186^{* * *}$ \\
\hline private & $2.707^{* * *}$ & $1.170^{* * *}$ & $3.329^{* * *}$ & $1.458^{* * *}$ & $3.278^{* * *}$ & $3.284^{* * *}$ & $1.492^{* * *}$ & $2.564^{* * *}$ & $0.944^{* * *}$ & $2.939^{* * *}$ & $2.436^{* * *}$ & $1.311^{* * *}$ & $3.119^{* * *}$ \\
\hline difference & $0.114^{* * *}$ & $0.118^{* * *}$ & 0.069 & $0.222^{* * *}$ & $0.071^{* * *}$ & -0.020 & $0.048^{*}$ & -0.012 & $0.211^{* * *}$ & 0.007 & -0.006 & $0.050^{* *}$ & $0.067^{* *}$ \\
\hline explained & $0.064^{* * *}$ & $0.101^{* * *}$ & -0.011 & $0.137^{* * *}$ & $0.035^{* *}$ & $0.052^{* *}$ & $0.046^{* * *}$ & 0.021 & $0.064^{* * *}$ & 0.001 & $0.064^{* * *}$ & -0.010 & $-0.038^{* *}$ \\
\hline pub. adv. & $0.043^{* *}$ & 0.015 & 0.076 & $0.070^{* *}$ & $0.031^{*}$ & $-0.067^{* *}$ & 0.002 & -0.030 & $0.135^{* * *}$ & 0.005 & $-0.060^{* *}$ & $0.046^{* * *}$ & $0.092^{* * *}$ \\
\hline pri. disadv. & $0.008^{* *}$ & 0.002 & 0.004 & $0.015^{* *}$ & $0.005^{*}$ & $-0.005^{* *}$ & 0.000 & -0.003 & $0.012^{* * *}$ & 0.000 & $-0.010^{* *}$ & $0.015^{* * *}$ & $0.013^{* * *}$ \\
\hline Obs. & 2,098 & 2,343 & 1,125 & 1,243 & 1,165 & 1,002 & 2,467 & 452 & 1,246 & 1,136 & 948 & 1,256 & 1,949 \\
\hline \multicolumn{14}{|c|}{ NON- TERTIARY } \\
\hline public & $2.683^{* * *}$ & $0.917^{* * *}$ & $3.263^{* * *}$ & $1.245^{* * *}$ & $3.082^{* * *}$ & $3.049^{* * *}$ & $1.345^{* * *}$ & $1.959^{* * *}$ & $0.548^{* * *}$ & $2.888^{* * *}$ & $1.997^{* * *}$ & $1.068^{* * *}$ & $2.842^{* * *}$ \\
\hline private & $2.435^{* * *}$ & $0.868^{* * *}$ & $2.721^{* * *}$ & $0.950^{* * *}$ & $2.935^{* * *}$ & $3.126^{* * *}$ & $1.065^{* * *}$ & $1.614^{* * *}$ & $0.369^{* * *}$ & $2.793^{* * *}$ & $1.859^{* * *}$ & $0.976^{* * *}$ & $2.748^{* * *}$ \\
\hline difference & $0.248^{* * *}$ & 0.048 & $0.542^{* * *}$ & $0.295^{* * *}$ & $0.147^{* * *}$ & $-0.078^{* * *}$ & $0.280^{* * *}$ & $0.345^{* * *}$ & $0.179 * * *$ & 0.095 & $0.139 * * *$ & $0.093^{* * *}$ & $0.094^{* * *}$ \\
\hline explained & $0.138^{* * *}$ & $0.054^{*}$ & $0.237^{* * *}$ & $0.099 * * *$ & $0.050^{* * *}$ & -0.002 & $0.142^{* * *}$ & $0.122^{* * *}$ & $0.101^{* * *}$ & 0.031 & $0.088^{* * *}$ & -0.001 & -0.006 \\
\hline pub. adv. & $0.098^{* * *}$ & -0.005 & $0.278^{* * *}$ & $0.182^{* * *}$ & $0.087^{* * *}$ & $-0.072^{* * *}$ & $0.131^{* * *}$ & $0.198^{* * *}$ & $0.074^{* *}$ & 0.062 & $0.049^{*}$ & $0.084^{* * *}$ & $0.089^{* * *}$ \\
\hline pri. disadv. & $0.012^{* * *}$ & -0.000 & $0.027^{* * *}$ & $0.014^{* * *}$ & $0.010^{* * *}$ & $-0.004^{* *}$ & $0.008^{* * *}$ & $0.025^{* * *}$ & $0.003^{* *}$ & 0.002 & $0.002^{*}$ & $0.010^{* * *}$ & $0.011^{* * *}$ \\
\hline Obs. & 8,121 & 1,232 & 1,787 & 2,483 & 1,320 & 1,126 & 6,119 & 2,325 & 3,342 & 1,357 & 2,417 & 4,265 & 2,490 \\
\hline
\end{tabular}




\begin{tabular}{|c|c|c|c|c|c|c|c|c|c|c|c|c|c|c|}
\hline & AT & $\mathrm{BE}$ & BG & $\mathrm{CY}$ & $\mathrm{CZ}$ & $\mathrm{DE}$ & DK & $\mathrm{EE}$ & ES & $\mathrm{FI}$ & GR & $\mathrm{HU}$ & IE & IS \\
\hline \multicolumn{15}{|c|}{ FULL SAMPLE } \\
\hline public & $2.847^{* * *}$ & $2.842^{* * *}$ & $0.428^{* * *}$ & $2.538^{* * *}$ & $1.539^{* * *}$ & $2.829^{* * *}$ & $3.211^{* * *}$ & $1.399^{* * *}$ & $2.536^{* * *}$ & $2.933^{* * *}$ & $2.507^{* * *}$ & $1.389^{* * *}$ & $3.180^{* * *}$ & $3.235^{* * *}$ \\
\hline private & $2.753^{* * *}$ & $2.839^{* * *}$ & $0.311^{* * *}$ & $2.242^{* * *}$ & $1.333^{* * *}$ & $2.794^{* * *}$ & $3.162^{* * *}$ & $1.266^{* * *}$ & $2.253^{* * *}$ & $2.805^{* * *}$ & $2.173^{* * *}$ & $1.098^{* * *}$ & $3.023^{* * *}$ & $3.082^{* * *}$ \\
\hline difference & $0.095^{* * *}$ & 0.004 & $0.117^{* * *}$ & $0.296^{* * *}$ & $0.206^{* * *}$ & $0.034^{* * *}$ & $0.049 * *$ & $0.133^{* * *}$ & $0.283^{* * *}$ & $0.128^{* * *}$ & $0.334^{* * *}$ & $0.291 * * *$ & $0.157^{* * *}$ & $0.153^{* * *}$ \\
\hline explained & $0.092^{* * *}$ & $0.036^{* * *}$ & $0.087^{* * *}$ & $0.097^{* * *}$ & $0.091^{* * *}$ & $0.087^{* * *}$ & 0.001 & $0.111^{* * *}$ & $0.151^{* * *}$ & $0.115^{* * *}$ & $0.144^{* * *}$ & $0.133^{* * *}$ & $0.061^{* * *}$ & $0.066^{* * *}$ \\
\hline pub. adv. & 0.003 & $-0.028^{* *}$ & 0.027 & $0.176^{* * *}$ & $0.108^{* * *}$ & $-0.045^{* * *}$ & $0.046^{* *}$ & 0.020 & $0.115^{* * *}$ & 0.012 & $0.159^{* * *}$ & $0.143^{* * *}$ & $0.081^{* * *}$ & $0.078^{* *}$ \\
\hline pri. disadv. & 0.000 & $-0.005^{* *}$ & 0.002 & $0.023^{* * *}$ & $0.007^{* * *}$ & $-0.007^{* * *}$ & $0.002^{* *}$ & 0.001 & $0.017^{* * *}$ & 0.001 & $0.031^{* * *}$ & $0.014^{* * *}$ & $0.014^{* * *}$ & $0.008^{* *}$ \\
\hline Obs. & 2,963 & 3,224 & 3,031 & 2,862 & 8,484 & 6,559 & 4,551 & 4,011 & 8,601 & 3,453 & 3,104 & 5,943 & 1,965 & 1,083 \\
\hline \multicolumn{15}{|l|}{ FEMALE } \\
\hline public & $2.763^{* * *}$ & $2.828^{* * *}$ & $0.290^{* * *}$ & $2.313^{* * *}$ & $1.425^{* * *}$ & $2.771^{* * *}$ & $3.163^{* * *}$ & $1.285^{* * *}$ & $2.472^{* * *}$ & $2.800^{* * *}$ & $2.428^{* * *}$ & $1.367^{* * *}$ & $3.145^{* * *}$ & $3.094^{* * *}$ \\
\hline private & $2.634^{* * *}$ & $2.787^{* * *}$ & $0.192^{* * *}$ & $2.056^{* * *}$ & $1.192^{* * *}$ & $2.680^{* * *}$ & $3.058^{* * *}$ & $1.083^{* * *}$ & $2.195^{* * *}$ & $2.700^{* * *}$ & $2.084^{* * *}$ & $1.046^{* * *}$ & $2.953^{* * *}$ & $3.006^{* * *}$ \\
\hline difference & $0.129 * * *$ & 0.041 & $0.098^{*}$ & $0.257^{* * *}$ & $0.233^{* * *}$ & $0.091 * * *$ & $0.104^{* * *}$ & $0.202^{* * *}$ & $0.277^{* * *}$ & $0.099 * * *$ & $0.344^{* * *}$ & $0.321 * * *$ & $0.192^{* * *}$ & 0.088 \\
\hline explained & $0.060^{* *}$ & 0.009 & $0.071^{* * *}$ & 0.070 & $0.100^{* * *}$ & $0.066^{* * *}$ & -0.001 & $0.149^{* * *}$ & $0.160^{* * *}$ & $0.102^{* * *}$ & $0.109^{* * *}$ & $0.106^{* * *}$ & $0.080^{* * *}$ & $0.051^{*}$ \\
\hline pub. adv. & $0.063^{* *}$ & 0.027 & 0.026 & $0.170^{* * *}$ & $0.125^{* * *}$ & 0.021 & $0.100^{* * *}$ & $0.049^{*}$ & $0.101^{* * *}$ & -0.003 & $0.199^{* * *}$ & $0.195^{* * *}$ & $0.094^{* * *}$ & 0.033 \\
\hline pri. disadv. & $0.006^{*}$ & 0.005 & 0.002 & $0.018^{* * *}$ & $0.009^{* * *}$ & 0.004 & $0.005^{* * *}$ & $0.004^{*}$ & $0.016^{* * *}$ & -0.000 & $0.035^{* * *}$ & $0.020^{* * *}$ & $0.019^{* * *}$ & 0.004 \\
\hline Obs. & 941 & 1,087 & 1,467 & 1,332 & 3,858 & 2,124 & 2,125 & 2,072 & 3,498 & 1,681 & 1,219 & 2,894 & 771 & 477 \\
\hline \multicolumn{15}{|l|}{ MALE } \\
\hline public & $2.880^{* * *}$ & $2.851^{* * * *}$ & $0.533^{* * *}$ & $2.674^{* * *}$ & $1.647^{* * *}$ & $2.861^{* * * *}$ & $3.264^{* * *}$ & $1.550^{* * *}$ & $2.585^{* * *}$ & $3.056^{* * *}$ & $2.552^{* * *}$ & $1.412^{* * * *}$ & $3.207^{* * *}$ & $3.354^{* * *}$ \\
\hline private & $2.809^{* * *}$ & $2.864^{* * *}$ & $0.425^{* * *}$ & $2.411^{* * *}$ & $1.449^{* * *}$ & $2.848^{* * *}$ & $3.252^{* * *}$ & $1.458^{* * *}$ & $2.292^{* * *}$ & $2.904^{* * *}$ & $2.231^{* * *}$ & $1.148^{* * *}$ & $3.067^{* * *}$ & $3.142^{* * *}$ \\
\hline difference & $0.071^{* *}$ & -0.013 & $0.108^{* *}$ & $0.263^{* * *}$ & $0.199 * * *$ & 0.013 & 0.012 & $0.092^{* *}$ & $0.292^{* * *}$ & $0.152^{* * *}$ & $0.320^{* * *}$ & $0.264^{* * *}$ & $0.140^{* * *}$ & $0.212^{* * *}$ \\
\hline explained & $0.096^{* * *}$ & $0.056^{* * *}$ & $0.063^{* * *}$ & $0.041^{*}$ & $0.106^{* * *}$ & $0.109^{* * *}$ & $0.027^{*}$ & $0.078^{* * *}$ & $0.148^{* * *}$ & $0.119^{* * *}$ & $0.154^{* * *}$ & $0.162^{* * *}$ & $0.072^{* * *}$ & $0.086^{* *}$ \\
\hline pub. adv. & -0.023 & $-0.059^{* * *}$ & 0.041 & $0.192^{* * *}$ & $0.088^{* * *}$ & $-0.083^{* * *}$ & -0.015 & 0.014 & $0.126^{* * *}$ & 0.031 & $0.138^{* * *}$ & $0.092^{* * *}$ & $0.058^{* *}$ & $0.115^{* *}$ \\
\hline pri. disadv. & -0.002 & $-0.009^{* * *}$ & 0.004 & $0.030^{* * *}$ & $0.005^{* * *}$ & $-0.013^{* * *}$ & -0.001 & 0.001 & $0.017^{* * *}$ & 0.002 & $0.029^{* * *}$ & $0.009^{* * *}$ & $0.009^{* *}$ & $0.012^{* *}$ \\
\hline Obs. & 2,022 & 2,137 & 1,564 & 1,530 & 4,626 & 4,435 & 2,426 & 1,939 & 5,103 & 1,772 & 1,885 & 3,049 & 1,194 & 606 \\
\hline
\end{tabular}


Table 9 Decompositions for subsamples of males and females with pay gap rows bolded (Continued)

\begin{tabular}{|c|c|c|c|c|c|c|c|c|c|c|c|c|c|}
\hline & IT & LT & LU & LV & $\mathrm{NL}$ & NO & $\mathrm{PL}$ & PT & RO & SE & SI & SK & UK \\
\hline \multicolumn{14}{|c|}{ FULL SAMPLE } \\
\hline public & $2.719^{* * *}$ & $1.221^{* * *}$ & $3.297^{* * *}$ & $1.486^{* * *}$ & $3.227^{* * *}$ & $3.171^{* * *}$ & $1.451^{* * *}$ & $2.047^{* * *}$ & $0.814^{* * *}$ & $2.928^{* * *}$ & $2.235^{* * *}$ & $1.185^{* * *}$ & $3.007^{* * *}$ \\
\hline private & $2.489^{* * *}$ & $1.062^{* * *}$ & $2.962^{* * *}$ & $1.106^{* * *}$ & $3.092^{* * *}$ & $3.200^{* * *}$ & $1.178^{* * *}$ & $1.770^{* * *}$ & $0.520^{* * *}$ & $2.858^{* * *}$ & $2.009^{* * *}$ & $1.043^{* * *}$ & $2.909^{* * *}$ \\
\hline difference & $0.230^{* * *}$ & $0.159^{* * *}$ & $0.335^{* * *}$ & $0.380^{* * *}$ & $0.134^{* * *}$ & -0.029 & $0.273^{* * *}$ & $0.277^{* * *}$ & $0.294 * * *$ & $0.070^{*}$ & $0.226^{* * *}$ & $0.142^{* * *}$ & $0.098^{* * *}$ \\
\hline explained & $0.143^{* * *}$ & $0.142^{* * *}$ & $0.106^{* * *}$ & $0.241^{* * * *}$ & $0.070^{* * *}$ & $0.044^{* * *}$ & $0.210^{* * *}$ & $0.124^{* * *}$ & $0.184^{* * *}$ & $0.042^{*}$ & $0.225^{* * *}$ & $0.063^{* * *}$ & 0.001 \\
\hline pub. adv. & $0.077^{* * *}$ & 0.015 & $0.212^{* * *}$ & $0.124^{* * *}$ & $0.056^{* * *}$ & $-0.069^{* * *}$ & $0.058^{* * *}$ & $0.135^{* * *}$ & $0.104^{* * *}$ & 0.027 & 0.001 & $0.068^{* * *}$ & $0.086^{* * *}$ \\
\hline pri. disadv. & $0.010^{* * *}$ & 0.001 & $0.017^{* * *}$ & $0.015^{* * *}$ & $0.008^{* * *}$ & $-0.004^{* * *}$ & $0.005^{* * *}$ & $0.017^{* * *}$ & $0.006^{* * *}$ & 0.001 & 0.000 & $0.011^{* * *}$ & $0.011^{* * *}$ \\
\hline Obs. & 10,219 & 3,575 & 2,912 & 3,726 & 2,485 & 2,128 & 8,586 & 2,777 & 4,588 & 2,493 & 3,365 & 5,521 & 4,439 \\
\hline \multicolumn{14}{|l|}{ FEMALE } \\
\hline public & $2.659^{* * *}$ & $1.170^{* * *}$ & $3.163^{* * *}$ & $1.467^{* * *}$ & $3.111^{* * *}$ & $3.060^{* * *}$ & $1.363^{* * *}$ & $1.971^{* * *}$ & $0.688^{* * *}$ & $2.764^{* * *}$ & $2.201^{* * *}$ & $1.099^{* * *}$ & $2.941^{* * *}$ \\
\hline private & $2.444^{* * *}$ & $0.935^{* * *}$ & $2.873^{* * *}$ & $1.012^{* * *}$ & $3.010^{* * *}$ & $3.085^{* * *}$ & $1.112^{* * *}$ & $1.718^{* * *}$ & $0.441^{* * *}$ & $2.750^{* * *}$ & $1.982^{* * *}$ & $0.927^{* * *}$ & $2.812^{* * *}$ \\
\hline difference & $0.215^{* * *}$ & $0.235^{* * *}$ & $0.290 * * *$ & $0.455^{* * *}$ & $0.101^{* * *}$ & -0.025 & $0.251^{* * *}$ & $0.253^{* * *}$ & $0.247^{* * *}$ & 0.014 & $0.219 * * *$ & $0.172^{* * *}$ & $0.129 * * *$ \\
\hline explained & $0.131^{* * *}$ & $0.141^{* * *}$ & 0.035 & $0.267^{* * *}$ & 0.010 & $0.039^{* *}$ & $0.206^{* * *}$ & $0.094^{* *}$ & $0.132^{* * *}$ & $-0.055^{* *}$ & $0.187^{* * *}$ & $0.100^{* * *}$ & 0.007 \\
\hline pub. adv. & $0.075^{* * *}$ & $0.086^{* *}$ & $0.241^{* * *}$ & $0.167^{* * *}$ & $0.079^{* * * *}$ & $-0.060^{*}$ & $0.041^{* *}$ & $0.144^{* * *}$ & $0.111^{* *}$ & 0.065 & 0.029 & $0.059^{* * *}$ & $0.104^{* * *}$ \\
\hline pri. disadv. & $0.010^{* * *}$ & $0.008^{* *}$ & $0.013^{* * *}$ & $0.021^{* * *}$ & $0.012^{* * *}$ & $-0.005^{*}$ & $0.005^{* *}$ & $0.015^{* * *}$ & $0.005^{* *}$ & 0.004 & 0.003 & $0.013^{* * *}$ & $0.018^{* * *}$ \\
\hline Obs. & 3,614 & 1,832 & 922 & 1,984 & 535 & 834 & 3,811 & 1,297 & 2,045 & 1,049 & 1,685 & 2,700 & 1,816 \\
\hline \multicolumn{14}{|l|}{ MALE } \\
\hline public & $2.749^{* * *}$ & $1.275^{* * *}$ & $3.336^{* * *}$ & $1.510^{* * *}$ & $3.264^{* * *}$ & $3.277^{* * *}$ & $1.553^{* * *}$ & $2.099^{* * *}$ & $0.879^{* * *}$ & $3.049^{* * *}$ & $2.275^{* * *}$ & $1.327^{* * *}$ & $3.081^{* * *}$ \\
\hline private & $2.514^{* * *}$ & $1.195^{* * *}$ & $3.005^{* * *}$ & $1.212^{* * *}$ & $3.115^{* * *}$ & $3.272^{* * *}$ & $1.229^{* * *}$ & $1.818^{* * *}$ & $0.585^{* * *}$ & $2.936^{* * *}$ & $2.035^{* * *}$ & $1.145^{* * *}$ & $2.972^{* * *}$ \\
\hline difference & $0.235^{* * *}$ & $0.079^{*}$ & $0.331^{* * *}$ & $0.299 * * *$ & $0.149 * * *$ & 0.006 & $0.324 * * *$ & $0.281^{* * *}$ & $0.294 * * *$ & $0.113^{* *}$ & $0.240^{* * *}$ & $0.182^{* * *}$ & $0.109 * * *$ \\
\hline explained & $0.143^{* * *}$ & $0.127^{* * *}$ & $0.104^{* * *}$ & $0.219^{* * *}$ & $0.098^{* * *}$ & $0.089^{* * *}$ & $0.244^{* * *}$ & $0.137^{* * *}$ & $0.180^{* * *}$ & $0.117^{* * *}$ & $0.268^{* * *}$ & $0.099^{* * *}$ & $0.034^{*}$ \\
\hline pub. adv. & $0.081^{* * *}$ & -0.044 & $0.209^{* * *}$ & $0.072^{*}$ & $0.045^{* * *}$ & $-0.079 * * *$ & $0.074 * * *$ & $0.126^{* * *}$ & $0.107^{* * *}$ & -0.004 & -0.027 & $0.075^{* * *}$ & $0.067^{* * *}$ \\
\hline pri. disadv. & $0.011^{* * *}$ & -0.004 & $0.019^{* * *}$ & $0.008^{*}$ & $0.006^{* * *}$ & $-0.004^{* * *}$ & $0.006^{* * *}$ & $0.018^{* * *}$ & $0.007^{* * *}$ & -0.000 & -0.002 & $0.008^{* * *}$ & $0.007^{* * * *}$ \\
\hline Obs. & 6,605 & 1,743 & 1,990 & 1,742 & 1,950 & 1,294 & 4,775 & 1,480 & 2,543 & 1,444 & 1,680 & 2,821 & 2,623 \\
\hline
\end{tabular}


Table 10 Decompositions for clerks only with pay gap rows bolded

\begin{tabular}{|c|c|c|c|c|c|c|c|c|c|c|c|c|c|c|}
\hline & AT & $\mathrm{BE}$ & BG & $\mathrm{CY}$ & $\mathrm{CZ}$ & $\mathrm{DE}$ & DK & $\mathrm{EE}$ & ES & $\mathrm{FI}$ & GR & $\mathrm{HU}$ & IE & IS \\
\hline \multicolumn{15}{|c|}{ FULL SAMPLE } \\
\hline public & $2.847^{* * *}$ & $2.842^{* * *}$ & $0.428^{* * *}$ & $2.538^{* * *}$ & $1.539^{* * *}$ & $2.829^{* * *}$ & $3.211^{* * *}$ & $1.399^{* * *}$ & $2.536^{* * *}$ & $2.933^{* * *}$ & $2.507^{* * *}$ & $1.389^{* * *}$ & $3.180^{* * *}$ & $3.235^{* * *}$ \\
\hline private & $2.753^{* * *}$ & $2.839^{* * *}$ & $0.311^{* * *}$ & $2.242^{* * *}$ & $1.333^{* * *}$ & $2.794^{* * *}$ & $3.162^{* * *}$ & $1.266^{* * *}$ & $2.253^{* * *}$ & $2.805^{* * *}$ & $2.173^{* * *}$ & $1.098^{* * *}$ & $3.023^{* * *}$ & $3.082^{* * *}$ \\
\hline difference & $0.095^{* * *}$ & 0.004 & $0.117^{* * *}$ & $0.296^{* * *}$ & $0.206^{* * *}$ & $0.034^{* * *}$ & $0.049^{* *}$ & $0.133^{* * *}$ & $0.283^{* * *}$ & $0.128^{* * *}$ & $0.334^{* * *}$ & $0.291^{* * *}$ & $0.157^{* * *}$ & $0.153^{* * *}$ \\
\hline explained & $0.092^{* * *}$ & $0.036^{* * *}$ & $0.087^{* * *}$ & $0.097^{* * *}$ & $0.091^{* * *}$ & $0.087^{* * *}$ & 0.001 & $0.111^{* * *}$ & $0.151^{* * *}$ & $0.115^{* * *}$ & $0.144^{* * *}$ & $0.133^{* * *}$ & $0.061^{* * *}$ & $0.066^{* * *}$ \\
\hline pub. adv. & 0.003 & $-0.028^{* *}$ & 0.027 & $0.176^{* * *}$ & $0.108^{* * *}$ & $-0.045^{* * *}$ & $0.046^{* *}$ & 0.020 & $0.115^{* * *}$ & 0.012 & $0.159^{* * *}$ & $0.143^{* * *}$ & $0.081^{* * *}$ & $0.078^{* *}$ \\
\hline pri. disadv. & 0.000 & $-0.005^{* *}$ & 0.002 & $0.023^{* * *}$ & $0.007^{* * *}$ & $-0.007^{* * *}$ & $0.002^{* *}$ & 0.001 & $0.017^{* * *}$ & 0.001 & $0.031^{* * *}$ & $0.014^{* * *}$ & $0.014^{* * *}$ & $0.008^{* *}$ \\
\hline Obs. & 2,963 & 3,224 & 3,031 & 2,862 & 8,484 & 6,559 & 4,551 & 4,011 & 8,601 & 3,453 & 3,104 & 5,943 & 1,965 & 1,083 \\
\hline \multicolumn{15}{|l|}{ CLERKS } \\
\hline public & $2.813^{* * *}$ & $2.780^{* * *}$ & $0.262^{* * *}$ & $2.233^{* * *}$ & $1.404^{* * *}$ & $2.725^{* * *}$ & $3.026^{* * *}$ & $1.026^{* * *}$ & $2.414^{* * *}$ & $2.635^{* * *}$ & $2.498^{* * *}$ & $1.251^{* * *}$ & $2.977^{* * *}$ & $2.814^{* * *}$ \\
\hline private & $2.789^{* * *}$ & $2.804^{* * *}$ & $0.298^{* * *}$ & $2.131^{* * *}$ & $1.304^{* * *}$ & $2.770^{* * *}$ & $3.042^{* * *}$ & $1.077^{* * *}$ & $2.277^{* * *}$ & $2.635^{* * *}$ & $2.240^{* * *}$ & $1.091^{* * *}$ & $2.863^{* * *}$ & $2.946^{* * *}$ \\
\hline difference & 0.025 & -0.023 & -0.036 & $0.103^{* *}$ & $0.100^{* * *}$ & -0.045 & -0.016 & -0.051 & $0.136^{* * *}$ & 0.000 & $0.259 * * *$ & $0.160^{* * *}$ & $0.114^{* * *}$ & -0.132 \\
\hline explained & 0.028 & $0.028^{* *}$ & -0.009 & -0.004 & 0.018 & 0.015 & $-0.055^{* * *}$ & -0.054 & $0.059^{* * *}$ & -0.001 & $0.095^{* * *}$ & -0.013 & $0.043^{* *}$ & -0.046 \\
\hline pub. adv. & -0.003 & $-0.042^{*}$ & -0.023 & $0.091^{* * *}$ & $0.071^{* *}$ & -0.056 & 0.037 & 0.002 & $0.062^{* * *}$ & 0.001 & $0.123^{* * *}$ & $0.153^{* * *}$ & $0.054^{*}$ & -0.077 \\
\hline pri. disadv. & -0.001 & $-0.010^{*}$ & -0.003 & $0.016^{* * *}$ & $0.011^{* *}$ & -0.005 & 0.003 & 0.000 & $0.016^{* * *}$ & 0.000 & $0.040^{* * *}$ & $0.019^{* * *}$ & $0.016^{*}$ & $-0.009^{*}$ \\
\hline Obs. & 432 & 662 & 208 & 405 & 769 & 749 & 455 & 210 & 1,314 & 235 & 538 & 542 & 288 & 78 \\
\hline
\end{tabular}


Table 10 Decompositions for clerks only with pay gap rows bolded (Continued)

\begin{tabular}{|c|c|c|c|c|c|c|c|c|c|c|c|c|c|}
\hline & IT & LT & LU & LV & NL & NO & $\mathrm{PL}$ & PT & RO & SE & $\mathrm{SI}$ & SK & UK \\
\hline \multicolumn{14}{|c|}{ FULL SAMPLE } \\
\hline public & $2.719^{* * *}$ & $1.221^{* * *}$ & $3.297^{* * *}$ & $1.486^{* * *}$ & $3.227^{* * *}$ & $3.171^{* * *}$ & $1.451^{* * *}$ & $2.047^{* * *}$ & $0.814^{* * *}$ & $2.928^{* * *}$ & $2.235^{* * *}$ & $1.185^{* * *}$ & $3.007^{* * *}$ \\
\hline private & $2.489^{* * *}$ & $1.062^{* * *}$ & $2.962^{* * *}$ & $1.106^{* * *}$ & $3.092^{* * *}$ & $3.200^{* * *}$ & $1.178^{* * *}$ & $1.770^{* * *}$ & $0.520^{* * *}$ & $2.858^{* * *}$ & $2.009^{* * *}$ & $1.043^{* * *}$ & $2.909^{* * *}$ \\
\hline difference & $0.230^{* * *}$ & $0.159 * * *$ & $0.335^{* * *}$ & $0.380^{* * *}$ & $0.134^{* * *}$ & -0.029 & $0.273^{* * *}$ & $0.277^{* * *}$ & $0.294^{* * *}$ & $0.070^{*}$ & $0.226^{* * *}$ & $0.142^{* * *}$ & $0.098^{* * *}$ \\
\hline explained & $0.143^{* * *}$ & $0.142^{* * *}$ & $0.106^{* * *}$ & $0.241^{* * *}$ & $0.070^{* * *}$ & $0.044^{* * *}$ & $0.210^{* * *}$ & $0.124^{* * *}$ & $0.184^{* * *}$ & $0.042^{*}$ & $0.225^{* * *}$ & $0.063^{* * *}$ & 0.001 \\
\hline pub. adv. & $0.077^{* * *}$ & 0.015 & $0.212^{* * *}$ & $0.124^{* * *}$ & $0.056^{* * *}$ & $-0.069^{* * *}$ & $0.058^{* * *}$ & $0.135^{* * *}$ & $0.104^{* * *}$ & 0.027 & 0.001 & $0.068^{* * *}$ & $0.086^{* * *}$ \\
\hline pri. disadv. & $0.010^{* * *}$ & 0.001 & $0.017^{* * *}$ & $0.015^{* * *}$ & $0.008^{* * *}$ & $-0.004^{* * *}$ & $0.005^{* * *}$ & $0.017^{* * *}$ & $0.006^{* * *}$ & 0.001 & 0.000 & $0.011^{* * *}$ & $0.011^{* * *}$ \\
\hline Obs. & 10,219 & 3,575 & 2,912 & 3,726 & 2,485 & 2,128 & 8,586 & 2,777 & 4,588 & 2,493 & 3,365 & 5,521 & 4,439 \\
\hline \multicolumn{14}{|l|}{ CLERKS } \\
\hline public & $2.632^{* * *}$ & $1.050^{* * *}$ & $3.171^{* * *}$ & $1.280^{* * *}$ & $3.061^{* * *}$ & $3.006^{* * *}$ & $1.225^{* * *}$ & $1.982^{* * *}$ & $0.576^{* * *}$ & $2.701^{* * *}$ & $1.984^{* * *}$ & $1.063^{* * *}$ & $2.812^{* * *}$ \\
\hline private & $2.543^{* * *}$ & $1.017^{* * *}$ & $2.970^{* * *}$ & $1.088^{* * *}$ & $2.944^{* * *}$ & $3.094^{* * *}$ & $1.169^{* * *}$ & $1.829 * * *$ & $0.560^{* * *}$ & $2.725^{* * *}$ & $2.005^{* * *}$ & $1.001^{* * *}$ & $2.736^{* * *}$ \\
\hline difference & $0.090^{* * *}$ & 0.033 & $0.201^{*}$ & $0.193^{*}$ & $0.117^{* * *}$ & -0.088 & 0.056 & $0.153^{* *}$ & 0.016 & -0.024 & -0.021 & $0.062^{*}$ & 0.076 \\
\hline explained & $0.087^{* * *}$ & -0.026 & -0.044 & -0.027 & 0.040 & -0.015 & 0.015 & 0.049 & 0.019 & 0.004 & 0.012 & -0.001 & 0.021 \\
\hline pub. adv. & 0.002 & 0.052 & $0.222^{* * *}$ & $0.203^{*}$ & $0.063^{* *}$ & -0.065 & 0.035 & 0.091 & -0.003 & -0.027 & -0.029 & $0.046^{* *}$ & 0.045 \\
\hline pri. disadv. & 0.000 & 0.008 & $0.023^{* *}$ & $0.017^{*}$ & $0.014^{* *}$ & -0.008 & 0.005 & 0.012 & -0.000 & -0.001 & -0.004 & $0.018^{* *}$ & 0.010 \\
\hline Obs. & 1,655 & 163 & 254 & 185 & 256 & 154 & 722 & 327 & 295 & 193 & 382 & 504 & 603 \\
\hline
\end{tabular}




\begin{tabular}{|c|c|c|c|c|c|c|c|c|c|c|c|c|c|c|}
\hline Variables & AT & $\mathrm{BE}$ & BG & $\mathrm{CY}$ & $\mathrm{CZ}$ & $\mathrm{DE}$ & DK & $\mathrm{EE}$ & ES & $\mathrm{FI}$ & GR & $\mathrm{HU}$ & IE & IS \\
\hline public & 0.006 & $-0.034^{* * *}$ & -0.000 & $0.083^{* * *}$ & $0.050^{* * *}$ & $-0.037^{* * *}$ & $0.028^{* * *}$ & 0.011 & $0.036^{* * *}$ & -0.002 & $0.081 * * *$ & $0.077^{* * *}$ & $0.033^{* * *}$ & $0.051^{* *}$ \\
\hline other & -0.006 & $0.034^{* * *}$ & 0.000 & $-0.083^{* * *}$ & $-0.050^{* * *}$ & $0.037^{* * *}$ & $-0.028^{* * *}$ & -0.011 & $-0.036^{* * *}$ & 0.002 & $-0.081^{* * *}$ & $-0.077^{* * *}$ & $-0.033^{* * *}$ & $-0.051^{* *}$ \\
\hline age25_29 & $-0.205^{* * *}$ & $-0.215^{* * *}$ & -0.004 & $-0.276^{* * *}$ & $-0.048^{* * *}$ & $-0.221^{* * *}$ & $-0.197^{* * *}$ & $0.078^{* * *}$ & $-0.181^{* * *}$ & $-0.120^{* * *}$ & $-0.341^{* * *}$ & $-0.125^{* * *}$ & $-0.289^{* * *}$ & $-0.193^{* * *}$ \\
\hline age30_34 & $-0.062^{* * *}$ & $-0.109^{* * *}$ & -0.001 & $-0.108^{* * *}$ & $0.022^{* *}$ & $-0.067^{* * *}$ & $-0.042^{* * *}$ & $0.096^{* * *}$ & $-0.109^{* * *}$ & $-0.058^{* * *}$ & $-0.173^{* * *}$ & -0.011 & $-0.149^{* * *}$ & $-0.097^{* * *}$ \\
\hline age35_39 & -0.016 & -0.012 & 0.031 & $-0.053^{* * *}$ & $0.035^{* * *}$ & $0.023^{* *}$ & $0.026^{* *}$ & $0.049^{* * *}$ & -0.010 & $-0.031^{* *}$ & $-0.043^{* * *}$ & $0.032^{* *}$ & 0.027 & 0.011 \\
\hline age40_44 & -0.010 & $0.051^{* * *}$ & 0.007 & $0.040^{* *}$ & 0.010 & $0.036^{* * *}$ & $0.057^{* * *}$ & $0.038^{* *}$ & $0.025^{* * *}$ & 0.020 & $0.059^{* * *}$ & $0.023^{*}$ & $0.074^{* * *}$ & $0.052^{*}$ \\
\hline age45_49 & $0.063^{* * *}$ & $0.082^{* * *}$ & 0.024 & $0.072^{* * *}$ & $0.024^{* *}$ & $0.079 * * *$ & $0.077^{* * *}$ & -0.015 & $0.064^{* * *}$ & $0.043^{* * *}$ & $0.150^{* * *}$ & -0.000 & $0.142^{* * *}$ & $0.085^{* * *}$ \\
\hline age50_54 & $0.072^{* * *}$ & $0.092^{* * *}$ & -0.019 & $0.157^{* * *}$ & -0.005 & $0.098^{* * *}$ & $0.044^{* * *}$ & $-0.055^{* * *}$ & $0.099^{* * *}$ & $0.064^{* * *}$ & $0.184^{* * *}$ & $0.057^{* * *}$ & $0.084^{* * *}$ & $0.074^{* * *}$ \\
\hline age55_60 & $0.156^{* * *}$ & $0.112^{* * *}$ & $-0.039^{*}$ & $0.168^{* * *}$ & $-0.038^{* * *}$ & $0.051^{* * *}$ & $0.035^{* * *}$ & $-0.192^{* * *}$ & $0.111^{* * *}$ & $0.083^{* * *}$ & $0.163^{* * *}$ & 0.025 & $0.112^{* * *}$ & $0.068^{* *}$ \\
\hline edL & $-0.211^{* * *}$ & $-0.119^{* * *}$ & $-0.152^{* * *}$ & $-0.101 * * *$ & $-0.220^{* * *}$ & $-0.097^{* * *}$ & $-0.072^{* * *}$ & $-0.150^{* * *}$ & $-0.133^{* * *}$ & $-0.112^{* * *}$ & $-0.144^{* * *}$ & $-0.234^{* * *}$ & $-0.160^{* * *}$ & $-0.117^{* * *}$ \\
\hline eds & 0.003 & $-0.017^{* *}$ & $-0.042^{* * *}$ & $-0.051^{* * *}$ & $-0.027^{* * *}$ & $-0.041^{* * *}$ & -0.006 & -0.013 & -0.006 & $-0.032^{* * *}$ & $-0.017^{*}$ & $-0.063^{* * *}$ & -0.023 & -0.015 \\
\hline $\mathrm{edH}$ & $0.208^{* * *}$ & $0.135^{* * *}$ & $0.195^{* * *}$ & $0.152^{* * *}$ & $0.247^{* * *}$ & $0.139^{* * *}$ & $0.078^{* * *}$ & $0.163^{* * *}$ & $0.139^{* * *}$ & $0.144^{* * *}$ & $0.162^{* * *}$ & $0.297^{* * *}$ & $0.183^{* * *}$ & $0.132^{* * *}$ \\
\hline female & $-0.126^{* * *}$ & $-0.068^{* * *}$ & $-0.152^{* * *}$ & $-0.188^{* * *}$ & $-0.164^{* * *}$ & $-0.127^{* * *}$ & $-0.125^{* * *}$ & $-0.220^{* * *}$ & $-0.103^{* * *}$ & $-0.127^{* * *}$ & $-0.134^{* * *}$ & $-0.100^{* * *}$ & $-0.107^{* * *}$ & $-0.154^{* * *}$ \\
\hline male & $0.126^{* * *}$ & $0.068^{* * *}$ & $0.152^{* * *}$ & $0.188^{* * *}$ & $0.164^{* * *}$ & $0.127^{* * *}$ & $0.125^{* * *}$ & $0.220^{* * *}$ & $0.103^{* * *}$ & $0.127^{* * *}$ & $0.134^{* * *}$ & $0.100^{* * *}$ & $0.107^{* * *}$ & $0.154^{* * *}$ \\
\hline temporary & $-0.070^{* * *}$ & $-0.057^{* * *}$ & $-0.064^{* * *}$ & $-0.274^{* * *}$ & $-0.028^{* * *}$ & $-0.107^{* * *}$ & na & -0.022 & $-0.083^{* * *}$ & $-0.084^{* * *}$ & $-0.074^{* * *}$ & $-0.078^{* * *}$ & -0.024 & $-0.091^{* *}$ \\
\hline permanent & $0.070^{* * *}$ & $0.057^{* * *}$ & $0.064^{* * *}$ & $0.274^{* * *}$ & $0.028^{* * *}$ & $0.107^{* * *}$ & na & 0.022 & $0.083^{* * *}$ & $0.084^{* * *}$ & $0.074^{* * *}$ & $0.078^{* * *}$ & 0.024 & $0.091^{* *}$ \\
\hline occup_d & $-0.223^{* * *}$ & $-0.175^{* * *}$ & $-0.103^{* * *}$ & $-0.370^{* * *}$ & $-0.189^{* * *}$ & $-0.257^{* * *}$ & $-0.161^{* * *}$ & $-0.142^{* * *}$ & $-0.198^{* * *}$ & $-0.186^{* * *}$ & $-0.217^{* * *}$ & $-0.205^{* * *}$ & $-0.188^{* * *}$ & $-0.117^{* * *}$ \\
\hline occup_c & $-0.081^{* * *}$ & $-0.101^{* * *}$ & $-0.149 * * *$ & $-0.190^{* * *}$ & $-0.136^{* * *}$ & $-0.100^{* * *}$ & $-0.146^{* * *}$ & $-0.230^{* * *}$ & $-0.154^{* * *}$ & $-0.188^{* * *}$ & $-0.131^{* * *}$ & $-0.172^{* * *}$ & $-0.174^{* * *}$ & $-0.145^{* * *}$ \\
\hline occup_b & $0.085^{* * *}$ & 0.009 & 0.022 & $0.113^{* * *}$ & $0.041^{* * *}$ & $0.090^{* * *}$ & $0.047^{* * *}$ & $0.125^{* * *}$ & $0.083^{* * *}$ & 0.011 & 0.020 & $0.074^{* * *}$ & $0.143^{* * *}$ & $0.075^{* * *}$ \\
\hline occup_a & $0.219^{* * *}$ & $0.268^{* * *}$ & $0.230^{* * *}$ & $0.447^{* * *}$ & $0.284^{* * *}$ & $0.267^{* * *}$ & $0.259^{* * *}$ & $0.247^{* * *}$ & $0.269^{* * *}$ & $0.363^{* * *}$ & $0.327^{* * *}$ & $0.303^{* * *}$ & $0.219^{* * *}$ & $0.186^{* * *}$ \\
\hline Constant & $7.827^{* * *}$ & $7.893^{* * *}$ & $5.495^{* * *}$ & $7.353^{* * *}$ & $6.593^{* * *}$ & $7.769^{* * *}$ & $8.249^{* * *}$ & $6.411^{* * *}$ & $7.480^{* * *}$ & $7.838^{* * *}$ & $7.481^{* * *}$ & $6.320^{* * *}$ & $8.083^{* * *}$ & $8.257^{* * *}$ \\
\hline Observations & 2,963 & 3,224 & 3,031 & 2,862 & 8,484 & 6,559 & 4,551 & 4,011 & 8,601 & 3,453 & 3,104 & 5,943 & 1,965 & 1,083 \\
\hline R-squared & 0.360 & 0.322 & 0.189 & 0.535 & 0.383 & 0.305 & 0.306 & 0.335 & 0.351 & 0.432 & 0.384 & 0.382 & 0.364 & 0.298 \\
\hline
\end{tabular}


Table 11 OLS regressions for monthly wage equations with the row for Public bolded (Continued)

\begin{tabular}{|c|c|c|c|c|c|c|c|c|c|c|c|c|c|}
\hline & IT & LT & LU & LV & NL & NO & PL & PT & RO & SE & SI & SK & UK \\
\hline public & $0.016^{* * *}$ & 0.013 & $0.102^{* * *}$ & $0.065^{* * *}$ & $0.015^{* *}$ & $-0.052^{* * *}$ & $0.029 * * *$ & $0.034^{* * *}$ & $0.046^{* * *}$ & 0.015 & -0.005 & $0.029 * * *$ & $0.039 * * *$ \\
\hline other & $-0.016^{* * *}$ & -0.013 & $-0.102^{* * *}$ & $-0.065^{* * *}$ & $-0.015^{* *}$ & $0.052^{* * *}$ & $-0.029 * * *$ & $-0.034^{* * *}$ & $-0.046^{* * *}$ & -0.015 & 0.005 & $-0.029 * * *$ & $-0.039 * * *$ \\
\hline age25_29 & $-0.192^{* * *}$ & 0.013 & $-0.247^{* * *}$ & 0.022 & $-0.255^{* * *}$ & $-0.131^{* * *}$ & $-0.156^{* * *}$ & $-0.230^{* * *}$ & $-0.121^{* * *}$ & $-0.173^{* * *}$ & $-0.155^{* * *}$ & $-0.041^{* * *}$ & $-0.171^{* * *}$ \\
\hline age30_34 & $-0.099^{* * *}$ & $0.077^{* * *}$ & $-0.169 * * *$ & $0.065^{* * *}$ & $-0.099^{* * *}$ & $-0.069 * * *$ & $-0.081^{* * *}$ & $-0.108^{* * *}$ & -0.015 & $-0.107^{* * *}$ & $-0.105^{* * *}$ & $-0.025^{*}$ & 0.001 \\
\hline age35_39 & $-0.033^{* * *}$ & $-0.045^{* *}$ & $-0.088^{* * *}$ & 0.023 & 0.015 & 0.031 & $0.035^{* * *}$ & -0.004 & 0.005 & -0.004 & -0.009 & $0.035^{* * *}$ & $0.052^{* * *}$ \\
\hline age40_44 & $0.022^{* * *}$ & 0.016 & -0.008 & -0.006 & $0.064^{* * *}$ & $0.051^{* *}$ & $0.065^{* * *}$ & $0.036^{*}$ & $0.061^{* * *}$ & $0.038^{*}$ & $0.032^{* *}$ & $0.025^{* *}$ & $0.047^{* * *}$ \\
\hline age45_49 & $0.076^{* * *}$ & 0.013 & $0.079^{* * *}$ & -0.009 & $0.079^{* * *}$ & $0.073^{* * *}$ & $0.051^{* * *}$ & $0.084^{* * *}$ & $0.033^{* *}$ & $0.068^{* * *}$ & $0.094^{* * *}$ & $0.018^{*}$ & $0.037^{* *}$ \\
\hline age50_54 & $0.101^{* * *}$ & -0.028 & $0.170^{* * *}$ & $-0.047^{* *}$ & $0.091^{* * *}$ & $0.047^{* *}$ & $0.034^{* * *}$ & $0.098^{* * *}$ & $0.033^{* *}$ & $0.083^{* * *}$ & $0.079^{* * *}$ & $0.021^{*}$ & 0.007 \\
\hline age55_60 & $0.124^{* * *}$ & $-0.044^{* *}$ & $0.262^{* * *}$ & $-0.049^{* *}$ & $0.105^{* * *}$ & -0.002 & $0.052^{* * *}$ & $0.123^{* * *}$ & 0.005 & $0.095^{* * *}$ & $0.065^{* * *}$ & $-0.033^{* *}$ & 0.027 \\
\hline edL & $-0.137^{* * *}$ & $-0.121^{* * *}$ & $-0.212^{* * *}$ & $-0.206^{* * *}$ & $-0.135^{* * *}$ & $-0.105^{* * *}$ & $-0.171^{* * *}$ & $-0.350^{* * *}$ & $-0.231^{* * *}$ & -0.023 & $-0.242^{* * *}$ & $-0.206^{* * *}$ & $-0.210^{* * *}$ \\
\hline eds & -0.008 & $-0.030^{*}$ & $-0.022^{* *}$ & $-0.069 * * *$ & $-0.055^{* * *}$ & 0.001 & $-0.032^{* * *}$ & $-0.056^{* * *}$ & $-0.045^{* * *}$ & -0.017 & $-0.061^{* * *}$ & 0.004 & -0.016 \\
\hline $\mathrm{edH}$ & $0.144^{* * *}$ & $0.151^{* * *}$ & $0.234^{* * *}$ & $0.276^{* * *}$ & $0.190^{* * *}$ & $0.104^{* * *}$ & $0.203^{* * *}$ & $0.407^{* * *}$ & $0.277^{* * *}$ & $0.039^{* *}$ & $0.303^{* * *}$ & $0.202^{* * *}$ & $0.226^{* * *}$ \\
\hline female & $-0.105^{* * *}$ & $-0.196^{* * *}$ & $-0.096^{* * *}$ & $-0.186^{* * *}$ & $-0.081^{* * *}$ & $-0.131^{* * *}$ & $-0.140^{* * *}$ & $-0.144^{* * *}$ & $-0.104^{* * *}$ & $-0.107^{* * *}$ & $-0.086^{* * *}$ & $-0.144^{* * *}$ & $-0.122^{* * *}$ \\
\hline male & $0.105^{* * *}$ & $0.196^{* * *}$ & $0.096^{* * *}$ & $0.186^{* * *}$ & $0.081^{* * *}$ & $0.131^{* * *}$ & $0.140^{* * *}$ & $0.144^{* * *}$ & $0.104^{* * *}$ & $0.107^{* * *}$ & $0.086^{* * *}$ & $0.144^{* * *}$ & $0.122^{* * *}$ \\
\hline temporary & $-0.121^{* * *}$ & -0.024 & $-0.109 * * *$ & -0.043 & $-0.058^{* * *}$ & $-0.075^{* * *}$ & $-0.085^{* * *}$ & $-0.072^{* * *}$ & $-0.063^{* * *}$ & $-0.134^{* * *}$ & $-0.100^{* * *}$ & $-0.044^{* * *}$ & na \\
\hline permanent & $0.121^{* * *}$ & 0.024 & $0.109^{* * *}$ & 0.043 & $0.058^{* * *}$ & $0.075^{* * *}$ & $0.085^{* * *}$ & $0.072^{* * *}$ & $0.063^{* * *}$ & $0.134^{* * *}$ & $0.100^{* * *}$ & $0.044^{* * *}$ & na \\
\hline occup_d & $-0.211^{* * *}$ & $-0.235^{* * *}$ & $-0.322^{* * *}$ & $-0.228^{* * *}$ & $-0.146^{* * *}$ & $-0.111^{* * *}$ & $-0.194^{* * *}$ & $-0.228^{* * *}$ & $-0.215^{* * *}$ & $-0.194^{* * *}$ & $-0.238^{* * *}$ & $-0.136^{* * *}$ & $-0.209^{* * *}$ \\
\hline occup_c & $-0.114^{* * *}$ & $-0.245^{* * *}$ & $-0.181^{* * *}$ & $-0.201^{* * *}$ & $-0.085^{* * *}$ & $-0.124^{* * *}$ & $-0.212^{* * *}$ & $-0.117^{* * *}$ & $-0.212^{* * *}$ & $-0.155^{* * *}$ & $-0.129^{* * *}$ & $-0.138^{* * *}$ & $-0.177^{* * *}$ \\
\hline occup_b & 0.005 & $0.145^{* * *}$ & $0.138^{* * *}$ & $0.134^{* * *}$ & $0.047^{* * *}$ & $0.052^{* * *}$ & $0.097^{* * *}$ & $0.151^{* * *}$ & $0.074^{* * *}$ & 0.023 & $0.084^{* * *}$ & $0.035^{* * *}$ & $0.104^{* * *}$ \\
\hline occup_a & $0.319^{* * *}$ & $0.335^{* * *}$ & $0.365^{* * *}$ & $0.295^{* * *}$ & $0.183^{* * *}$ & $0.183^{* * *}$ & $0.309^{* * *}$ & $0.194^{* * *}$ & $0.353^{* * *}$ & $0.326^{* * *}$ & $0.283^{* * *}$ & $0.240^{* * *}$ & $0.283^{* * *}$ \\
\hline Constant & $7.648^{* * *}$ & $6.176^{* * *}$ & $8.237^{* * *}$ & $6.377^{* * *}$ & $8.056^{* * *}$ & $8.140^{* * *}$ & $6.391^{* * *}$ & $7.168^{* * *}$ & $5.752^{* * *}$ & $7.800^{* * *}$ & $7.148^{* * *}$ & $6.205^{* * *}$ & $8.035^{* * *}$ \\
\hline Observations & 10,219 & 3,575 & 2,912 & 3,726 & 2,485 & 2,128 & 8,586 & 2,777 & 4,588 & 2,493 & 3,365 & 5,521 & 4,439 \\
\hline R-squared & 0.303 & 0.276 & 0.574 & 0.291 & 0.396 & 0.219 & 0.289 & 0.498 & 0.382 & 0.206 & 0.450 & 0.293 & 0.327 \\
\hline
\end{tabular}


Table 12 Decomposition using monthly wage with pay gap rows bolded

\begin{tabular}{|c|c|c|c|c|c|c|c|c|c|c|c|c|c|}
\hline & AT & $\mathrm{BE}$ & BG & $\mathrm{CY}$ & $\mathrm{CZ}$ & $\mathrm{DE}$ & $\mathrm{EE}$ & ES & $\mathrm{FI}$ & GR & $\mathrm{HU}$ & IE & IS \\
\hline \multicolumn{14}{|c|}{ MONTHLY WAGE } \\
\hline public & $8.035^{* * *}$ & $7.948^{* * *}$ & $5.563^{* * *}$ & $7.650^{* * *}$ & $6.698^{* * *}$ & $8.009^{* * *}$ & $6.535^{* * *}$ & $7.608^{* * *}$ & $8.025^{* * *}$ & $7.625^{* * *}$ & $6.528^{* * *}$ & $8.256^{* * *}$ & $8.515^{* * *}$ \\
\hline private & $7.920^{* * *}$ & $7.978^{* * *}$ & $5.479^{* * *}$ & $7.387^{* * *}$ & $6.508^{* * *}$ & $7.994^{* * *}$ & $6.407^{* * *}$ & $7.405^{* * *}$ & $7.919^{* * *}$ & $7.335^{* * *}$ & $6.247^{* * *}$ & $8.149^{* * *}$ & $8.356^{* * *}$ \\
\hline difference & $0.115^{* * *}$ & $-0.030^{*}$ & $0.084^{* *}$ & $0.264^{* * *}$ & $0.191^{* * *}$ & 0.016 & $0.128^{* * *}$ & $0.203^{* * *}$ & $0.106^{* * *}$ & $0.290 * * *$ & $0.281^{* * *}$ & $0.107^{* * *}$ & $0.158^{* * *}$ \\
\hline explained & $0.104^{* * *}$ & $0.034^{* * *}$ & $0.085^{* * *}$ & $0.106^{* * *}$ & $0.095^{* * *}$ & $0.087^{* * *}$ & $0.107^{* * *}$ & $0.135^{* * *}$ & $0.111^{* * *}$ & $0.140^{* * *}$ & $0.134^{* * *}$ & $0.044^{* *}$ & $0.062^{* *}$ \\
\hline pub. adv. & 0.010 & $-0.055^{* * *}$ & -0.000 & $0.139^{* * *}$ & $0.090^{* * *}$ & $-0.061^{* * *}$ & 0.020 & $0.059^{* * *}$ & -0.004 & $0.126^{* * *}$ & $0.134^{* * *}$ & $0.053^{* * *}$ & $0.087^{* *}$ \\
\hline pri. disadv. & 0.001 & $-0.009^{* * *}$ & -0.000 & $0.018^{* * *}$ & $0.006^{* * *}$ & $-0.010^{* * *}$ & 0.001 & $0.009^{* * *}$ & -0.000 & $0.025^{* * *}$ & $0.013^{* * *}$ & $0.009^{* * *}$ & $0.009^{* *}$ \\
\hline Obs. & 2,963 & 3,224 & 3,031 & 2,862 & 8,484 & 6,559 & 4,011 & 8,601 & 3,453 & 3,104 & 5,943 & 1,965 & 1,083 \\
\hline \multicolumn{14}{|c|}{ HOURLY WAGE } \\
\hline public & $2.847^{* * *}$ & $2.842^{* * *}$ & $0.428^{* * *}$ & $2.538^{* * *}$ & $1.539^{* * *}$ & $2.829^{* * *}$ & $1.399^{* * *}$ & $2.536^{* * *}$ & $2.933^{* * *}$ & $2.507^{* * *}$ & $1.389^{* * *}$ & $3.180^{* * *}$ & $3.235^{* * *}$ \\
\hline private & $2.753^{* * *}$ & $2.839^{* * *}$ & $0.311^{* * *}$ & $2.242^{* * *}$ & $1.333^{* * *}$ & $2.794^{* * *}$ & $1.266^{* * *}$ & $2.253^{* * *}$ & $2.805^{* * *}$ & $2.173^{* * *}$ & $1.098^{* * *}$ & $3.023^{* * *}$ & $3.082^{* * *}$ \\
\hline difference & $0.095^{* * *}$ & 0.004 & $0.117^{* * *}$ & $0.296^{* * *}$ & $0.206^{* * *}$ & $0.034 * * *$ & $0.133^{* * *}$ & $0.283^{* * *}$ & $0.128 * * *$ & $0.334^{* * *}$ & $0.291^{* * *}$ & $0.157^{* * *}$ & $0.153^{* * *}$ \\
\hline explained & $0.092^{* * *}$ & $0.036^{* * *}$ & $0.087^{* * *}$ & $0.097^{* * *}$ & $0.091^{* * *}$ & $0.087^{* * *}$ & $0.111^{* * *}$ & $0.151^{* * *}$ & $0.115^{* * *}$ & $0.144^{* * *}$ & $0.133^{* * *}$ & $0.061^{* * *}$ & $0.066^{* * *}$ \\
\hline pub. adv. & 0.003 & $-0.028^{* *}$ & 0.027 & $0.176^{* * *}$ & $0.108^{* * *}$ & $-0.045^{* * *}$ & 0.020 & $0.115^{* * *}$ & 0.012 & $0.159^{* * *}$ & $0.143^{* * *}$ & $0.081^{* * *}$ & $0.078^{* *}$ \\
\hline pri. disadv. & 0.000 & $-0.005^{* *}$ & 0.002 & $0.023^{* * *}$ & $0.007^{* * *}$ & $-0.007^{* * *}$ & 0.001 & $0.017^{* * *}$ & 0.001 & $0.031^{* * *}$ & $0.014^{* * *}$ & $0.014^{* * *}$ & $0.008^{* *}$ \\
\hline Obs. & 2,963 & 3,224 & 3,031 & 2,862 & 8,484 & 6,559 & 4,011 & 8,601 & 3,453 & 3,104 & 5,943 & 1,965 & 1,083 \\
\hline
\end{tabular}


Table 12 Decomposition using monthly wage with pay gap rows bolded (Continued)

\begin{tabular}{|c|c|c|c|c|c|c|c|c|c|c|c|c|c|c|}
\hline & IT & LT & LU & LV & NL & NO & PL & PT & RO & SE & SI & SK & DK & UK \\
\hline \multicolumn{15}{|c|}{ MONTHLY WAGE } \\
\hline public & $7.791^{* * *}$ & $6.357^{* * *}$ & $8.450^{* * *}$ & $6.636^{* * *}$ & $8.278^{* * *}$ & $8.274^{* * *}$ & $6.593^{* * *}$ & $7.093^{* * *}$ & $5.954^{* * *}$ & $7.947^{* * *}$ & $7.380^{* * *}$ & $6.307^{* * *}$ & $8.294^{* * *}$ & $8.151^{* * *}$ \\
\hline private & $7.626^{* * *}$ & $6.193^{* * *}$ & $8.154^{* * *}$ & $6.279^{* * *}$ & $8.187^{* * *}$ & $8.329^{* * *}$ & $6.350^{* * *}$ & $6.907^{* * *}$ & $5.681^{* * *}$ & $7.877^{* * *}$ & $7.167^{* * *}$ & $6.200^{* * *}$ & $8.239^{* * *}$ & $8.099^{* * *}$ \\
\hline difference & $0.164^{* * *}$ & $0.165^{* * *}$ & $0.296^{* * *}$ & $0.356^{* * *}$ & $0.091^{* * *}$ & $-0.056^{*}$ & $0.242^{* * *}$ & $0.186^{* * *}$ & $0.274^{* * *}$ & $0.071^{*}$ & $0.213^{* * *}$ & $0.108^{* * *}$ & $0.054^{* *}$ & $0.051 * *$ \\
\hline explained & $0.134^{* * *}$ & $0.140^{* * *}$ & $0.103^{* * *}$ & $0.234^{* * *}$ & $0.063^{* * *}$ & $0.045^{* *}$ & $0.189^{* * *}$ & $0.120^{* * *}$ & $0.184^{* * *}$ & $0.042^{*}$ & $0.222^{* * *}$ & $0.053^{* * *}$ & -0.002 & -0.024 \\
\hline pub. adv. & $0.027^{* * *}$ & 0.022 & $0.179^{* * *}$ & $0.110^{* * *}$ & $0.025^{* *}$ & $-0.095^{* * *}$ & $0.049^{* * *}$ & $0.059^{* * *}$ & $0.085^{* * *}$ & 0.027 & -0.008 & $0.047^{* * *}$ & $0.054^{* * *}$ & $0.067^{* * *}$ \\
\hline pri. disadv. & $0.004^{* * *}$ & 0.002 & $0.014^{* * *}$ & $0.013^{* * *}$ & $0.003^{* *}$ & $-0.006^{* * *}$ & $0.005^{* * *}$ & $0.007^{* * *}$ & $0.005^{* * *}$ & 0.001 & -0.001 & $0.007^{* * *}$ & $0.002^{* * *}$ & $0.009^{* * *}$ \\
\hline Obs. & 10,219 & 3,575 & 2,912 & 3,726 & 2,485 & 2,128 & 8,586 & 2,777 & 4,588 & 2,493 & 3,365 & 5,521 & 4,551 & 4,439 \\
\hline \multicolumn{15}{|c|}{ HOURLY WAGE } \\
\hline public & $2.719^{* * *}$ & $1.221^{* * *}$ & $3.297^{* * *}$ & $1.486^{* * *}$ & $3.227^{* * *}$ & $3.171^{* * *}$ & $1.451^{* * *}$ & $2.047^{* * *}$ & $0.814^{* * *}$ & $2.928^{* * *}$ & $2.235^{* * *}$ & $1.185^{* * *}$ & $3.211^{* * *}$ & $3.007^{* * *}$ \\
\hline private & $2.489^{* * *}$ & $1.062^{* * *}$ & $2.962^{* * *}$ & $1.106^{* * *}$ & $3.092^{* * *}$ & $3.200^{* * *}$ & $1.178^{* * *}$ & $1.770^{* * *}$ & $0.520^{* * *}$ & $2.858^{* * *}$ & $2.009^{* * *}$ & $1.043^{* * *}$ & $3.162^{* * *}$ & $2.909^{* * *}$ \\
\hline difference & $0.230^{* * *}$ & $0.159 * * *$ & $0.335^{* * *}$ & $0.380 * * *$ & $0.134^{* * *}$ & -0.029 & $0.273^{* * *}$ & $0.277^{* * *}$ & $0.294^{* * *}$ & $0.070^{*}$ & $0.226^{* * *}$ & $0.142^{* * *}$ & $0.049^{* *}$ & $0.098^{* * *}$ \\
\hline explained & $0.143^{* * *}$ & $0.142^{* * *}$ & $0.106^{* * *}$ & $0.241^{* * *}$ & $0.070^{* * *}$ & $0.044^{* * *}$ & $0.210^{* * *}$ & $0.124^{* * *}$ & $0.184^{* * *}$ & $0.042^{*}$ & $0.225^{* * *}$ & $0.063^{* * *}$ & 0.001 & 0.001 \\
\hline pub. adv. & $0.077^{* * *}$ & 0.015 & $0.212^{* * *}$ & $0.124^{* * *}$ & $0.056^{* * *}$ & $-0.069 * * *$ & $0.058^{* * *}$ & $0.135^{* * *}$ & $0.104^{* * *}$ & 0.027 & 0.001 & $0.068^{* * *}$ & $0.046^{* *}$ & $0.086^{* * *}$ \\
\hline pri. disadv. & $0.010^{* * *}$ & 0.001 & $0.017^{* * *}$ & $0.015^{* * *}$ & $0.008^{* * *}$ & $-0.004^{* * *}$ & $0.005^{* * *}$ & $0.017^{* * *}$ & $0.006^{* * *}$ & 0.001 & 0.000 & $0.011^{* * *}$ & $0.002^{* *}$ & $0.011^{* * *}$ \\
\hline Obs. & 10,219 & 3,575 & 2,912 & 3,726 & 2,485 & 2,128 & 8,586 & 2,777 & 4,588 & 2,493 & 3,365 & 5,521 & 4,551 & 4,439 \\
\hline
\end{tabular}


Table 13 Selection-corrected hourly wage equation with a dummy for Public (ML) and its row bolded

\begin{tabular}{|c|c|c|c|c|c|c|c|c|c|c|c|c|c|c|}
\hline & AT & BE & BG & $\mathrm{CY}$ & $\mathrm{CZ}$ & $\mathrm{DE}$ & DK & EE & ES & $\mathrm{FI}$ & GR & $\mathrm{HU}$ & IE & IS \\
\hline public & 0.002 & $-0.017^{* *}$ & 0.016 & $0.101 * * *$ & $0.060^{* * *}$ & $-0.027^{* * *}$ & $0.024^{* *}$ & 0.016 & $0.069 * * *$ & 0.009 & $0.102^{* * *}$ & $0.079 * * *$ & $0.059 * * *$ & $0.044^{* *}$ \\
\hline other & -0.002 & $0.017^{* *}$ & -0.016 & $-0.101^{* * *}$ & $-0.060^{* * *}$ & $0.027^{* * *}$ & $-0.024^{* *}$ & -0.016 & $-0.069^{* * *}$ & -0.009 & $-0.102^{* * *}$ & $-0.079^{* * *}$ & $-0.059^{* * *}$ & $-0.044^{* *}$ \\
\hline age25_29 & $-0.194^{* * *}$ & $-0.202^{* * *}$ & -0.003 & $-0.274^{* * *}$ & $-0.044^{* * *}$ & $-0.210^{* * *}$ & $-0.199^{* * *}$ & $0.054^{* * *}$ & $-0.202^{* * *}$ & $-0.123^{* * *}$ & $-0.345^{* * *}$ & $-0.172^{* * *}$ & $-0.269 * * *$ & $-0.187^{* * *}$ \\
\hline age30_34 & $-0.064^{* * *}$ & $-0.096^{* * *}$ & -0.014 & $-0.128^{* * *}$ & $0.025^{* *}$ & $-0.079^{* * *}$ & $-0.033^{* *}$ & $0.077^{* * *}$ & $-0.135^{* * *}$ & $-0.071^{* * *}$ & $-0.177^{* * *}$ & $-0.061^{* * *}$ & $-0.147^{* * *}$ & $-0.101^{* * *}$ \\
\hline age35_39 & -0.013 & 0.000 & 0.021 & $-0.089^{* * *}$ & $0.033^{* * *}$ & 0.018 & $0.023^{*}$ & $0.046^{* *}$ & $-0.020^{*}$ & $-0.039^{* *}$ & $-0.063^{* * *}$ & 0.014 & 0.020 & 0.023 \\
\hline age40_44 & -0.004 & $0.060^{* * *}$ & 0.008 & 0.020 & 0.000 & $0.038^{* * *}$ & $0.054^{* * *}$ & $0.041^{* *}$ & $0.021^{* *}$ & $0.030^{* *}$ & $0.056^{* * *}$ & $0.044^{* * *}$ & $0.068^{* * *}$ & $0.064^{* *}$ \\
\hline age45_49 & $0.058^{* * *}$ & $0.089^{* * *}$ & 0.025 & $0.078^{* * *}$ & $0.020^{* *}$ & $0.084^{* * *}$ & $0.065^{* * *}$ & -0.010 & $0.066^{* * *}$ & $0.070^{* * *}$ & $0.135^{* * *}$ & $0.029^{* *}$ & $0.151^{* * *}$ & $0.085^{* * *}$ \\
\hline age50_54 & $0.078^{* * *}$ & $0.083^{* * *}$ & -0.010 & $0.172^{* * *}$ & -0.002 & $0.099^{* * *}$ & $0.039^{* * *}$ & $-0.043^{* *}$ & $0.112^{* * *}$ & $0.078^{* * *}$ & $0.198^{* * *}$ & $0.099^{* * *}$ & $0.091^{* * *}$ & 0.043 \\
\hline age55_60 & $0.139 * * *$ & $0.065^{* *}$ & -0.026 & $0.220^{* * *}$ & $-0.032^{* * *}$ & $0.049^{* * *}$ & $0.051^{* * *}$ & $-0.165^{* * *}$ & $0.158^{* * *}$ & $0.055^{* * *}$ & $0.198^{* * *}$ & $0.046^{* * *}$ & $0.086^{* * *}$ & $0.072^{* *}$ \\
\hline edL & $-0.209^{* * *}$ & $-0.131^{* * *}$ & $-0.145^{* * *}$ & $-0.056^{* * *}$ & $-0.206^{* * *}$ & $-0.112^{* * *}$ & $-0.068^{* * *}$ & $-0.204^{* * *}$ & $-0.109^{* * *}$ & $-0.150^{* * *}$ & $-0.134^{* * *}$ & $-0.369^{* * *}$ & $-0.248^{* * *}$ & $-0.140^{* * *}$ \\
\hline edS & 0.007 & -0.007 & $-0.051^{* * *}$ & $-0.070^{* * *}$ & $-0.029^{* * *}$ & $-0.032^{* * *}$ & -0.004 & -0.008 & -0.009 & $-0.030^{* * *}$ & -0.016 & $-0.029^{* * *}$ & -0.001 & -0.007 \\
\hline edH & $0.202^{* * *}$ & $0.139^{* * *}$ & $0.197^{* * *}$ & $0.126^{* * *}$ & $0.235^{* * *}$ & $0.144^{* * *}$ & $0.071^{* * *}$ & $0.212^{* * *}$ & $0.118^{* * *}$ & $0.180^{* * *}$ & $0.150^{* * *}$ & $0.398^{* * *}$ & $0.249 * * *$ & $0.147^{* * *}$ \\
\hline female & $-0.109^{* * *}$ & $-0.064^{* * *}$ & $-0.138^{* * *}$ & $-0.093^{* * *}$ & $-0.131^{* * *}$ & $-0.122^{* * *}$ & $-0.091^{* * *}$ & $-0.222^{* * *}$ & $-0.034^{* * *}$ & $-0.126^{* * *}$ & $-0.076^{* * *}$ & $-0.128^{* * *}$ & $-0.139^{* * *}$ & $-0.079^{* * *}$ \\
\hline male & $0.109^{* * *}$ & $0.064^{* * *}$ & $0.138^{* * *}$ & $0.093^{* * *}$ & $0.131^{* * *}$ & $0.122^{* * *}$ & $0.091^{* * *}$ & $0.222^{* * *}$ & $0.034^{* * *}$ & $0.126^{* * *}$ & $0.076^{* * *}$ & $0.128^{* * *}$ & $0.139 * * *$ & $0.079^{* * *}$ \\
\hline temporary & $-0.073^{* * *}$ & $-0.072^{* * *}$ & $-0.071^{* * *}$ & $-0.274^{* * *}$ & $-0.025^{* * *}$ & $-0.106^{* * *}$ & na & -0.039 & $-0.080^{* * *}$ & $-0.083^{* * *}$ & $-0.087^{* * *}$ & $-0.082^{* * *}$ & -0.029 & $-0.110^{* * *}$ \\
\hline permanent & $0.073^{* * *}$ & $0.072^{* * *}$ & $0.071^{* * *}$ & $0.274^{* * *}$ & $0.025^{* * *}$ & $0.106^{* * *}$ & na & 0.039 & $0.080^{* * *}$ & $0.083^{* * *}$ & $0.087^{* * *}$ & $0.082^{* * *}$ & 0.029 & $0.110^{* * *}$ \\
\hline occup_d & $-0.188^{* * *}$ & $-0.137^{* * *}$ & $-0.097^{* * *}$ & $-0.326^{* * *}$ & $-0.162^{* * *}$ & $-0.223^{* * *}$ & $-0.123^{* * *}$ & $-0.137^{* * *}$ & $-0.177^{* * *}$ & $-0.170^{* * *}$ & $-0.208^{* * *}$ & $-0.174^{* * *}$ & $-0.168^{* * *}$ & $-0.114^{* * *}$ \\
\hline occup_c & $-0.065^{* * *}$ & $-0.064^{* * *}$ & $-0.153^{* * *}$ & $-0.176^{* * *}$ & $-0.119^{* * *}$ & $-0.087^{* * *}$ & $-0.122^{* * *}$ & $-0.218^{* * *}$ & $-0.134^{* * *}$ & $-0.158^{* * *}$ & $-0.124^{* * *}$ & $-0.150^{* * *}$ & $-0.150^{* * *}$ & $-0.098^{* * *}$ \\
\hline occup_b & $0.100^{* * *}$ & $0.029^{* * *}$ & $0.037^{*}$ & $0.176^{* * *}$ & $0.063^{* * *}$ & $0.104^{* * *}$ & $0.065^{* * *}$ & $0.130^{* * *}$ & $0.127^{* * *}$ & $0.028^{* * *}$ & $0.041^{* *}$ & $0.078^{* * *}$ & $0.157^{* * *}$ & $0.069^{* * *}$ \\
\hline occup_a & $0.153^{* * *}$ & $0.172^{* * *}$ & $0.212^{* * *}$ & $0.326^{* * *}$ & $0.219^{* * *}$ & $0.206^{* * *}$ & $0.181^{* * *}$ & $0.226^{* * *}$ & $0.184^{* * *}$ & $0.300^{* * *}$ & $0.291^{* * *}$ & $0.246^{* * *}$ & $0.161^{* * *}$ & $0.143^{* * *}$ \\
\hline constant & $2.634^{* * *}$ & $2.701^{* * *}$ & $0.350^{* * *}$ & $2.278^{* * *}$ & $1.423^{* * *}$ & $2.532^{* * *}$ & $3.169^{* * *}$ & $1.163^{* * *}$ & $2.418^{* * *}$ & $2.637^{* * *}$ & $2.367^{* * *}$ & $0.983^{* * *}$ & $2.812^{* * *}$ & $2.987^{* * *}$ \\
\hline athrho & 0.062 & 0.313 & -0.105 & $-0.797^{* * *}$ & -0.108 & $0.250^{* * *}$ & $-0.523^{* * *}$ & $1.063^{* * *}$ & $-0.471^{* * *}$ & $0.631^{* * *}$ & -0.196 & $1.426^{* * *}$ & $0.818^{* * *}$ & -0.251 \\
\hline Insigma & $-1.043^{* * *}$ & $-1.113^{* * *}$ & $-0.766^{* * *}$ & $-0.746^{* * *}$ & $-1.089^{* * *}$ & $-0.929 * * *$ & $-1.153^{* * *}$ & $-0.751^{* * *}$ & $-0.908^{* * *}$ & $-1.071^{* * *}$ & $-0.924^{* * *}$ & $-0.740^{* * *}$ & $-0.804^{* * *}$ & $-0.931^{* * *}$ \\
\hline Obs & 2,963 & 3,221 & 3,031 & 2,857 & 8,482 & 6,557 & 4,551 & 4,007 & 8,584 & 3,452 & 3,097 & 5,936 & 1,959 & 1,063 \\
\hline
\end{tabular}


Table 13 Selection-corrected hourly wage equation with a dummy for Public (ML) and its row bolded (Continued)

\begin{tabular}{|c|c|c|c|c|c|c|c|c|c|c|c|c|c|}
\hline & IT & LT & LU & LV & $\mathrm{NL}$ & NO & PL & PT & RO & SE & SI & SK & UK \\
\hline public & $0.050 * * *$ & 0.011 & $0.120^{* * *}$ & $0.076^{* * *}$ & $0.040^{* * *}$ & $-0.038^{* * *}$ & $0.041 * * *$ & $0.079 * * *$ & $0.053^{* * *}$ & 0.015 & 0.004 & $0.043^{* * *}$ & $0.056^{* * *}$ \\
\hline other & $-0.050^{* * *}$ & -0.011 & $-0.120^{* * *}$ & $-0.076^{* * *}$ & $-0.040^{* * *}$ & $0.038^{* * *}$ & $-0.041^{* * *}$ & $-0.079 * * *$ & $-0.053^{* * *}$ & -0.015 & -0.004 & $-0.043^{* * *}$ & $-0.056^{* * *}$ \\
\hline age25_29 & $-0.220^{* * *}$ & 0.021 & $-0.250^{* * *}$ & 0.023 & $-0.220^{* * *}$ & $-0.157^{* * *}$ & $-0.176^{* * *}$ & $-0.238^{* * *}$ & $-0.139 * * *$ & $-0.174^{* * *}$ & $-0.188^{* * *}$ & $-0.037^{* * *}$ & $-0.174^{* * *}$ \\
\hline age30_34 & $-0.118^{* * *}$ & $0.085^{* * *}$ & $-0.178^{* * *}$ & $0.061^{* *}$ & $-0.084^{* * *}$ & $-0.095^{* * *}$ & $-0.083^{* * *}$ & $-0.135^{* * *}$ & $-0.034^{* *}$ & $-0.109^{* * *}$ & $-0.084^{* * *}$ & $-0.031^{* *}$ & -0.013 \\
\hline age35_39 & $-0.030^{* * *}$ & $-0.044^{* *}$ & $-0.092^{* * *}$ & 0.017 & 0.016 & 0.022 & $0.064^{* * *}$ & -0.030 & 0.009 & -0.003 & $0.041^{* *}$ & $0.029^{* * *}$ & 0.023 \\
\hline age40_44 & $0.035^{* * *}$ & 0.019 & -0.007 & -0.002 & $0.065^{* * *}$ & $0.053^{* * *}$ & $0.099^{* * *}$ & 0.016 & $0.073^{* * *}$ & $0.038^{*}$ & $0.069^{* * *}$ & $0.028^{* * *}$ & $0.044^{* * *}$ \\
\hline age45_49 & $0.092^{* * *}$ & 0.011 & $0.082^{* * * *}$ & -0.006 & $0.083^{* * *}$ & $0.088^{* * *}$ & $0.077^{* * *}$ & $0.089 * * *$ & $0.049^{* * *}$ & $0.068^{* * *}$ & $0.117^{* * *}$ & $0.019^{*}$ & $0.049^{* * *}$ \\
\hline age50_54 & $0.129^{* * *}$ & -0.032 & $0.180^{* * *}$ & $-0.057^{* *}$ & $0.090^{* * *}$ & $0.067^{* * *}$ & $0.046^{* * *}$ & $0.116^{* * *}$ & $0.043^{* * *}$ & $0.084^{* * *}$ & $0.061^{* * *}$ & $0.020^{*}$ & $0.038^{* *}$ \\
\hline age55_60 & $0.112^{* * *}$ & $-0.059 * * *$ & $0.265^{* * *}$ & -0.036 & $0.050^{* * *}$ & 0.022 & -0.028 & $0.181^{* * *}$ & -0.000 & $0.095^{* * *}$ & -0.016 & $-0.028^{* *}$ & $0.033^{*}$ \\
\hline edt & $-0.187^{* * *}$ & $-0.213^{* * *}$ & $-0.193^{* * *}$ & $-0.256^{* * *}$ & $-0.170^{* * *}$ & $-0.134^{* * *}$ & $-0.320^{* * *}$ & $-0.337^{* * *}$ & $-0.347^{* * *}$ & -0.027 & $-0.339 * * *$ & $-0.163^{* * *}$ & $-0.281^{* * *}$ \\
\hline eds & 0.007 & -0.012 & -0.014 & $-0.069 * * *$ & $-0.050^{* * *}$ & 0.009 & $-0.022^{* *}$ & $-0.065^{* * *}$ & $-0.028^{* * *}$ & -0.016 & $-0.052^{* * *}$ & -0.016 & 0.012 \\
\hline $\mathrm{edH}$ & $0.180^{* * *}$ & $0.225^{* * *}$ & $0.207^{* * *}$ & $0.324^{* * *}$ & $0.220^{* * *}$ & $0.126^{* * *}$ & $0.342^{* * *}$ & $0.403^{* * *}$ & $0.375^{* * *}$ & $0.043^{* *}$ & $0.391^{* * *}$ & $0.179^{* * *}$ & $0.268^{* * *}$ \\
\hline female & $-0.139 * * *$ & $-0.203^{* * *}$ & $-0.080^{* * *}$ & $-0.183^{* * *}$ & $-0.140 * * *$ & $-0.128^{* * *}$ & $-0.187^{* * *}$ & $-0.083^{* * *}$ & $-0.138^{* * *}$ & $-0.108^{* * *}$ & $-0.105^{* * *}$ & $-0.118^{* * *}$ & $-0.143^{* * *}$ \\
\hline male & $0.139^{* * *}$ & $0.203^{* * *}$ & $0.080^{* * * *}$ & $0.183^{* * *}$ & $0.140^{* * *}$ & $0.128^{* * *}$ & $0.187^{* * *}$ & $0.083^{* * *}$ & $0.138^{* * *}$ & $0.108^{* * *}$ & $0.105^{* * *}$ & $0.118^{* * *}$ & $0.143^{* * *}$ \\
\hline temporary & $-0.118^{* * *}$ & $-0.051^{* *}$ & $-0.103^{* * *}$ & $-0.055^{*}$ & $-0.057^{* * * *}$ & na & $-0.098^{* * * *}$ & $-0.076^{* * *}$ & $-0.067^{* * * *}$ & $-0.136^{* * *}$ & $-0.097^{* * *}$ & $-0.049 * * * *$ & na \\
\hline permanent & $0.118^{* * *}$ & $0.051^{* *}$ & $0.103^{* * *}$ & $0.055^{*}$ & $0.057^{* * *}$ & na & $0.098^{* * *}$ & $0.076^{* * *}$ & $0.067^{* * *}$ & $0.136^{* * *}$ & $0.097^{* * *}$ & $0.049^{* * *}$ & na \\
\hline occup_d & $-0.179 * * *$ & $-0.228^{* * *}$ & $-0.286^{* * *}$ & $-0.222^{* * *}$ & $-0.143^{* * *}$ & $-0.086^{* * *}$ & $-0.185^{* * *}$ & $-0.189^{* * *}$ & $-0.190^{* * *}$ & $-0.193^{* * *}$ & $-0.223^{* * *}$ & $-0.128^{* * *}$ & $-0.206^{* * *}$ \\
\hline occup_c & $-0.083^{* * *}$ & $-0.249 * * *$ & $-0.152^{* * *}$ & $-0.211^{* * *}$ & $-0.084^{* * *}$ & $-0.095^{* * *}$ & $-0.194^{* * *}$ & $-0.083^{* * *}$ & $-0.208^{* * *}$ & $-0.154^{* * *}$ & $-0.116^{* * *}$ & $-0.134^{* * *}$ & $-0.120^{* * * *}$ \\
\hline occup_b & $0.039^{* * *}$ & $0.162^{* * *}$ & $0.147^{* * * *}$ & $0.143^{* * *}$ & $0.058^{* * *}$ & $0.052^{* * *}$ & $0.118^{* * *}$ & $0.190^{* * *}$ & $0.100^{* * *}$ & 0.024 & $0.088^{* * *}$ & $0.051^{* * *}$ & $0.107^{* * *}$ \\
\hline occup_a & $0.224^{* * *}$ & $0.315^{* * *}$ & $0.291^{* * *}$ & $0.290^{* * *}$ & $0.169^{* * *}$ & $0.128^{* * *}$ & $0.261^{* * *}$ & 0.081 & $0.298^{* * *}$ & $0.323^{* * *}$ & $0.251^{* * *}$ & $0.210^{* * *}$ & $0.219^{* * *}$ \\
\hline constant & $2.418^{* * *}$ & $0.888^{* * *}$ & $3.064^{* * *}$ & $1.126^{* * *}$ & $2.883^{* * *}$ & $3.080^{* * *}$ & $1.029 * * *$ & $2.120^{* * *}$ & $0.472^{* * *}$ & $2.771 * * *$ & $1.845^{* * *}$ & $1.089^{* * * *}$ & $2.741^{* * * *}$ \\
\hline athrho & $0.668^{* * *}$ & $0.839 * * *$ & -0.019 & $0.438^{* *}$ & $0.846^{* * *}$ & 0.044 & $1.129 * * *$ & $-0.661^{* * *}$ & $0.864^{* * *}$ & 0.057 & $0.832^{* * *}$ & $-0.359 * *$ & $1.163^{* * *}$ \\
\hline Insigma & $-0.991 * * *$ & $-0.655^{* * *}$ & $-0.952^{* * *}$ & $-0.580^{* * *}$ & $-1.156^{* * *}$ & $-0.921 * * *$ & $-0.659^{* * *}$ & $-0.802^{* * *}$ & $-0.856^{* * *}$ & $-0.853^{* * *}$ & $-0.889 * * *$ & $-1.059 * * *$ & $-0.738^{* * *}$ \\
\hline Obs & 10,209 & 3,574 & 2,910 & 3,721 & 2,485 & 4,025 & 8,553 & 2,773 & 4,579 & 2,493 & 3,327 & 5,506 & 4,435 \\
\hline
\end{tabular}

*** $p<0.01, * * p<0.05, * p<0.1$. 


\begin{tabular}{|c|c|c|c|c|c|c|c|c|c|c|c|c|c|c|}
\hline & AT & $\mathrm{BE}$ & BG & $\mathrm{CY}$ & $\mathrm{CZ}$ & $\mathrm{DE}$ & DK & $\mathrm{EE}$ & ES & $\mathrm{FI}$ & GR & $\mathrm{HU}$ & $\mathrm{IE}$ & IS \\
\hline age30_34 & -0.012 & -0.044 & $0.217^{* *}$ & -0.008 & $0.400^{* * *}$ & 0.009 & -0.066 & $0.218^{* *}$ & -0.018 & 0.071 & $0.257^{* * *}$ & $0.259^{* * *}$ & -0.025 & 0.070 \\
\hline age35_39 & 0.142 & -0.113 & $0.236^{* *}$ & 0.089 & $0.648^{* * *}$ & 0.093 & 0.143 & $0.284^{* * *}$ & $-0.150^{* *}$ & $0.141^{*}$ & $0.386^{* * *}$ & $0.348^{* * *}$ & 0.114 & $0.492^{* *}$ \\
\hline age40_44 & $0.286^{* * *}$ & -0.087 & $0.222^{* *}$ & 0.096 & $0.692^{* * *}$ & 0.086 & $0.384^{* * *}$ & $0.348^{* * *}$ & -0.077 & $0.191^{* *}$ & $0.337^{* * *}$ & $0.444^{* * *}$ & $0.212^{* *}$ & $0.825^{* * *}$ \\
\hline age45_49 & 0.164 & $-0.191^{*}$ & $0.203^{* *}$ & -0.005 & $0.661^{* * *}$ & -0.067 & $0.264^{*}$ & $0.200^{* *}$ & $-0.102^{*}$ & $0.282^{* * *}$ & $0.317^{* * *}$ & $0.369^{* * *}$ & 0.104 & $0.526^{* *}$ \\
\hline age50_54 & -0.028 & $-0.592^{* * *}$ & $0.195^{*}$ & -0.120 & $0.570^{* * *}$ & $-0.255^{* * *}$ & 0.159 & $0.160^{*}$ & $-0.241^{* * *}$ & 0.115 & $0.216^{* *}$ & $0.446^{* * *}$ & 0.018 & 0.321 \\
\hline age55_60 & $-0.632^{* * *}$ & $-1.088^{* * *}$ & -0.104 & $-0.360^{* * *}$ & $0.363^{* * *}$ & $-0.545^{* * *}$ & -0.131 & $0.212^{* *}$ & $-0.573^{* * *}$ & $-0.302^{* * *}$ & $-0.293^{* * *}$ & $0.324^{* * *}$ & $-0.204^{*}$ & 0.086 \\
\hline eds & $0.584^{* * *}$ & $0.571^{* * *}$ & $1.118^{* * *}$ & $0.604^{* * *}$ & $0.711^{* * *}$ & $0.542^{* * *}$ & $0.302^{* * *}$ & $0.330^{* * *}$ & $0.565^{* * *}$ & $0.305^{* * *}$ & $0.351^{* * *}$ & $0.738^{* * *}$ & $0.706^{* * *}$ & 0.143 \\
\hline $\mathrm{edH}$ & $1.052^{* * *}$ & $1.259^{* * *}$ & $1.611^{* * *}$ & $1.122^{* * *}$ & $0.855^{* * *}$ & $1.116^{* * *}$ & $0.502^{* * *}$ & $0.708^{* * *}$ & $1.155^{* * *}$ & $0.734^{* * *}$ & $0.848^{* * *}$ & $1.277^{* * *}$ & $1.202^{* * *}$ & $0.662^{* * *}$ \\
\hline male & $1.483^{* * *}$ & $1.138^{* * *}$ & $0.487^{* * *}$ & $1.349^{* * *}$ & $0.916^{* * *}$ & $1.233^{* * *}$ & $0.660^{* * *}$ & $0.421^{* * *}$ & $1.222^{* * *}$ & $0.539 * * *$ & $1.484^{* * *}$ & $0.631^{* * *}$ & $1.112^{* * *}$ & $1.079^{* * *}$ \\
\hline married & $-0.230^{* * *}$ & 0.007 & $0.178^{* * *}$ & 0.005 & $0.189^{* * *}$ & 0.012 & $0.158^{* *}$ & 0.041 & $-0.075^{* *}$ & 0.027 & -0.023 & 0.050 & 0.076 & -0.218 \\
\hline childn & $-0.399 * * *$ & $-0.258^{* * *}$ & 0.013 & $-0.123^{* * *}$ & $-0.294^{* * *}$ & $-0.317^{* * *}$ & $-0.281 * * *$ & $-0.100^{* * *}$ & $-0.058^{* *}$ & $-0.082^{* * *}$ & $-0.118^{* * *}$ & $-0.194^{* * *}$ & -0.331 *** & $-0.230^{* *}$ \\
\hline exog inc & -0.001 & $-0.006^{* *}$ & $-0.193^{* * *}$ & $-0.005^{*}$ & $-0.014^{*}$ & $-0.011^{* * *}$ & -0.000 & $-0.043^{* *}$ & 0.001 & $-0.003^{* *}$ & $-0.015^{* *}$ & -0.005 & -0.003 & $-0.003^{* *}$ \\
\hline relativec & $0.287^{* * *}$ & $0.713^{* * *}$ & 0.112 & $0.749 * * *$ & 0.006 & $-0.145^{* * *}$ & na & $0.202^{* *}$ & $0.876^{* * *}$ & $0.555^{* * *}$ & $0.971^{* * *}$ & $0.157^{* * *}$ & $1.006^{* * *}$ & $5.290^{* * *}$ \\
\hline paidc & $-0.383^{* * *}$ & 0.135 & $-0.559^{* * *}$ & -0.118 & $-0.540^{* * *}$ & $-0.183^{* * *}$ & $0.385^{* * *}$ & $-0.655^{* * *}$ & $-0.222^{* * *}$ & $-0.521^{* * *}$ & $-0.254^{* * *}$ & $-0.151^{* * *}$ & $0.336^{* * *}$ & 0.051 \\
\hline constant & -0.085 & $-0.166^{*}$ & $-0.425^{* * *}$ & -0.009 & -0.008 & $-0.302^{* * *}$ & $0.959^{* * *}$ & $0.537^{* * *}$ & $-0.088^{*}$ & 0.129 & $-0.558^{* * *}$ & $-0.388^{* * *}$ & $-0.718^{* * *}$ & $0.529^{* * *}$ \\
\hline Obs & 3,884 & 4,343 & 3,839 & 3,499 & 9,681 & 8,760 & 4,770 & 4,555 & 11,967 & 4,643 & 4,529 & 7,593 & 3,100 & 1,196 \\
\hline
\end{tabular}


Table 14 Probit selection equation results (ML) (Continued)

\begin{tabular}{|c|c|c|c|c|c|c|c|c|c|c|c|c|c|}
\hline & IT & LT & LU & LV & $\mathrm{NL}$ & NO & PL & PT & RO & SE & SI & SK & UK \\
\hline age30_34 & $0.115^{* *}$ & -0.053 & $-0.245^{* *}$ & 0.076 & -0.080 & 0.113 & $0.216^{* * *}$ & -0.033 & 0.085 & $0.212^{*}$ & $0.372^{* * *}$ & $0.161^{*}$ & 0.127 \\
\hline age35_39 & $0.296^{* * *}$ & -0.164 & $-0.318^{* * *}$ & -0.049 & -0.171 & $0.409^{* *}$ & $0.446^{* * *}$ & -0.073 & $0.326^{* * *}$ & $0.376^{* * *}$ & $0.542^{* * *}$ & $0.346^{* * *}$ & $0.210^{* *}$ \\
\hline age40_44 & $0.350^{* * *}$ & -0.186 & $-0.319^{* * *}$ & 0.068 & -0.211 & $0.455^{* * *}$ & $0.321^{* * *}$ & -0.006 & $0.204^{* *}$ & $0.197^{*}$ & $0.534^{* * *}$ & $0.211^{* *}$ & $0.309^{* * *}$ \\
\hline age45_49 & $0.374^{* * *}$ & $-0.254^{* *}$ & $-0.362^{* * *}$ & $-0.158^{*}$ & $-0.276^{*}$ & 0.262 & $0.256^{* * *}$ & -0.123 & $0.222^{* *}$ & 0.080 & $0.475^{* * *}$ & $0.236^{* * *}$ & $0.233^{* * *}$ \\
\hline age50_54 & $0.343^{* * *}$ & $-0.265^{* *}$ & $-0.681^{* * *}$ & $-0.222^{* *}$ & $-0.571^{* * *}$ & 0.074 & 0.059 & -0.121 & $0.157^{*}$ & 0.168 & $0.190^{* *}$ & $0.240^{* * *}$ & $0.228^{* *}$ \\
\hline age55_60 & $-0.130^{* *}$ & $-0.426^{* * *}$ & $-1.015^{* * *}$ & $-0.184^{*}$ & $-1.139^{* * *}$ & -0.070 & $-0.357^{* * *}$ & $-0.477^{* * *}$ & -0.078 & 0.189 & $-0.320^{* * *}$ & $0.222^{* *}$ & $0.150^{*}$ \\
\hline edS & $0.603^{* * *}$ & $0.700^{* * *}$ & $0.184^{* * *}$ & $0.562^{* * *}$ & $0.456^{* * *}$ & $0.528^{* * *}$ & $0.672^{* * *}$ & $0.458^{* * *}$ & $0.887^{* * *}$ & $0.624^{* * *}$ & $0.640^{* * *}$ & $1.166^{* * *}$ & $0.668^{* * *}$ \\
\hline $\mathrm{edH}$ & $0.914^{* * *}$ & $1.147^{* * *}$ & $0.666^{* * *}$ & $1.090^{* * *}$ & $0.999 * * *$ & $0.976^{* * *}$ & $1.459^{* * *}$ & $0.940^{* * *}$ & $1.857^{* * *}$ & $0.876^{* * *}$ & $1.393^{* * *}$ & $1.781^{* * *}$ & $0.996^{* * *}$ \\
\hline male & $1.364^{* * *}$ & $0.333^{* * *}$ & $1.492^{* * *}$ & $0.434^{* * *}$ & $2.055^{* * *}$ & $0.943^{* * *}$ & $0.929^{* * *}$ & $0.867^{* * *}$ & $0.997^{* * *}$ & $0.536^{* * *}$ & $0.514^{* * *}$ & $0.430^{* * *}$ & $0.956^{* * *}$ \\
\hline married & $-0.098^{* * *}$ & $0.310^{* * *}$ & $-0.317^{* * *}$ & 0.064 & $-0.533^{* * *}$ & -0.059 & $0.173^{* * *}$ & $0.207^{* * *}$ & $-0.130^{* *}$ & 0.089 & $0.098^{* *}$ & $0.160^{* * *}$ & -0.044 \\
\hline childn & $-0.117^{* * *}$ & -0.002 & $-0.360^{* * *}$ & -0.021 & $-0.252^{* * *}$ & $-0.307^{* * *}$ & $-0.152^{* * *}$ & $-0.114^{*}$ & $-0.210^{* * *}$ & $-0.210^{* * *}$ & -0.021 & $-0.303^{* * *}$ & $-0.451^{* * *}$ \\
\hline exog inc & $-0.011^{* * *}$ & 0.024 & -0.001 & -0.010 & $-0.017^{* * *}$ & -0.001 & $-0.035^{* * *}$ & $-0.042^{* * *}$ & $-0.200^{* * *}$ & -0.004 & $-0.021^{*}$ & -0.039 & $-0.004^{* * *}$ \\
\hline relativec & $0.444^{* * *}$ & $0.796^{* * *}$ & $0.625^{* * *}$ & $0.980^{* * *}$ & $0.243^{* * *}$ & 0.645 & $0.532^{* * *}$ & $0.371^{* * *}$ & 0.086 & -0.280 & $0.429^{* * *}$ & $0.361^{* * *}$ & $0.396^{* * *}$ \\
\hline paidc & $-0.096^{* *}$ & $-0.490^{* * *}$ & $0.384^{* * *}$ & $-0.894^{* * *}$ & $-0.211^{*}$ & 0.037 & $-0.279^{* * *}$ & $0.410^{* * *}$ & na & $0.191^{*}$ & 0.133 & 0.047 & $0.371^{* * *}$ \\
\hline constant & $-0.652^{* * *}$ & 0.162 & $0.560^{* * *}$ & $0.329^{* * *}$ & -0.016 & $0.903^{* * *}$ & $-0.592^{* * *}$ & $0.264^{* * *}$ & $-0.261^{* * *}$ & 0.120 & $-0.755^{* * *}$ & $-0.282^{* * *}$ & -0.043 \\
\hline Obs & 15,598 & 4,071 & 3,809 & 4,472 & 3,730 & 4,188 & 11,071 & 3,495 & 5,652 & 2,859 & 4,892 & 6,136 & 5,333 \\
\hline
\end{tabular}


Table 15 Decompositions of offered wage gap (adjusted for selection), with pay gap rows bolded

\begin{tabular}{|c|c|c|c|c|c|c|c|c|c|c|c|c|c|c|}
\hline & AT & $\mathrm{BE}$ & BG & $\mathrm{CY}$ & $\mathrm{CZ}$ & $\mathrm{DE}$ & DK & $\mathrm{EE}$ & ES & $\mathrm{FI}$ & GR & $\mathrm{HU}$ & $\mathrm{IE}$ & IS \\
\hline \multicolumn{15}{|l|}{ overall } \\
\hline public & $2.847^{* * *}$ & $2.842^{* * *}$ & $0.428^{* * *}$ & $2.538^{* * *}$ & $1.539^{* * *}$ & $2.829^{* * *}$ & $3.211^{* * *}$ & $1.399^{* * *}$ & $2.537^{* * *}$ & $2.933^{* * *}$ & $2.507^{* * *}$ & $1.389^{* * *}$ & $3.180^{* * *}$ & $3.235^{* * *}$ \\
\hline private & $2.753^{* * *}$ & $2.839^{* * *}$ & $0.311^{* * *}$ & $2.241^{* * *}$ & $1.333^{* * *}$ & $2.794^{* * *}$ & $3.162^{* * *}$ & $1.265^{* * *}$ & $2.254^{* * *}$ & $2.805^{* * *}$ & $2.174^{* * *}$ & $1.099 * * *$ & $3.025^{* * *}$ & $3.091^{* * *}$ \\
\hline difference & $0.095^{* * *}$ & 0.004 & $0.117^{* * *}$ & $0.296 * * *$ & $0.206^{* * *}$ & $0.034^{* * *}$ & $0.049 * *$ & $0.133^{* * *}$ & $0.283^{* * *}$ & $0.128^{* * *}$ & $0.333^{* * *}$ & $0.291^{* * *}$ & $0.155^{* * *}$ & $0.144^{* * *}$ \\
\hline \multicolumn{15}{|l|}{ adjusted } \\
\hline public & $2.832^{* * *}$ & $2.820^{* * *}$ & $0.377^{* *}$ & $2.616^{* * *}$ & $1.546^{* * *}$ & $2.839 * * *$ & $3.168^{* * *}$ & $1.381^{* * *}$ & $2.633^{* * *}$ & $2.944^{* * *}$ & $2.456^{* * *}$ & $1.418^{* * *}$ & $3.094^{* * *}$ & $3.251^{* * *}$ \\
\hline private & $2.750^{* * *}$ & $2.845^{* * *}$ & $0.339 * * *$ & $2.347^{* * *}$ & $1.334^{* * *}$ & $2.755^{* * *}$ & $3.221^{* * *}$ & $1.255^{* * *}$ & $2.312^{* * *}$ & $2.773^{* * *}$ & $2.187^{* * *}$ & $1.079^{* * *}$ & $2.996^{* * *}$ & $3.108^{* * *}$ \\
\hline difference & $0.082^{*}$ & -0.025 & 0.037 & $0.269 * * *$ & $0.213^{* * *}$ & $0.084^{* * *}$ & -0.053 & $0.126^{* *}$ & $0.321 * * *$ & $0.171 * * *$ & $0.269^{* * *}$ & $0.339 * * *$ & 0.099 & $0.143^{*}$ \\
\hline explained & $0.092^{* * *}$ & $0.035^{* * *}$ & $0.082^{* * *}$ & $0.069^{* * *}$ & $0.091^{* * *}$ & $0.086^{* * *}$ & 0.009 & $0.112^{* * *}$ & $0.145^{* * *}$ & $0.119^{* * *}$ & $0.143^{* * *}$ & $0.135^{* * *}$ & $0.058^{* * *}$ & $0.060^{* *}$ \\
\hline pub. adv. & -0.009 & -0.046 & -0.041 & $0.176^{* * *}$ & $0.114^{* * *}$ & 0.001 & -0.060 & 0.013 & $0.152^{* * *}$ & 0.049 & $0.105^{* * *}$ & $0.191^{* * *}$ & 0.030 & 0.070 \\
\hline pri. disadv. & -0.001 & $-0.014^{*}$ & -0.003 & $0.024^{* * *}$ & $0.007^{* * *}$ & -0.004 & -0.001 & 0.001 & $0.024^{* * *}$ & 0.003 & $0.022^{* *}$ & $0.013^{* *}$ & 0.010 & $0.014^{* *}$ \\
\hline Mills $p$-value & 0.709 & 0.832 & 0.476 & 0.000 & 0.821 & 0.008 & 0.000 & 0.404 & 0.000 & 0.095 & 0.860 & 0.159 & 0.228 & 0.344 \\
\hline Obs & 2,963 & 3,221 & 3,031 & 2,857 & 8,482 & 6,557 & 4,546 & 4,007 & 8,584 & 3,452 & 3,097 & 5,936 & 1,959 & 1,051 \\
\hline
\end{tabular}


Table 15 Decompositions of offered wage gap (adjusted for selection), with pay gap rows bolded (Continued)

\begin{tabular}{|c|c|c|c|c|c|c|c|c|c|c|c|c|c|}
\hline & IT & LT & LU & LV & $\mathrm{NL}$ & NO & PL & PT & RO & SE & SI & SK & UK \\
\hline \multicolumn{14}{|l|}{ overall } \\
\hline public & $2.719^{* * *}$ & $1.221^{* * *}$ & $3.297^{* * *}$ & $1.486^{* * *}$ & $3.227^{* * *}$ & $3.169^{* * *}$ & $1.452^{* * *}$ & $2.047^{* * *}$ & $0.814^{* * *}$ & $2.928^{* * *}$ & $2.235^{* * *}$ & $1.186^{* * *}$ & $3.009^{* * *}$ \\
\hline private & $2.489^{* * *}$ & $1.062^{* * *}$ & $2.963^{* * *}$ & $1.107^{* * *}$ & $3.092^{* * *}$ & $3.207^{* * *}$ & $1.179^{* * *}$ & $1.771^{* * *}$ & $0.520^{* * *}$ & $2.858^{* * *}$ & $2.012^{* * *}$ & $1.043^{* * *}$ & $2.909^{* * *}$ \\
\hline difference & $0.230^{* * *}$ & $0.159 * * *$ & $0.334^{* * *}$ & $0.379 * * *$ & $0.134^{* * *}$ & -0.038 & $0.273^{* * *}$ & $0.276^{* * *}$ & $0.294^{* * *}$ & $0.070^{*}$ & $0.223^{* * *}$ & $0.143^{* * *}$ & $0.099 * * *$ \\
\hline \multicolumn{14}{|l|}{ adjusted } \\
\hline public & $2.687^{* * *}$ & $1.310^{* * *}$ & $3.319^{* * *}$ & $1.450^{* * *}$ & $3.230^{* * *}$ & $3.119^{* * *}$ & $1.449 * * *$ & $2.069^{* * *}$ & $0.851^{* * *}$ & $2.884^{* * *}$ & $2.334^{* * *}$ & $1.168^{* * *}$ & $2.943^{* * *}$ \\
\hline private & $2.465^{* * *}$ & $1.046^{* * *}$ & $2.963^{* * *}$ & $1.070^{* * *}$ & $3.056^{* * *}$ & $3.201^{* * *}$ & $1.129^{* * *}$ & $1.859^{* * *}$ & $0.519^{* * *}$ & $2.828^{* * *}$ & $1.918^{* * *}$ & $1.047^{* * *}$ & $2.878^{* * *}$ \\
\hline difference & $0.222^{* * *}$ & $0.264^{* * *}$ & $0.357^{* * *}$ & $0.380^{* * *}$ & $0.174^{* * *}$ & -0.082 & $0.320 * * *$ & $0.210^{* *}$ & $0.332^{* * *}$ & 0.056 & $0.416^{* * *}$ & $0.121^{* * *}$ & 0.065 \\
\hline explained & $0.146^{* * *}$ & $0.143^{* * *}$ & $0.105^{* * *}$ & $0.247^{* * *}$ & $0.068^{* * *}$ & $0.038^{* *}$ & $0.218^{* * *}$ & $0.119^{* * *}$ & $0.185^{* * *}$ & $0.046^{*}$ & $0.241^{* * *}$ & $0.063^{* * *}$ & -0.000 \\
\hline pub. adv. & $0.066^{*}$ & 0.108 & $0.229 * * *$ & 0.113 & $0.092^{* * *}$ & $-0.118^{* *}$ & $0.094^{* *}$ & 0.078 & $0.142^{* *}$ & 0.005 & $0.159^{*}$ & 0.050 & 0.056 \\
\hline pri. disadv. & $0.010^{*}$ & $0.013^{*}$ & $0.023^{* * *}$ & $0.019^{* *}$ & $0.014^{* * *}$ & $-0.002^{*}$ & $0.007^{*}$ & 0.013 & 0.005 & 0.005 & 0.016 & 0.009 & $0.009^{*}$ \\
\hline Mills p-value & 0.114 & 0.867 & 0.692 & 0.254 & 0.001 & 0.485 & 0.002 & 0.005 & 0.898 & 0.532 & 0.027 & 0.867 & 0.003 \\
\hline Obs & 10,209 & 3,574 & 2,910 & 3,721 & 2,485 & 4,025 & 8,553 & 2,773 & 4,579 & 2,493 & 3,327 & 5,506 & 4,435 \\
\hline
\end{tabular}


Table 16 Probit first-stage results in Heckman corrections

\begin{tabular}{|c|c|c|c|c|c|c|c|c|c|c|c|c|c|c|}
\hline & AT & $\mathrm{BE}$ & BG & $\mathrm{CY}$ & $C Z$ & $\mathrm{DE}$ & DK & $\mathrm{EE}$ & ES & $\mathrm{FI}$ & GR & $\mathrm{HU}$ & IE & IS \\
\hline age30_34 & -0.014 & -0.060 & $0.218^{* *}$ & 0.029 & $0.405^{* * *}$ & 0.002 & -0.073 & $0.179^{*}$ & 0.006 & 0.076 & $0.270^{* * *}$ & $0.257^{* * *}$ & -0.034 & 0.057 \\
\hline age35_39 & 0.140 & -0.144 & $0.238^{* *}$ & 0.096 & $0.655^{* * *}$ & 0.085 & 0.136 & $0.255^{* * *}$ & $-0.102^{*}$ & 0.120 & $0.412^{* * *}$ & $0.365^{* * *}$ & 0.026 & $0.470^{* *}$ \\
\hline age40_44 & $0.282^{* *}$ & -0.125 & $0.225^{* *}$ & 0.075 & $0.694^{* * *}$ & 0.075 & $0.396^{* * *}$ & $0.248^{* *}$ & -0.029 & $0.164^{*}$ & $0.353^{* * *}$ & $0.403^{* * *}$ & 0.154 & $0.840^{* * *}$ \\
\hline age45_49 & 0.161 & $-0.222^{* *}$ & $0.208^{* *}$ & -0.068 & $0.669^{* * *}$ & -0.080 & $0.254^{*}$ & 0.101 & -0.064 & $0.247^{* * *}$ & $0.329^{* * *}$ & $0.305^{* * *}$ & 0.016 & $0.543^{* *}$ \\
\hline age50_54 & -0.029 & $-0.622^{* * *}$ & $0.198^{*}$ & $-0.225^{*}$ & $0.573^{* * *}$ & $-0.271^{* * *}$ & 0.185 & 0.088 & $-0.211^{* * *}$ & 0.067 & $0.234^{* *}$ & $0.356^{* * *}$ & -0.113 & 0.351 \\
\hline age55_60 & $-0.635^{* * *}$ & $-1.119^{* * *}$ & -0.103 & $-0.483^{* * *}$ & $0.366^{* * *}$ & $-0.561^{* * *}$ & -0.114 & $0.184^{*}$ & $-0.549^{* * *}$ & $-0.367^{* * *}$ & $-0.277^{* * *}$ & $0.200^{* *}$ & $-0.336^{* * *}$ & 0.131 \\
\hline edS & $0.584^{* * *}$ & $0.575^{* * *}$ & $1.119^{* * *}$ & $0.562^{* * *}$ & $0.712^{* * *}$ & $0.543^{* * *}$ & $0.301^{* * *}$ & $0.358^{* * *}$ & $0.559 * * *$ & $0.305^{* * *}$ & $0.357^{* * *}$ & $0.762^{* * *}$ & $0.711^{* * *}$ & 0.139 \\
\hline edH & $1.053^{* * *}$ & $1.255^{* * *}$ & $1.606^{* * *}$ & $0.925^{* * *}$ & $0.854^{* * *}$ & $1.117^{* * *}$ & $0.477^{* * *}$ & $0.735^{* * *}$ & $1.121^{* * *}$ & $0.725^{* * *}$ & $0.846^{* * *}$ & $1.161^{* * *}$ & $1.202^{* * *}$ & $0.660^{* * *}$ \\
\hline male & $1.486^{* * *}$ & $1.147^{* * *}$ & $0.484^{* * *}$ & $1.345^{* * *}$ & $0.911^{* * *}$ & $1.242^{* * *}$ & $0.647^{* * *}$ & $0.324^{* * *}$ & $1.211^{* * *}$ & $0.529^{* * *}$ & $1.476^{* * *}$ & $0.562^{* * *}$ & $1.148^{* * *}$ & $1.077^{* * *}$ \\
\hline married & $-0.233^{* * *}$ & 0.018 & $0.173^{* * *}$ & -0.021 & $0.184^{* * *}$ & 0.026 & $0.153^{*}$ & 0.079 & $-0.112^{* * *}$ & $0.086^{*}$ & -0.046 & $0.130^{* * *}$ & $0.170^{* * *}$ & $-0.258^{* *}$ \\
\hline childn & $-0.398^{* * *}$ & $-0.248^{* * *}$ & 0.014 & $-0.200^{* * *}$ & $-0.298^{* * *}$ & $-0.311^{* * *}$ & $-0.251^{* * *}$ & $-0.132^{* * *}$ & $-0.085^{* * *}$ & $-0.093^{* * *}$ & $-0.130^{* * *}$ & $-0.281^{* * *}$ & $-0.373^{* * *}$ & $-0.204^{* *}$ \\
\hline exoginc & -0.001 & -0.004 & $-0.199 * * *$ & -0.005 & $-0.015^{* *}$ & $-0.008^{* *}$ & 0.000 & -0.007 & -0.005 & $-0.003^{*}$ & $-0.018^{* * *}$ & -0.002 & -0.002 & $-0.003^{* *}$ \\
\hline relativec & $0.287^{* * *}$ & $0.735^{* * *}$ & 0.113 & $0.874^{* * *}$ & -0.003 & $-0.131^{* *}$ & na & $0.250^{* * *}$ & $0.919^{* * *}$ & $0.638^{* * *}$ & $0.972^{* * *}$ & $0.201^{* * *}$ & $1.051^{* * *}$ & na \\
\hline paidc & $-0.380^{* * *}$ & 0.100 & $-0.557^{* * *}$ & -0.124 & $-0.530^{* * *}$ & $-0.207^{* * *}$ & $0.335^{* * *}$ & $-0.861^{* * *}$ & $-0.231^{* * *}$ & $-0.572^{* * *}$ & $-0.253^{* * *}$ & $-0.319^{* * *}$ & $0.372^{* * *}$ & 0.028 \\
\hline constant & -0.083 & $-0.153^{*}$ & $-0.422^{* * *}$ & 0.162 & -0.008 & $-0.306^{* * *}$ & $0.975^{* * *}$ & $0.647^{* * *}$ & -0.066 & $0.154^{*}$ & $-0.548^{* * *}$ & $-0.252^{* * *}$ & $-0.692^{* * *}$ & $0.531^{* * *}$ \\
\hline Obs & 3,884 & 4,343 & 3,839 & 3,499 & 9,681 & 8,760 & 4,765 & 4,555 & 11,967 & 4,643 & 4,529 & 7,593 & 3,100 & 1,184 \\
\hline
\end{tabular}


Table 16 Probit first-stage results in Heckman corrections (Continued)

\begin{tabular}{|c|c|c|c|c|c|c|c|c|c|c|c|c|c|}
\hline & IT & LT & LU & LV & $\mathrm{NL}$ & NO & $\mathrm{PL}$ & PT & RO & SE & SI & SK & UK \\
\hline age30_34 & $0.102^{* *}$ & -0.061 & $-0.244^{* *}$ & 0.062 & -0.150 & 0.114 & $0.164^{* * *}$ & 0.013 & 0.052 & $0.210^{*}$ & $0.354^{* * *}$ & $0.172^{* *}$ & 0.052 \\
\hline age35_39 & $0.271^{* * *}$ & -0.156 & $-0.317^{* * *}$ & -0.066 & $-0.339^{* *}$ & $0.411^{* *}$ & $0.370^{* * *}$ & -0.017 & $0.310^{* * *}$ & $0.374^{* * *}$ & $0.527^{* * *}$ & $0.358^{* * *}$ & 0.116 \\
\hline age40_44 & $0.312^{* * *}$ & $-0.227^{*}$ & $-0.317^{* * *}$ & 0.046 & $-0.410^{* * *}$ & $0.453^{* * *}$ & $0.243^{* * *}$ & 0.015 & $0.195^{* *}$ & $0.195^{*}$ & $0.489^{* * *}$ & $0.231^{* * *}$ & $0.212^{* *}$ \\
\hline age45_49 & $0.325^{* * *}$ & $-0.298^{* *}$ & $-0.360^{* * *}$ & $-0.184^{* *}$ & $-0.494^{* * *}$ & 0.259 & $0.172^{* * *}$ & -0.139 & $0.180^{* *}$ & 0.075 & $0.434^{* * *}$ & $0.255^{* * *}$ & 0.101 \\
\hline age50_54 & $0.310^{* * *}$ & $-0.323^{* * *}$ & $-0.679^{* * *}$ & $-0.239^{* *}$ & $-0.762^{* * *}$ & 0.073 & -0.020 & -0.159 & 0.126 & 0.163 & 0.124 & $0.254^{* * *}$ & 0.092 \\
\hline age55_60 & $-0.188^{* * *}$ & $-0.479 * * *$ & $-1.013^{* * *}$ & $-0.206^{* *}$ & $-1.348^{* * *}$ & -0.072 & $-0.497^{* * *}$ & $-0.517^{* * *}$ & -0.105 & 0.184 & $-0.377^{* * *}$ & $0.232^{* *}$ & -0.038 \\
\hline edS & $0.613^{* * *}$ & $0.679^{* * *}$ & $0.184^{* * *}$ & $0.567^{* * *}$ & $0.486^{* * *}$ & $0.527^{* * *}$ & $0.669^{* * *}$ & $0.435^{* * *}$ & $0.896^{* * *}$ & $0.625^{* * *}$ & $0.637^{* * *}$ & $1.169^{* * *}$ & $0.697^{* * *}$ \\
\hline $\mathrm{edH}$ & $0.890^{* * *}$ & $1.124^{* * *}$ & $0.666^{* * *}$ & $1.089^{* * *}$ & $1.025^{* * *}$ & $0.973^{* * *}$ & $1.453^{* * *}$ & $0.869^{* * *}$ & $1.837^{* * *}$ & $0.874^{* * *}$ & $1.327^{* * *}$ & $1.781^{* * *}$ & $1.030^{* * *}$ \\
\hline male & $1.385^{* * *}$ & $0.287^{* * *}$ & $1.491^{* * *}$ & $0.426^{* * *}$ & $2.152^{* * *}$ & $0.942^{* * *}$ & $0.929^{* * *}$ & $0.830^{* * *}$ & $1.019^{* * *}$ & $0.536^{* * *}$ & $0.501^{* * *}$ & $0.413^{* * *}$ & $1.056^{* * *}$ \\
\hline married & $-0.073^{* *}$ & $0.365^{* * *}$ & $-0.318^{* * *}$ & 0.078 & $-0.571^{* * *}$ & -0.057 & $0.259^{* * *}$ & $0.230^{* * *}$ & $-0.104^{*}$ & 0.094 & $0.121^{* * *}$ & $0.166^{* * *}$ & 0.052 \\
\hline childn & $-0.129^{* * *}$ & -0.033 & $-0.360^{* * *}$ & -0.033 & $-0.282^{* * *}$ & $-0.306^{* * *}$ & $-0.176^{* * *}$ & $-0.192^{* * *}$ & $-0.251^{* * *}$ & $-0.210^{* * *}$ & -0.068 & $-0.310^{* * *}$ & $-0.569 * * *$ \\
\hline exoginc & $-0.007^{* * *}$ & 0.014 & -0.002 & -0.009 & $-0.013^{* * *}$ & -0.001 & $-0.025^{* *}$ & $-0.041^{* *}$ & $-0.196^{* * *}$ & -0.004 & -0.003 & -0.084 & $-0.004^{*}$ \\
\hline relativec & $0.516^{* * *}$ & $0.894^{* * *}$ & $0.623^{* * *}$ & $1.008^{* * *}$ & $0.332^{* * *}$ & 0.635 & $0.680^{* * *}$ & $0.404^{* * *}$ & 0.083 & -0.270 & $0.451^{* * *}$ & $0.337^{* * *}$ & $0.402^{* * *}$ \\
\hline paidc & $-0.076^{*}$ & $-0.608^{* * *}$ & $0.385^{* * *}$ & $-0.908^{* * *}$ & -0.174 & 0.030 & $-0.362^{* * *}$ & $0.403^{* * *}$ & na & $0.185^{*}$ & $0.160^{*}$ & 0.074 & $0.641^{* * *}$ \\
\hline constant & $-0.653^{* * *}$ & $0.216^{*}$ & $0.560^{* * *}$ & $0.345^{* * *}$ & 0.128 & $0.907^{* * *}$ & $-0.572^{* * *}$ & $0.299^{* * *}$ & $-0.253^{* * *}$ & 0.121 & $-0.711^{* * *}$ & $-0.288^{* * *}$ & 0.031 \\
\hline Obs & 15,598 & 4,071 & 3,809 & 4,472 & 3,730 & 4,188 & 11,071 & 3,495 & 5,652 & 2,859 & 4,892 & 6,136 & 5,333 \\
\hline
\end{tabular}

Note: The small differences in the number of observations between Tables 14 and 16 in the Appendix arise because of differences in the manner in which the two Stata routines treat variables with very few observations (for relative and paidc). Because the number of observations dropped by Stata is small, the results are unaffected. 


\section{Hourly vs Monthly wage}

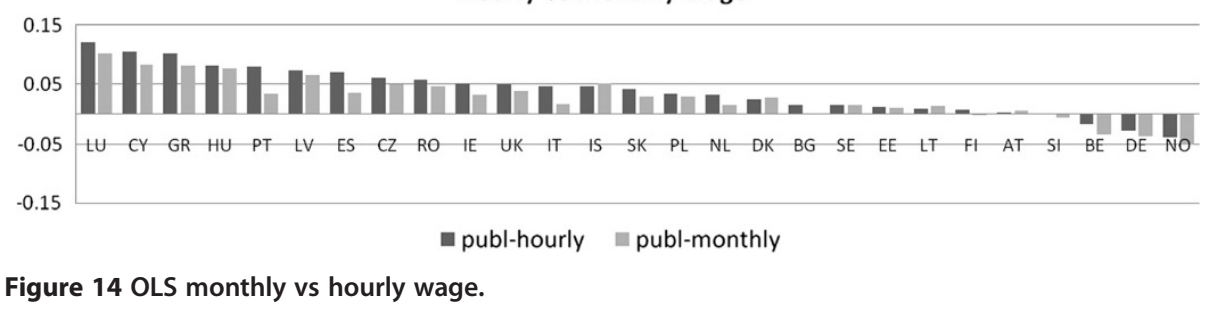

Competing interests

The IZA Journal of European Labor Studies is committed to the IZA Guiding Principles of Research Integrity. The authors declare that they have observed these principles.

\section{Acknowledgements}

We are indebted to the editors and referees of the journal for helpful comments.

Responsible editor: Sara De la Rica

Received: 9 June 2013 Accepted: 19 September 2013

Published: 25 October 2014

\section{References}

Adamchik VA, Bedi AS (2000) Wage differentials between the public and the private sectors: evidence from an economy in transition. Labour Econ 7:203-224

Anghel B, De la Rica S, Dolado JJ (2011) The effect of public sector employment on women's labour market outcomes. IZA Discussion Paper 5825

Bargain O, Melly B (2008) Public sector pay gap in France: New evidence using panel data. IZA Discussion Papers No 3427

Blackaby DH, Murphy PD, O'Leary NC (1999) The payment of public sector workers in the UK: reconciliation with North American findings. Econ Lett 65:239-243

Chernozukhov V, Fernandez-Val I, Melly B (2013) Inference on counterfactual distributions, CeMMAP working papers CWP17/13, Centre for Microdata Methods and Practice, Institute for Fiscal Studies

Christofides LN, Pashardes P (2002) Self/Paid-employment, public/private sector selection and wage differentials. Labour Econ 9:737-762

Christofides LN, Polycarpou A, Vrachimis K (2013) Gender wage gaps, 'Sticky floors' and 'Glass ceilings' in Europe. Labour Econ 21:86-102

Dustmann C, Van Soest A (1998) Public and private sector wages of male workers in Germany. Eur Econ Rev 42:1417-1441

Elder TE, Goddeeris JH, Haider SJ (2010) Unexplained gaps and Oaxaca-Blinder decompositions. Labour Econ 17:284-290

Fallaris EM (2004) Private and public sector wages in Bulgaria. J Comp Econ 32:56-72

Fortin N, Lemieux T, Firpo S (2011) Decomposition methods in economics. In: Ashenfelter O, Card D (eds) Handbook of Labor Economics, vol 4. pp 1-102

Giordano R, Depalo D, Pereira MC, Eugene B, Papapetrou E, Perez J, Reiss L, Roter M (2011) The public sector pay gap in a selection of euro area countries. European Central Bank Working Paper, No1406

Glinskaya E, Lokshin M (2007) Wage differentials between the public and private sectors in India. J Int Dev 19:333-355

Gregory RG, Borland J (1999) Recent developments in public sector labour markets. In: Ashenfelter O, Card D (eds) Handbook of Labor Economics, vol. 3c. Elsevier, pp 3573-3630

Gyourko J, Tracy J (1988) An analysis of the public and private sector wages allowing for endogenous choices of both government and union status. J Labour Econ 6:229-253

Hartog J, Oosterbeek H (1993) Public and private sector wages in the Netherlands. Eur Econ Rev 37:37-114

Heitmueller A (2006) Public-private sector pay differentials in a devolved Scotland. J Appl Econ 9:295-323

Jann B (2008) The Blinder-Oaxaca decomposition for linear regression models. Stata J 8:453-479

Kanellopoulos CN (1997) Public-private wage differentials in Greece. Appl Econ 29:1023-1032

Lucifora C, Meurs D (2006) The public sector pay gap in France, Great Britain and Italy. Review of Income and wealth 52:43-59

Machado J, Mata J (2005) Counterfactual decomposition of changes in wage distributions using quantile regressions. J Appl Econ 20:445-465

Melly B (2005) Public-private sector wage differentials in Germany: Evidence from quantile regression. Empir Econ 30:505-520

Mueller RE (1998) Public- private sector wage differentials in Canada: evidence from quantile regressions. Econ Lett 60:229-235

Neuman S, Oaxaca RL (2004) Wage decompositions with selectivity-corrected wage equations: A methodological note. J Econ Inequal 2:3-10

Nõpo H (2008) Matching as a tool to decompose wage gaps. Rev Econ Stat 90:290-299

Oaxaca R, Ransom M (1994) On discrimination and the decomposition of wage differentials. J Econ 61:5-21 
Petersen PJ, Schmidt-Sorensen JB, Smith N, Westergard-Nielsen N (1990) Wage differentials between the public and private sectors. J Public Econ 41:125-145

Poterba J, Rueben K (1994) The distribution of public sector wage premia: New evidence using quantile regression methods. NBER Working Paper No 4734

Rees H, Shah A (1995) Public Private sector wage differential in the UK. Manch Sch 63:52-68

Van Der Gaag J, Vijverberg W (1988) A switching regression mode for wage determinants in the public sectors of a developing country. Rev Econ Stat 70:244-252

Van Kerm P (2012) Generalised measures of wage differentials. Empir Econ, published on line, http://dx.doi.org/10.1007/ s00181-012-0608-y. (in press)

Van Ophem H (1993) A modified switching regressions model for earnings differentials between the public and private sectors in the Netherlands. Rev Econ Stat 75:215-224

Yun M (2005) A simple solution to the identification problem in detailed wage decompositions. Economic Enquiry 43:766-772

doi:10.1186/2193-9012-2-15

Cite this article as: Christofides and Michael: Exploring the public-private sector wage gap in European countries. IZA Journal of European Labor Studies 2013 2:15.

Submit your manuscript to a SpringerOpen ${ }^{\circ}$ journal and benefit from:

- Convenient online submission

- Rigorous peer review

- Immediate publication on acceptance

- Open access: articles freely available online

- High visibility within the field

- Retaining the copyright to your article

Submit your next manuscript at $\boldsymbol{~ s p r i n g e r o p e n . c o m ~}$ 